\title{
Wave-, wind-, and tide-driven circulation at a well-mixed ocean inlet
}

by

Anna Wargula

\author{
B.S., Grove City College, 2011
}

Submitted to the Joint Program in Applied Ocean Science \& Engineering in partial fulfillment of the requirements for the degree of

Doctor of Philosophy

at the

MASSACHUSETTS INSTITUTE OF TECHNOLOGY

and the

WOODS HOLE OCEANOGRAPHIC INSTITUTION

June 2017

$$
\text { (C)2017 Anna Wargula. All rights reserved. }
$$

The author hereby grants to MIT and WHOI permission to reproduce and to distribute publicly paper and electronic copies of this thesis document in whole or in part in any medium now known or hereafter created.

Author

Joint Program in Oceanography/Applied Ocean Science \& Engineering Massachusetts Institute of Technology \& Woods Hole Oceanographic Institution

May 5, 2017

Certified by

Britt Raubenheimer

Senior Scientist, Applied Ocean Physics and Engineering Woods Hole Oceanographic Institution

Thesis Supervisor

Accepted by

Rohan Abeyaratne

Chairman, Committee for Graduate Students Massachusetts Institute of Technology

Accepted by

Henrik Schmidt

Chairman, Joint Committee for Applied Ocean Science \& Engineering Massachusetts Institute of Technology Woods Hole Oceanographic Institution 


\title{
Wave-, wind-, and tide-driven circulation at a well-mixed ocean inlet
}

by

\author{
Anna Wargula
}

Submitted to the Joint Program in Oceanography/Applied Ocean Science \& Engineering Massachusetts Institute of Technology \& Woods Hole Oceanographic Institution on May 5, 2017, in partial fulfillment of the requirements for the degree of

Doctor of Philosophy

\begin{abstract}
The effects of waves, wind, and bathymetry on tidal and subtidal hydrodynamics at unstratified, shallow New River Inlet, NC, are evaluated using field observations and numerical simulations. Tidal flows are ebb-dominated $(-1.5$ to $0.6 \mathrm{~m} / \mathrm{s}$, positive is inland) inside the main (2 to $5 \mathrm{~m}$ deep) channel on the ( 1 to $2 \mathrm{~m}$ deep) ebb shoal, owing to inflow and outflow asymmetry at the inlet mouth. Ebb-dominance of the flows is reduced during large waves $(>1 \mathrm{~m})$ owing to breaking-induced onshore momentum flux. Shoaling and breaking of large waves cause depression (setdown, offshore of the ebb shoal) and super-elevation (setup, on the shoal and in the inlet) of the mean water levels, resulting in changes to the cross-shoal pressure gradient, which can weaken onshore flows. At a 90-degree bend 800-m inland of the inlet mouth, centrifugal acceleration owing to curvature drives two-layered cross-channel flows $(0.1$ to 0.2 $\mathrm{m} / \mathrm{s}$ ) with surface flows going away from and bottom flows going toward the bend. The depthaveraged dynamics are tidally asymmetric. Subtidal cross-channel flows are correlated $\left(r^{2}>0.5\right)$ with cross-channel wind speed, suggesting that winds are enhancing and degrading the localcurvature-induced two-layer flow, and driving three-layer flow.
\end{abstract}

Thesis Supervisor: Britt Raubenheimer

Senior Scientist, Applied Ocean Physics and Engineering

Woods Hole Oceanographic Institution 


\title{
Dedication
}

\author{
To the memory of Michele Dufault (1988 - 2011) \\ your unquenchable curiosity, \\ your readiness to be astonished and delighted by the world, \\ and your gracious generosity \\ continue to inspire me.
}

"The river seems to be holding itself up before you like a page opened to be read. There is no knowing how the currents move. They shift and boil and eddy. They are swifter in some places than in others. To think of 'a place' on the flowing surface soon baffles your mind, for the 'places' are ever changing and moving. The current in all its various motions and speeds flows along, and that flowing may be stirred again at the surface by the wind in all its various motions. Who can think of it? Maybe the ducks have mastered it, and the little grebes who are as much at home underneath as on top and who ride the currents for pleasure."

- Jayber Crow, by Wendell Berry 


\section{Acknowledgements}

Britt Raubenheimer and Steve Elgar, thanks. You have been incredibly generous and supportive mentors. I've found myself at the top of many (real and metaphorical) daunting black diamonds these past few years because of you. Thanks for taking every opportunity to teach and prepare me and for sharing the fun of the run down. I've really enjoyed working with such inspiring and resourceful colleagues and friends. I am also grateful to my committee, Rocky Geyer, Dick Yue, and Tom Hsu, for bringing diverse perspectives to my work with enthusiasm and creativity. I have learned a lot from you all and this work has benefited immensely from our discussions.

A great deal of grit, persistence, and good humor went into collecting this extensive dataset from New River Inlet amidst intense waves and currents. Many thanks to the PVLAB field crew: Levi Gorrell, Danik Forsman, Sean Kilgallin, Christen Rivera, Jenna Walker, Regina Yopak, Seth Zippel, David Clark, Jeff Hansen, Mara Orescanin, and Melissa Moulton. I am also grateful to Jesse McNinch and the staff of the US Army Corps of Engineers Field Research Facility for bathymetry data and assistance with instrument deployment; Jim Thomson for the onsite wind data; the Coastal Ocean Research and Monitoring Program (Station 41038) for offshore wind data; Rocky Geyer, Peter Traykovski, and Jay Sisson for Reynolds stress data; and Tom Lippman for density data. I also owe thanks to Julie Chen, Fengyan Shi, and Tom Hsu for sharing numerical model outputs and for advice on the processing and analysis of the results.

Funding for this work was provided by: a National Defense Sciences and Engineering Graduate Fellowship, Office of Naval Research, Office of the Assistant Secretary of Defense of Research and Engineering, the National Science Foundation, WHOI Coastal Ocean Institute, and WHOI Academic Programs Office.

I owe thanks to many colleagues for insightful input and feedback: Jamie MacMahan for his insights from his New River study, John Trowbridge and Malcolm Scully for guidance on postprocessing of Reynolds stress data, Maitane Olabarrieta for helpful comments on Chapter 3, and Dave Ortiz-Suslow for teaching me the complexity of nearshore wind stress. I'm also grateful to the COFDL students and postdocs for their ready enthusiasm for looking over plots, practicing talks, and chatting over coffee. Erika, Julia, Mara, Melissa, Katie, Bryce, Jenny, Rachel, Suzi, Julie, Shawn: navigating our unique field alongside you all has been such a treat.

Many thanks to the MIT/WHOI Academic Programs Office and WHOI staff and security, for all their work behind the scenes to keep the joint program running smoothly and for their help with administrative issues as well as their cheerful and kind words that brightened ordinary days.

I am thankful to the support of friends from outside the walls of Bigelow and the Green Building; you know who you are and that I am ever indebted to your kindness, humor, and sense of adventure. I also want to acknowledge the many incredible teachers and mentors who taught me how to learn and how to love the rewarding and, at times, grueling process. A special shoutout goes to Erik Anderson (MIT/WHOI '05), who changed the course of my career. Finally, I'm grateful to my family. Many thanks to Billy and Carolyn, who have been trailblazing ahead or fast on my heels for as long as I can remember; you two inspire me and keep me on my toes. Thank you, Oviett, for always cheering me on as a sister. Mom and Dad, thank you for your unwavering support and prayers through every chapter of my life. 頑張ったよ。 


\section{Contents}

$\begin{array}{lr}\text { Abstract } & 3\end{array}$

Dedication 5

$\begin{array}{ll}\text { Acknowledgements } & 7\end{array}$

$\begin{array}{llr}1 & \text { Introduction } & 11\end{array}$

2 Flow asymmetry owing to inertia and waves on an unstratified, shallow ebb shoal 13

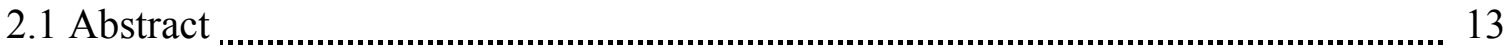

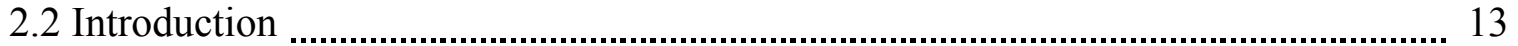

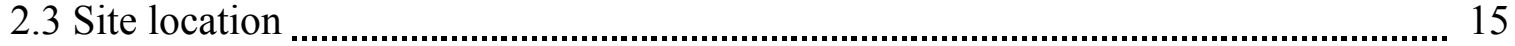

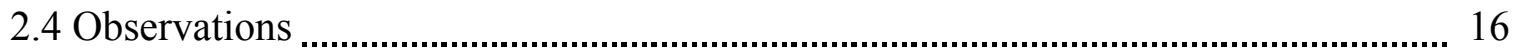

2.4.1 Waves and water levels ............................................................................ 17

2.4.2 Flows and discharge ............................................................................. 18

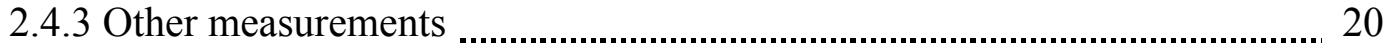

2.4.4 Ebb-dominance of the ebb shoal channel flows ....................................... 21

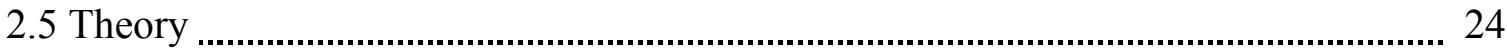

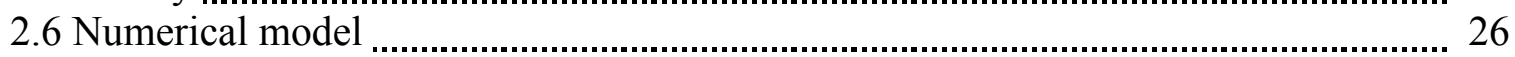

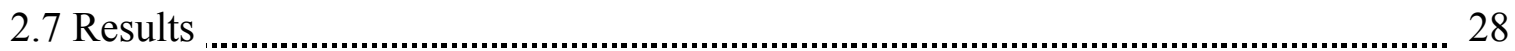

2.7.1 Observation-based momentum estimates and model validation ................. 28

2.7.2 Modeled momentum balance .............................................................. 32

2.7.2.1 Mid-shoal balance .................................................................. 32

2.7.2.2 Cross-shoal variability .................................................................. 33

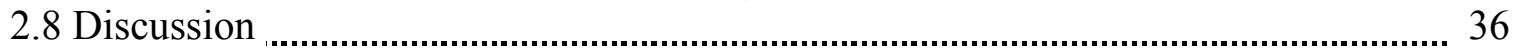

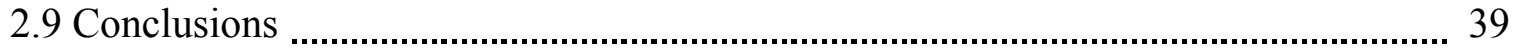

2.10 Appendix: Reynolds stresses and bottom drag coefficient ....................................... 39

3 Wave-driven along-channel subtidal flows

in a well-mixed ocean inlet 43

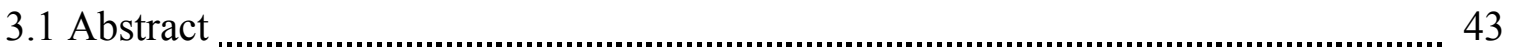

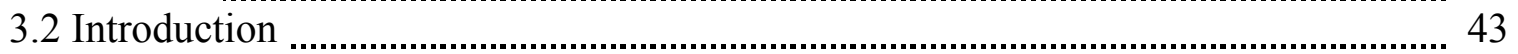

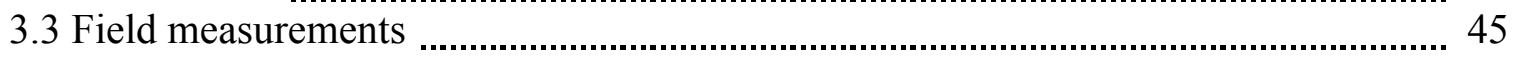

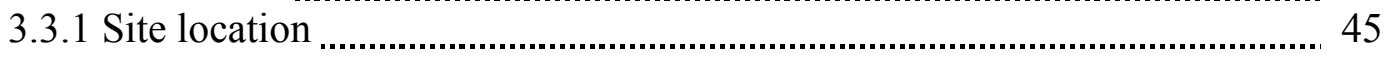

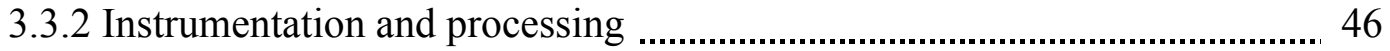

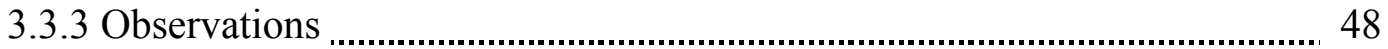

3.4 Theory: momentum balance .................................................................................. 51 


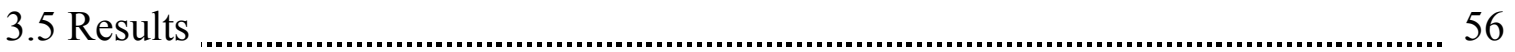

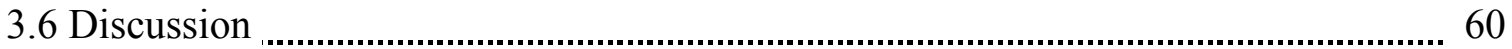

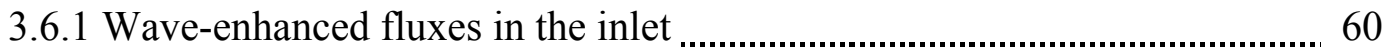

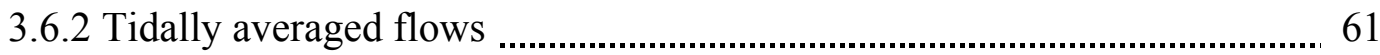

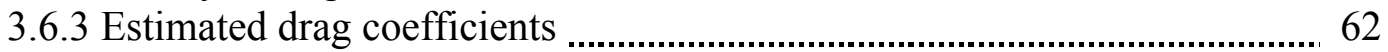

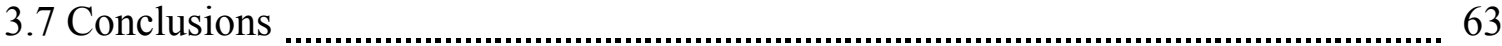

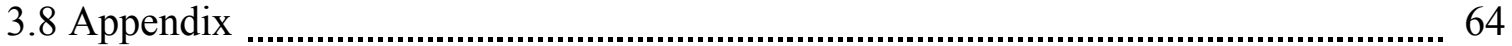

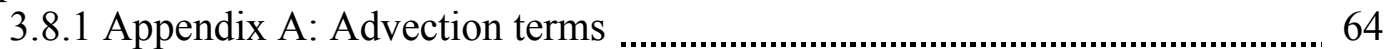

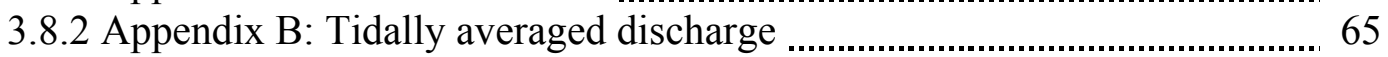

4 Curvature- and wind-driven effects on cross-channel flows $\begin{array}{ll}\text { in an unstratified tidal bend } & 67\end{array}$

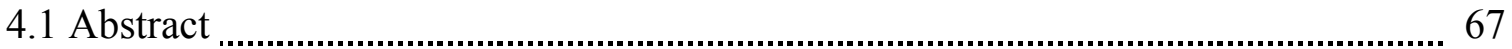

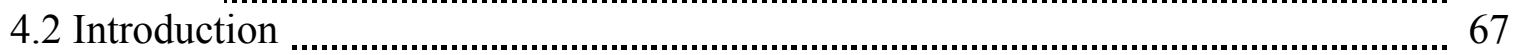

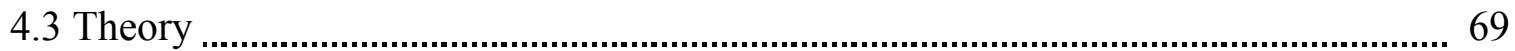

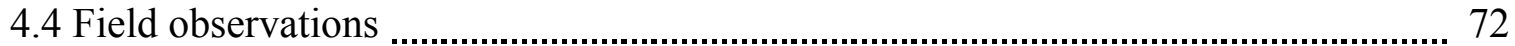

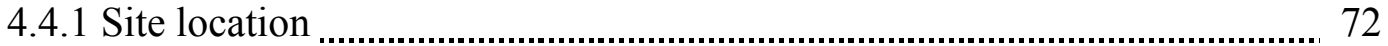

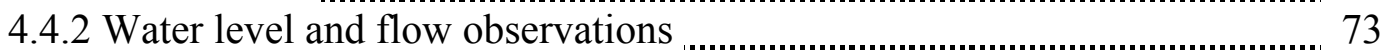

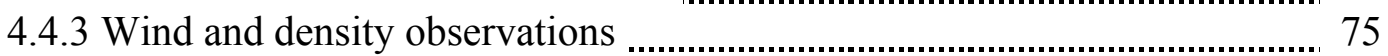

4.5 Results and discussion ..................................................................................... 77

4.5.1 Depth-averaged flows and dynamics ......................................................... 77

4.5.2 Depth-varying momentum balance ………............................................. 81

4.5.3 Subtidal wind-driven flows ………………………………………..... 85

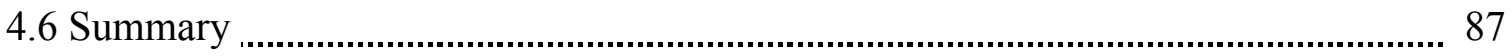

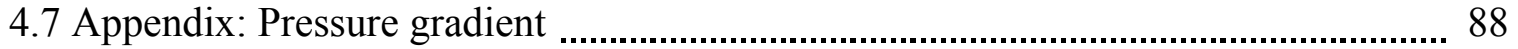

$5 \quad$ Conclusions and future work $\quad 91$

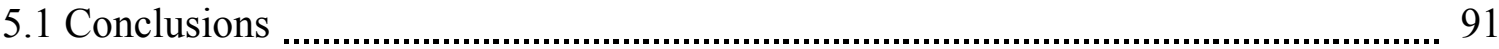

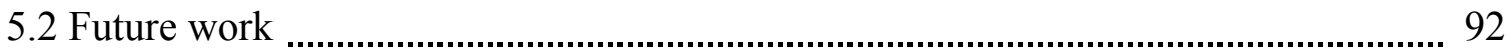

$\begin{array}{lr}\text { References } & 93\end{array}$ 


\section{Chapter 1}

\section{Introduction}

Tidal inlets are conduits for the exchange of water masses, nutrients, sediments, contaminants, and biota between inland waters and the ocean (Smith, 1976). Numerical simulations suggest that the processes governing the hydrodynamics of shallow, unstratified tidal inlets vary over short spatial and temporal scales (Hench and Luettich, 2003). However, the effects of waves and winds are not understood well, especially over and near complex natural shoals, channels, and shorelines (Blanckaert and de Vriend, 2003; Olabarrieta et al., 2014) and during storms with large waves and strong winds (Sanay and Valle-Levinson, 2005; Bertin et al., 2009). Field observations that resolve the spatial and temporal variability in flows and dynamics are essential to improve understanding of the interactions and feedbacks between tides, waves, wind, and bathymetry at inlets.

The objective of this dissertation is to investigate the effects of waves, wind, and geometry on the tidal and subtidal hydrodynamics of an unstratified, shallow inlet using field observations from New River Inlet, NC. Each chapter is written as a stand-alone work. In Chapter 2, field observations and numerical model simulations (Chen et al., 2015) are used to evaluate the spatially variable effects of waves and inertia on tidal asymmetry of the flows and dynamics on the ebb shoal. In Chapter 3, breaking waves are shown to enhance subtidal flows into the inlet (reproduced with permission from Journal of Geophysical Research: Oceans (Wargula et al., 2014)). In Chapter 4, cross-channel flows at an inlet bend are shown to be affected by upstream geometry and winds. A summary of the results and suggestions for future research are presented in Chapter 5. 


\section{Chapter 2}

\section{Flow asymmetry owing to inertia and waves on an unstratified, shallow ebb shoal}

\subsection{Abstract}

Observations of water levels, waves, currents, and bathymetry collected for a month at an unstratified tidal inlet with a shallow ( 1 to $2 \mathrm{~m}$ deep) ebb shoal are used to evaluate the asymmetry in flows and dynamics owing to inertia and waves. Along-channel currents ranged from -1.5 to $0.6 \mathrm{~m} / \mathrm{s}$ (positive is inland) inside the main ( 3 to $5 \mathrm{~m}$ deep) channel crossing the ebb shoal. Net discharge owing to the upstream river was negligible, and ebb-dominance of the flows in the channel may be owing to inflow and outflow asymmetries at the inlet mouth. Offshore wave heights ranged from 0.5 to $2.5 \mathrm{~m}$, and during large wave events (greater than $1.2 \mathrm{~m}$ ) wave radiation-stress gradients enhanced onshore mass flux near the shoal edge and inside the inlet, leading to reduced ebb-dominance of the flows. Momentum balances estimated with the water depths, currents, and waves simulated with a quasi-3D numerical model reproduce the momentum balances estimated from the observations reasonably well. Both the observations and the simulations suggest that ebb-dominant bottom stresses are balanced by ebb-dominant pressure gradient and tidally asymmetric inertia, which is a sink (source) of momentum on flood (ebb). Simulations with and without waves suggest that waves drive nonlocal changes to the pressure gradient through setdown and setup near the outer edge of the shoal and increased water levels inside the inlet.

\subsection{Introduction}

Asymmetries in flows and dynamics in and near tidal inlets affect the exchange of water masses, nutrients, sediments, and biota between inland waters and the coastal ocean. Flow asymmetries in tidal inlets can arise from many sources, including river discharge or mass exchange with connected inlets (Boon and Byrne, 1981; Salles et al., 2005; Pacheco et al., 2010), tidal distortion 
and the generation of overtides in shallow water (Speer and Aubrey, 1985; Friedrichs and Aubrey, 1988, 1994; Blanton et al., 2002), Stokes drift (Li and O'Donnell, 1997), geometric effects leading to tidal differences in horizontal flow structure (Stommel and Farmer, 1952; Hench and Luettich, 2003), and bathymetric-induced flow variations over channels and shoals (Li and O'Donnell, 1997, 2005; Hench and Luettich, 2003; Buijsman and Ridderinkhof, 2007). Although these processes often result in tidal asymmetries in the flow inertia and frictional dissipation (Friedrichs and Aubrey 1988; Hench et al., 2002), there are few field studies that resolve the relative importance of these two terms (Geyer et al., 2000).

In addition, numerical simulations suggest that wave forcing affects water fluxes and momentum in ocean inlets (Piedracoba et al., 2005; Bertin et al., 2009; Malhadas et al., 2009; Olabarrieta et al., 2011; Dodet et al., 2013; Chen et al., 2015). Wave heights and wave breaking are tidally modulated at inlets owing to changing flows and water depths (Kang and Di Iorio, 2006), leading to spatially and temporally varying wave effects on the flows and dynamics. Model simulations and field observations suggest wave momentum flux (radiation-stress) gradients owing to dissipation across the ebb shoal can decrease the offshore extent of the ebb jet (Olabarrieta et al., 2014) and drive fluxes into the inlet (Bertin et al. 2009; Malhadas et al., 2009; Orescanin et al., 2014; Wargula et al., 2014; Chen et al., 2015). Enhanced influx may result in increased bay water levels (Olabarrieta et al., 2011; Dodet et al., 2013). Along the shoreline on either side of the inlet, cross-shore decreases in wave radiation stresses owing to wave breaking are balanced by increases in the mean sea level (setup) (Longuet-Higgins and Stewart, 1964; Raubenheimer et al., 2001; Apotsos et al., 2007; Apotsos et al., 2008), which may enhance flows converging on the inlet (Bertin et al., 2009). If the shoals are asymmetric and waves break primarily on one side of an inlet connected to an enclosed bay, flows into the inlet driven by the wave breaking may be balanced by a return flow on the opposite side of the inlet (Piedracoba et al., 2005). In addition, wave-forced flows may constrict the ebb current jet, causing it to narrow and intensify in the main inlet channel, depending on the jet outflow rate, wave energy, and inlet morphology (Olabarrieta et al., 2011, 2014; Chen et al., 2015).

Here, in situ field measurements and quasi-3D numerical model simulations of water levels, currents, and waves at an unstratified tidal inlet with complex bathymetry are used to show the 
importance of flow inertia (advection) and waves to tidal flow asymmetry and to investigate the effects of waves in driving set-up and flows on a shallow ebb shoal.

\subsection{Site location}

New River Inlet, located $\sim 100 \mathrm{~km}$ south of Cape Hatteras, North Carolina, is $1000 \mathrm{~m}$ wide at the mouth and tapers to $200 \mathrm{~m}$ about $800 \mathrm{~m}$ inland where there is a sharp $90^{\circ}$ bend (Figure 2.1). The shallow $\sim 800$-m radius semicircular ebb shoal is 1 to $2 \mathrm{~m}$ deep (Figure 2.1, red-yellow contours). There are two channels extending across the ebb shoal, including one that was dredged in April 2012 ( 3 to $5 \mathrm{~m}$ deep, to the southwest) and one that is a remnant of a former main channel ( $2 \mathrm{~m}$ deep, to the northeast).

The bathymetry was surveyed (relative to NAVD88) five times (16-17 April; 1-2, 10-11, 1718, and 25 May) in 2012. Temporal changes in the sand levels on the ebb shoal and in the inlet mouth typically were less than $0.3 \mathrm{~m}$, and the results are not sensitive to which bathymetry is used (elevation changes at the sensors used in the momentum balance analysis were less than 0.1 $\mathrm{m})$. Thus, bathymetry from 10-11 May, the middle of the study period, is used here.

New River extends about $25 \mathrm{~km}$ upstream from the inlet, and the backbay (Figure 2.1a, partially shown) has an area of about $68 \mathrm{~km}^{2}$ (MacMahan et al., 2014). About $3 \mathrm{~km}$ upstream from the mouth, the inlet intersects the Intracoastal Waterway (ICW), which connects to other inlets, including Browns Inlet $12 \mathrm{~km}$ to the north (Figure 2.1a) and New Topsail Inlet $36 \mathrm{~km}$ to the south (not shown). 


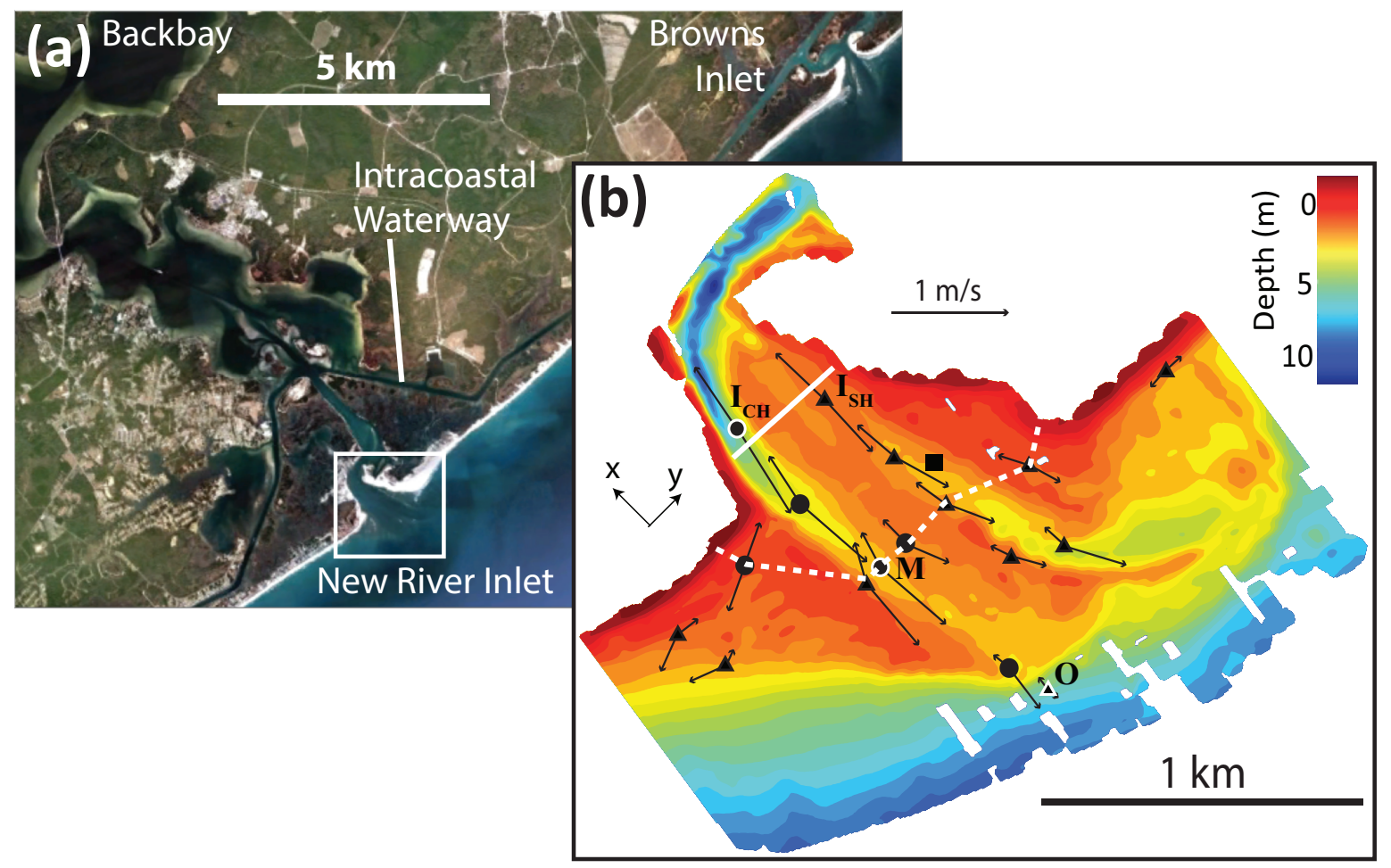

Figure 2.1. (a) Google Earth image of the North Carolina coast showing New River (Inlet and Backbay), the Intracoastal Waterway, and Browns Inlet, and (b) close-up view of New River Inlet (white square in Figure 2.1a) with instrument locations (circles (ADCPs) and triangles (ADVs) colocated with pressure gages), phase-averaged flood and ebb velocities (black arrows, $1 \mathrm{~m} / \mathrm{s}$ scale indicated above contours), and bathymetry (color contours, scale on the right, red is shallow, blue is deeper water). The black square is the location of Reynolds stress measurements. Instruments used in the momentum balance were located at the three locations labeled $\mathrm{O}$ (offshore), $\mathrm{M}$ (mid-shoal), and $\mathrm{I}_{\mathrm{CH}}$ (inlet channel) (symbols with white outlines). The solid white line indicates the location of boat-mounted current-profiler measurements, which were used in conjunction with measurements at the instruments marked $\mathrm{I}_{\mathrm{CH}}$ and $\mathrm{I}_{\mathrm{SH}}$ (inlet shoals) to estimate inlet discharge. The dashed white curve and the instruments located along it indicate the "semicircular" region used for estimates of discharge on the shoal. Cross- and alongshore directions are indicated with the black arrows labeled $\mathrm{x}$ and $\mathrm{y}$.

\subsection{Observations}

Observations of water depths waves, and currents were collected nearly continuously during May 2012. Wave heights and tidal elevations were measured at $2 \mathrm{~Hz}$ for $3072 \mathrm{~s}$ starting at the top of each hour with pressure gages deployed at 17 sites (Figure 2.1b, black symbols) near and in the inlet mouth. These sensors were colocated with acoustic Doppler velocimeters (ADVs, Figure 2.1b, triangles) and with acoustic Doppler current profilers (ADCPs, Figure 2.1b, circles). At most locations, the pressure gages were buried about $0.10 \mathrm{~m}$ below the seafloor to avoid dynamic pressure fluctuations (Raubenheimer et al., 2001). The two most onshore pressure 
sensors used in the momentum balance (Figure $2.1 \mathrm{~b}, \mathrm{I}_{\mathrm{CH}}$ and $\mathrm{M}$ ) initially were mounted on the seafloor and then were buried about $0.10 \mathrm{~m}$ below the seafloor on May 4, 2012 (the resulting shift in mean pressure was accounted for in the processing so that all pressure data are relative to the survey datum). Retaining the 3 days during which the sensors were unburied does not affect the results.

Flows and wave directions were estimated from measurements with ADVs at 11 sites (Figure $2.1 \mathrm{~b}$, triangles), which sampled velocity and pressure at $2 \mathrm{~Hz}$ for $3072 \mathrm{~s}$ starting at the top of every hour. The locations of the velocity sample volumes and internal pressure gages for the ADVs were about 0.78 and $0.45 \mathrm{~m}$ above the seafloor, respectively. Noisy data from the ADVs (e.g., owing to bio-fouling or bubbles) were removed (Elgar et al., 2001, 2005). Flows inside the inlet channel (Figure 2.1b, $\mathrm{I}_{\mathrm{CH}}$ ) were estimated from an upward-looking ADCP, which sampled near-surface flows and near-bed pressure at $2 \mathrm{~Hz}$ for $1024 \mathrm{~s}$ starting at the top of the hour and the half hour. In addition, this instrument measured 1-min-averaged current profiles in $0.50 \mathrm{~m}$ vertical bins from about $0.70 \mathrm{~m}$ above the bed to about $0.50 \mathrm{~m}$ below the water surface for 12 min ending on the half hour and hour. Upward-looking ADCPs at other channel locations (Figure 2.1b, circles, including $\mathrm{M}$ ) measured 1-min-averaged currents in $0.25 \mathrm{~m}$ vertical bins from about $0.45 \mathrm{~m}$ above the bed to about $0.25 \mathrm{~m}$ below the water surface.

\subsubsection{Waves and water levels}

Pressure measurements were corrected with atmospheric pressure fluctuations measured at ground level about $5 \mathrm{~km}$ inland. Water depths were estimated from the pressure measurements assuming hydrostatic pressure and a water density of $1025.6 \mathrm{~kg} / \mathrm{m}^{3}$ (based on salinity of $\sim 36 \mathrm{psu}$ and temperature of $\sim 20^{\circ} \mathrm{C}$ measured near the inlet mouth in late April 2012). Mean water depths $h$ were estimated by averaging the data over each 3072-s record. Water levels $\eta$ were estimated from the mean water depths and the bathymetry. The water-level fluctuations from the nearbottom pressure sensors were corrected to sea-surface elevation fluctuations using linear theory

(Raubenheimer et al., 1998), and significant wave heights $H_{\text {sig }}$ were calculated as 4 times the standard deviation of the sea-surface elevation fluctuations in the wind-wave frequency $(f)$ band $(0.05<f<0.30 \mathrm{~Hz})$. Accounting for wave-current interactions (Smith, 2002) did not significantly affect the wave height or wave forcing estimates. Energy-weighted wave directions 
in the wind-wave frequency band were estimated from the synchronized velocity and pressure measurements (Kuik et al., 1988).

Offshore significant wave heights $H_{\text {sig }}$ ranged from 0.5 to $2.5 \mathrm{~m}$ (Figure 2.2a) and centroidal (energy-weighted over the wind wave band) frequencies ranged from 0.11 to $0.18 \mathrm{~Hz}$ (not shown). Offshore centroidal wave directions usually were between $0^{\circ}$ and $20^{\circ}$ relative to the channel axis. During the nor'easter (Figure 2.2a, 15 May), waves approached from about $0^{\circ}$. Refraction resulted in approximately $10^{\circ}$ changes in wave directions around the semicircular ebb shoal. Wave breaking was primarily depth-limited (Chen et al., 2015; Zippel and Thomson, 2015). Wave heights on the ebb shoal (Figure 2.1b, M) ranged from 0 to $0.7 \mathrm{~m}$ (note shown), with average wave heights of 0.2 and $0.4 \mathrm{~m}$ on ebb (low tide) and flood (high tide), respectively.

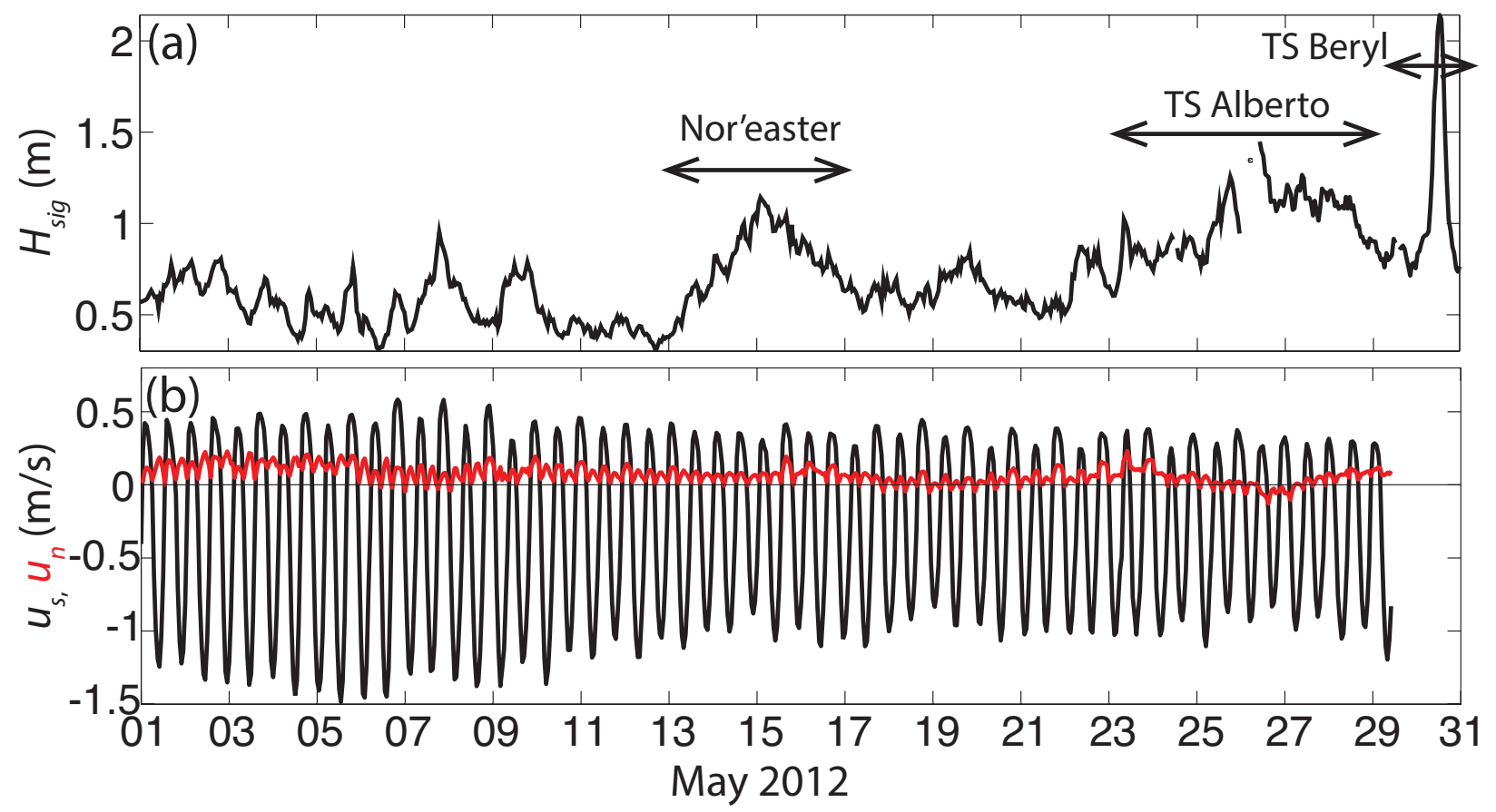

Figure 2.2. (a) Wave height $H_{\text {sig }}$ at the ebb shoal edge (Figure 2.1b, O), and (b) depth-averaged cross-shore $\left(u_{s}\right.$, black curve) and alongshore flows $\left(u_{n}\right.$, red curve) on the ebb shoal (Figure $2.1 \mathrm{~b}$, $\mathrm{M})$ versus time. A nor'easter and named tropical storms are indicated with black arrows.

\subsubsection{Flows and discharge}

Time-mean flows were estimated by averaging over the observations in each hour-long period. Hourly-averaged current profiles measured with the ADCPs were extrapolated to the bed using a 
logarithmic fit assuming a no-slip condition and to the surface using a parabolic fit assuming a no-shear condition (Geyer et al., 2000). Mean flows were rotated to cross- and alongshore (along- and cross-channel) $(x, y)$ directions (positive into the inlet and to the northeast), defined by the principal flow axis at the profiler on the ebb shoal (Figure 2.1b, M), estimated as (Emery and Thomson, 2001):

$$
\theta_{p}=\frac{1}{2} \tan ^{-1}\left[\frac{2\left\langle v^{\prime} u^{\prime}\right\rangle}{\left\langle v^{\prime 2}\right\rangle-\left\langle u^{\prime 2}\right\rangle}\right]
$$

where $\theta_{p}$ is the principal axis angle relative to north (clockwise positive), $v^{\prime}$ and $u^{\prime}$ are the demeaned north-south and east-west velocity fluctuations, and the brackets \langle\rangle indicate time averaging. The resulting major axis angle was $-45^{\circ}$ (Figure $2.1 \mathrm{~b}$, coordinate system shown on left).

In the southwestern channel on the ebb shoal (Figure 2.1b, M), tidal currents ranged from -1.5 to $0.6 \mathrm{~m} / \mathrm{s}$ (Figure $2.2 \mathrm{~b}$ ) and water levels ranged from 0.9 to $1.5 \mathrm{~m}$ (not shown). Tidal currents were nearly depth-uniform (not shown). The dominant tidal constituent was the M2 (12.4 h semidiurnal lunar) tide. Although New River Inlet is a short channel relative to the tidal wavelength (the ratio of channel length to a quarter of a tidal wavelength is about 0.3 ) (Li and O'Donnell, 2005), the tides are progressive with peak ebbs (floods) occurring within about 30 min of low (high) water levels (MacMahan et al., 2014).

Boat-mounted current profile transects were conducted across the inlet mouth (Figure 2.1b, white solid line) for $14 \mathrm{~h}$ on both 11 and 14 May. The downward-facing profiler was positioned $0.20 \mathrm{~m}$ below the water surface and sampled at $1 \mathrm{~Hz}$ in vertical bins from 0.02 to $0.50 \mathrm{~m}$ and blanking distances of 0.20 to $0.50 \mathrm{~m}$, depending on the water depth (measured by a separate vertical acoustic beam) and velocity conditions. Boat velocity and position were measured by GPS with real-time kinematic corrections. The profiling system uses a power-law velocity profile (Chen, 1991) to extrapolate the flows to areas above and below the measured profiles. Near-stationary flow measurements were collected and averaged over 120 to $240 \mathrm{~s}$ near the inlet edges and used to extrapolate the flow measurements to the shore assuming sloped banks and a visually 
determined distance. Less than $10 \%$ of the total discharge is within top, bottom, and edge regions, and the estimated discharges from the profiler surveys are not sensitive to the extrapolation methods.

Discharge also was estimated using the inlet bathymetry and the velocities and water levels measured at the two most onshore locations inside the inlet mouth (Figure 2.1b, $\mathrm{I}_{\mathrm{CH}}$ and $\mathrm{I}_{\mathrm{SH}}$ ), assuming that the fixed measurements are representative of the southwestern channel and northeastern shoals areas, respectively. The resulting hour-averaged discharge estimates are 10 to $40 \%$ larger than those estimated from the boat-mounted profiler (not shown), and the estimated 12-h averaged discharge is $8 \%$ and $18 \%$ larger than that estimated from the boat-mounted profiler on 11 and 14 May, respectively. The overestimation using fixed profilers may be owing to the overestimation of the extrapolated velocities in shallow regions of the inlet.

There were large gaps in the observations on the shoals (Figure 2.1b, $\mathrm{I}_{\mathrm{SH}}$ ) at the beginning of May, and thus discharge was estimated from the fixed sensors for 23 days from 10 May to 1 June. The hour-averaged discharge (the "tidal transport") estimated inside the inlet mouth (Figure 2.1b, $\mathrm{I}_{\mathrm{CH}}$ and $\mathrm{I}_{\mathrm{SH}}$ ) ranged from -1200 to $1600 \mathrm{~m}^{3} / \mathrm{s}$ (not shown). Average discharge over these 23 days was $-50 \mathrm{~m}^{3} / \mathrm{s}$, less than $5 \%$ of the maximum tidal transport, suggesting that export from upstream rivers and exchange with other inlets is small.

\subsubsection{Other measurements}

Winds were measured (5 min means) from 1 to 21 May with an anemometer about $4.3 \mathrm{~m}$ above NAVD88 (approximately mean sea level) in 2-m water depth southwest of the inlet mouth. Hourly offshore winds from a buoy in 10-m water depth (NDBC station 41038), $55 \mathrm{~km}$ southwest of New River Inlet were used to extend the dataset. The onsite and NDBC wind measurements were correlated $\left(r^{2} \sim 0.7\right)$ with 95\% confidence. Measured winds were converted to $10 \mathrm{~m}$ winds assuming a logarithmic layer, neutral stability, and a roughness length $z_{0}=$ $\alpha u_{*}^{2} / g$ (Charnock, 1955), where $\alpha$ is an empirical parameter, $u *$ is the friction velocity, and $g$ is gravitational acceleration. The results are not sensitive to variations in $\alpha$ over the range $0.008<\alpha$ $<0.070$ (Kraus, 1972; Smith, 1980; Sempreviva et al., 1990; Peña and Gryning, 2008; Brown 
and Wolf, 2009). Wind speeds ranged from 0 to $16 \mathrm{~m} / \mathrm{s}$ and wind directions most frequently were from the south or southwest (not shown).

Temperature and salinity were measured with a conductivity-depth-temperature (CTD) sensor over 6 days at different tidal stages (flood/ebb/slack, spring/neap) from 3 to 20 May. Density on the ebb shoal estimated from 39 profiles within $100 \mathrm{~m}$ of the profiler on the ebb shoal (Figure $2.1 \mathrm{~b}, \mathrm{M}$ ) ranged from 1024 to $1025 \mathrm{~kg} / \mathrm{m}^{3}$ and was nearly vertically uniform (buoyancy frequency $\mathrm{N}^{2}=O\left(10^{-9}\right) \mathrm{s}^{-2}$, and thus baroclinic effects on the flows are neglected. Horizontal variability in density also was negligible.

\subsubsection{Ebb-dominance of the ebb shoal channel flows}

Flows in the channels crossing the ebb shoal are ebb-dominated (Figure 2.2b, and compare flood and ebb arrow lengths in Figure 2.1b). Inflow and outflow discharge at a constriction can be represented conceptually by a semi-circular region of uniform flow on flood $\left(Q_{f}=\pi b h_{f} u_{f}\right.$, where $b$ is the radius of the semi-circular region, and $h_{f}$ and $u_{f}$ are the water depth and flows on flood) and a jet-like region of flow on ebb $\left(Q_{e}=a h_{e} u_{e}\right.$, where $a$ is the jet or channel width, and $h_{e}$ and $u_{e}$ are the water depth and flows on ebb in the jet or channel area) (Stommel and Farmer, 1952). Assuming zero net discharge $\left(Q_{f}=Q_{e}\right)$, the ratio of ebb to flood flows is $u_{e} / u_{f}=$ $\pi b h_{f} / a h_{e}$.

Discharge was estimated from the observed water depths (the bathymetry and water levels) and flows at six locations around the ebb shoal (Figure 2.1b, white dashed curve). Flows were extrapolated to the shores and interpolated between the measurements by assuming that the water level and the depth-integrated bottom stress are constant along the semi-circular "cross-section," such that $u_{2}=u_{1} \sqrt{\left(\eta+h_{2}\right) /\left(\eta+h_{1}\right)}$ (where $\eta$ is the water level, $u_{1}$ is the velocity measured in water depth $h_{1}$, and $u_{2}$ is the velocity estimated at a new location with depth $h_{2}$ ). Discharge estimates are not sensitive to the interpolation scheme. Integrating over the curve surrounding the inlet (Figure 2.1b, white dashed curve), the estimated ebb and flood discharges are similar (maximum estimates were -1100 and $1000 \mathrm{~m}^{3} / \mathrm{s}$, respectively, and average discharges over all ebbs and floods were -760 and $600 \mathrm{~m}^{3} / \mathrm{s}$ ). The estimated discharge is $7 \%$ stronger and $23 \%$ weaker than the discharge estimated inside the inlet on ebb and flood, respectively (within the 
error of the inlet-discharge estimates). The larger difference on flood may be owing to poor velocity resolution over the shallow areas. Owing to the progressive tide, the average water depth over the entire semi-circular region is deeper on flood $(1.8 \mathrm{~m})$ than on ebb $(1.2 \mathrm{~m})$.

Consistent with the theoretical representation (Stommel and Framer, 1952), the interpolated flows are nearly spatially uniform on flood and are concentrated in the main channel on ebb. Flood flows surrounding the inlet vary by less than $\pm 20 \%$ (Figure $2.3 \mathrm{~b}$, dashed red curve, the $H_{\text {sig }}$ $<0.5 \mathrm{~m}$ results are representative of the overall average). Ebb flows in the main (southwestern) channel were $20 \%$ stronger than the cross-sectional average and ebb flows outside the channel were $20 \%$ to $60 \%$ weaker than the cross-sectional average (Figure $2.3 \mathrm{~b}$, dashed blue curve, the $H_{\text {sig }}<0.5 \mathrm{~m}$ results are representative of the overall average).

On flood, the average (including all wave conditions) depth and velocity over the semi-circular region (which has a radius $b$ of about $500 \mathrm{~m}$, half the width from shore-to-shore of the inlet mouth) surrounding the inlet is $h_{f}=1.8 \mathrm{~m}$ and $u_{f}=0.2 \mathrm{~m} / \mathrm{s}$. On ebb, the average flow and depth for all wave conditions using only estimates in the "channel region" (Figure 2.3, between vertical dashed lines) is $h_{e}=1.9 \mathrm{~m}$ and $u_{e}=-0.5 \mathrm{~m} / \mathrm{s}$. The "channel" width $a$ including the intervening shoals is approximately $600 \mathrm{~m}$. Note that assuming ebb flows are constrained to channels that are deep relative to the shoals results in $h_{f} \approx h_{e}$ (whereas the average depth including the entire semicircular region is deeper on flood), but also results in smaller $a$.

Using these parameters, the average flood discharge is overestimated by $5 \%$ and the average ebb discharge is underestimated by $20 \%$, suggesting the conceptual representation explains the observed New River Inlet flow asymmetry reasonably well. The lower percentage of ebb flux may be because there is some "leakage" of the ebb flows to areas outside the channel region, particularly through the shallow "flood channel" at the southwestern corner of the inlet mouth (Figure 2.3, along-transect distance $=150 \mathrm{~m}$ ). This leakage would result in reduced ebbdominance in the channels. Thus, the ebb-dominance in the "channel region" of New River is driven by the tidal variability in flow surface area $(\pi b / a \gg 1)$ and the amount of leakage through the "flood channel." 
In the absence of a constriction, alongshore variability in bathymetry can lead to higher nonlinearity and friction over the shallow regions compared with those in the channel, leading to enhanced ebb flows in the channel and flood flows on the shoals (Li and O'Donnell, 1997, 2005; Blanton et al., 2002). At New River Inlet, the M4 overtide is 9\% of the M2 tide and slightly enhances ebb flows in the channel. However, this effect on tidal asymmetry is secondary to that of the change in flow surface area.

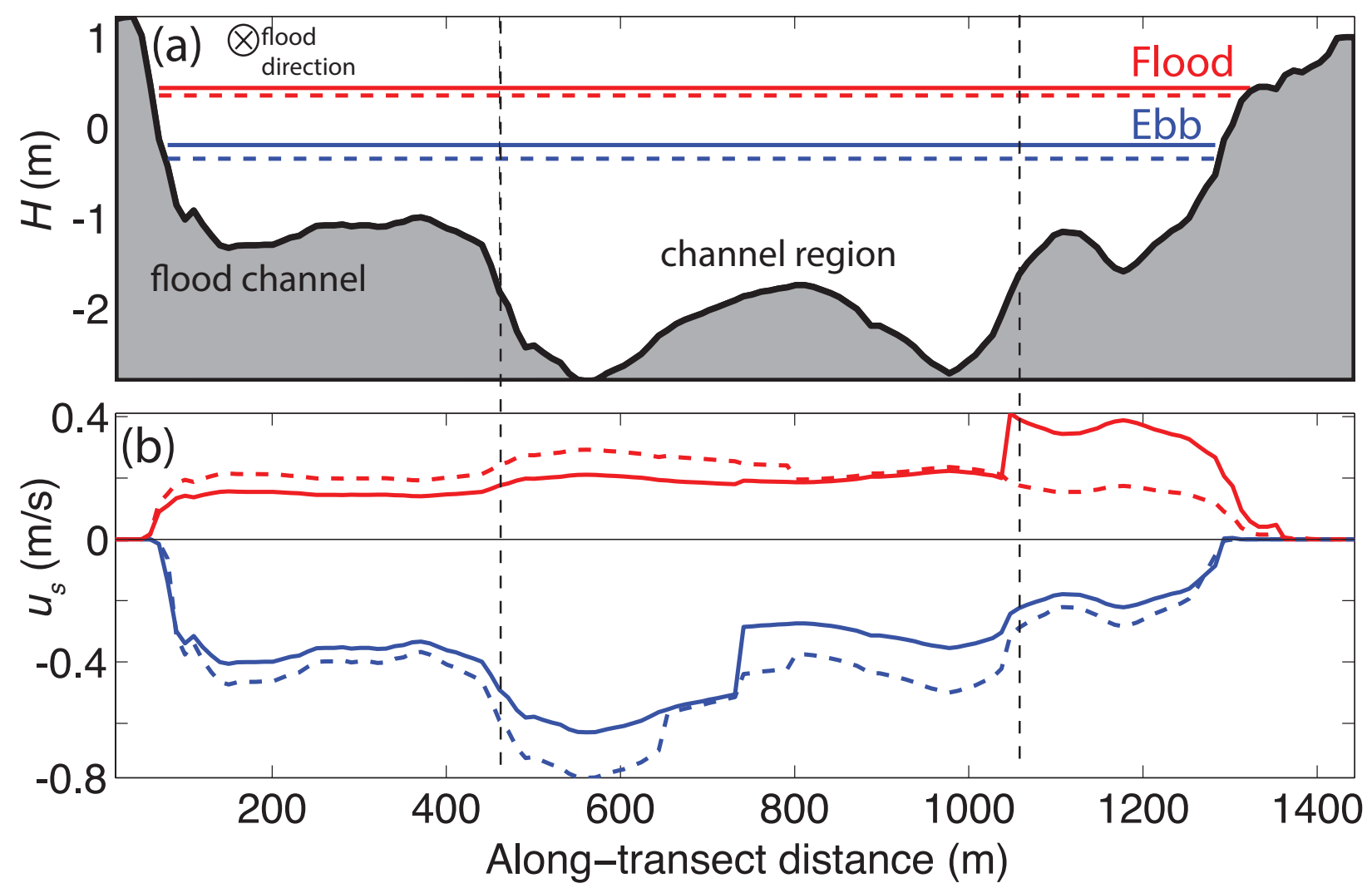

Figure 2.3. (a) Observed water levels $H$, bathymetry (thick black curve) and (b) observed and interpolated streamwise flows $u_{s}$ versus along-transect distance $(0 \mathrm{~m}$ is at the southwestern edge of the inlet, flood direction is into the page, Figure 2.1b, white dashed curve) averaged over flood (red curves) and ebb (blue curves) during offshore wave heights less than $0.5 \mathrm{~m}$ (dashed curves) and greater than $1.2 \mathrm{~m}$ (solid curves), excluding the large spring tides (results are similar including spring tides). Vertical dashed lines outline the channel region. The ebb shoal profiler used in the momentum balance (Figure 2.1b, M) is at along-transect distance $=580 \mathrm{~m}$.

Spatial and tidal variability in water depth can lead to complex wave breaking patterns (Kang and Di Iorio, 2006; Zippel and Thomson, 2015) that drive asymmetric changes to the water levels and flows (Piedracoba et al., 2005; Olabarrieta et al., 2011, 2014; Chen et al. 2015). In 
particular, as offshore wave height increases, the ebb flows become more spatially uniform (Figure 2.3, compare solid with dashed blue curve). For offshore wave heights less than $0.5 \mathrm{~m}, h_{e}$ $=1.9 \mathrm{~m}$ and $u_{e}=-0.6 \mathrm{~m} / \mathrm{s}$, resulting in a conceptual discharge estimate that is $82 \%$ of the average ebb discharge during small waves, whereas for offshore wave heights greater than $1.2 \mathrm{~m}, h_{e}=2.0$ $\mathrm{m}$ and $u_{e}=-0.4 \mathrm{~m} / \mathrm{s}$, resulting in a conceptual discharge that is only $77 \%$ of the average ebb discharge during large waves. The conceptual representation works equally well (less than a $2 \%$ difference) for small and big waves on flood (Figure 2.3, red curves, $h_{f}=1.8 \mathrm{~m}$ and $u_{f}=0.2 \mathrm{~m} / \mathrm{s}$ for both cases), although spatial variability of flows is somewhat larger for larger waves, possibly owing to enhanced breaking on the shoals. The effects of momentum on tidal asymmetry are discussed further below.

\subsection{Theory}

Wave effects on the tidal asymmetry are evaluated using the depth-integrated cross-shore momentum balance:

$$
\frac{\partial H u}{\partial t}+\frac{\partial H u^{2}}{\partial x}+\frac{\partial H u v}{\partial y}-F H v=-\frac{H}{\rho_{0}} \frac{\partial P_{b}}{\partial x}+\frac{\tau^{s x}}{\rho_{0}}-\frac{\tau^{b x}}{\rho_{0}}-\frac{1}{\rho_{0}}\left[\frac{\partial S_{x x}}{\partial x}+\frac{\partial S_{x y}}{\partial y}\right]
$$

where $t$ is time, $x$ and $y$ are the cross- and alongshore coordinates (positive into the inlet and to the northeast, Figure $2.1 \mathrm{~b}$, coordinate system to the left), $u$ and $v$ are the cross- and alongshore velocities, $H$ is the time-varying water depth $(H=\eta+h$, where $\eta$ is the time-varying sea-surface elevation and $h$ is the time-mean depth), $F$ is the Coriolis parameter, $\rho_{0}$ is the time-mean density $\left(1026 \mathrm{~kg} / \mathrm{m}^{3}\right), P_{b}$ is the bottom pressure, $\tau^{s x}$ and $\tau^{b x}$ are the wind and bottom stresses, and $S_{x x}$ and $S_{x y}$ are the cross-shore and diagonal wave radiation stresses. Tidal sea-level variations $\eta$ are significant (tidal amplitude is about a third of the depth in the deep channel), and cannot be neglected (Lentz et al., 1999).

The bottom pressure $P_{b}$ is simplified by the constant density hydrostatic equation $P_{b}=\rho_{0} g H$, where $g$ is the gravitational acceleration. Wind stress $\tau^{s x}$ is approximated as $\tau^{s x}=\rho_{a} C_{w} u_{w}\left|U_{w}\right|$, where $\rho_{a}$ is the air density, $C_{w}$ is the wind drag coefficient (Large and Pond, 1981), and $u_{w}$ and $\left|U_{w}\right|$ are the cross-shore and total wind speed at $10 \mathrm{~m}$ above the water surface. Bottom stress $\tau^{b x}$ is 
approximated with the quadratic drag law $\tau^{b x}=\rho_{0} C_{D} u|U|$, where $C_{D}=0.005$ is the bottom drag coefficient estimated from the Reynolds stress measurements (see Appendix) and $|U|$ is the total flow speed $\left(|U|=\sqrt{u^{2}+v^{2}}\right)$. Wave-driven enhancement of the bottom drag coefficient (Grant and Madsen, 1979) is negligible (see Appendix). The wave radiation stresses are approximated as (Longuet-Higgins and Stewart, 1964; Raubenheimer et al., 2001; Apotsos et al., 2008):

$$
\begin{gathered}
S_{x x}=E_{w}\left[\left(\cos ^{2} \theta_{b}+1\right) \frac{c_{g}}{c}-\frac{1}{2}\right] \\
S_{x y}=E_{w} \cos \theta_{b} \sin \theta_{b} \frac{c_{g}}{c}
\end{gathered}
$$

where $\theta_{b}$ is the centroidal wave direction (relative to the along-channel direction), $c_{g}$ and $c$ are the group velocity and phase speed (estimated from the centroidal frequency and the water depth), and $E_{w}$ is the wave energy, calculated as:

$$
E_{w}=\frac{1}{16} \rho_{0} g H_{\text {sig }}^{2}
$$

The results are not sensitive to the roughly 10 to $15 \%$ overestimation during large wave events of radiation stresses estimated using the bulk formulae (Equations 2.3 and 2.4) relative to those estimated using a frequency-dependent directional moment technique (Herbers and Guza, 1990; Elgar et al., 1994; Raubenheimer et al., 2001; Feddersen, 2004). Coriolis acceleration is neglected because it is small $\left(O\left(10^{-5}\right) \mathrm{m}^{2} / \mathrm{s}^{2}\right)$ and the Rossby number is large at the inlet. Wind stress is small $\left(O\left(10^{-5}\right.\right.$ to $\left.\left.10^{-4}\right) \mathrm{m}^{2} / \mathrm{s}^{2}\right)$ relative to the other terms and is neglected.

The simplified depth-averaged (divide Equation 2.2 by $H$ ) momentum balance is:

$$
\frac{1}{H} \frac{\partial H u}{\partial t}+\frac{1}{H}\left[\frac{\partial H u^{2}}{\partial x}+\frac{\partial H u v}{\partial y}\right]=-g \frac{\partial \eta}{\partial x}-\frac{C_{D} u|U|}{H}-\frac{1}{\rho_{0} H}\left[\frac{\partial S_{x x}}{\partial x}+\frac{\partial S_{x y}}{\partial y}\right]
$$


where, from left to right, the terms are the local acceleration, cross- and alongshore advection, barotropic pressure gradient, bottom stress, and cross- and alongshore wave radiation-stress gradients.

\subsection{Numerical model}

Observational estimates of the momentum terms are used to evaluate a numerical model, which is used (Section 2.7.2) to examine the spatial variability of wave effects on the momentum balance. The model, NearCoM-TVD (Shi et al., 2003; Chen et al., 2014, 2015) couples the spectral wave model SWAN (Booij et al., 1999) with the nearshore circulation model SHORECIRC (Svendsen et al., 2002). The quasi-3D SHORECIRC is a two-dimensional horizontal $(2 \mathrm{DH})$ model that incorporates the mixing effect induced by the vertical variation of wave-induced horizontal circulation. The curvilinear model grid extends offshore to $27 \mathrm{~m}$ depth, and alongshore $32000 \mathrm{~m}$ centered on the inlet, and includes the backbay, and the ICW. The digital elevation model (DEM) is comprised of three datasets: the DEM of Onslow Beach and the ICW bathymetry (November 2005, US Army Corps of Engineers (USACE)) and Swath bathymetry (August 2008, Virginia Institute of Marine Science), the DEM in New River Estuary from Swath bathymetry (August 2009, USACE), and the DEM (Figure 2.1b) surveyed on 01 May 2012 (USACE) covering the inlet and the ebb tidal delta. These three digital elevation models were combined and interpolated onto the curvilinear grid with 10-m resolution near the inlet and 200-m resolution in the backbay and offshore regions. The model bathymetry was smoothed near the steep channel slopes to ensure stability. Bottom friction is modeled using a data-based method (Soulsby et al., 1993) that accounts for bed stresses owing to both waves and currents. The eddy viscosity formulation accounts for mixing owing to wave breaking, bottomgenerated turbulence, and subgrid stresses (Smagorinsky, 1963; Nadaoka and Kondoh, 1982; Svendsen, 1987). The model is driven with the spatially varying amplitudes and phases of the M2, S2, N2, K2, O1, and K1 tidal constituents provided by the ADCIRC (Luettich et al., 1992) database on the offshore and alongshore boundaries. The tidal forcing is constant along the boundaries and tides do not propagate. Wave forcing is based on the significant wave height and peak period observed at NOAA station 41036 (25 m depth) and mean wave directions observed at NOAA station 41109 (13 m depth). More details on NearCoM-TVD and the model setup at New River Inlet can be found elsewhere (Chen et al., 2015; Spydell et al., 2015). 
Model simulations reproduce the water levels, waves, and currents observed at New River Inlet reasonably well (Chen et al., 2015). Modeled flows in the channel at the mid-shoal location are tidally asymmetric, with ebb flows three times stronger than flood flows, similar to the observations. However, the magnitudes of the flows are 20 to $30 \%$ weaker in the model than in the observations. Simulated wave heights are $8 \%$ larger than the observations offshore of the ebb shoal and 12\% larger than the observations during flood on the ebb shoal (both observed and simulated wave heights were small on the ebb shoal during ebb).

The conservative form of the momentum balance required by the combined finite-volume and finite-difference numerical scheme (Shi et al., 2003) does not allow explicit evaluation of the pressure gradient and advection (see Chen et al., 2014 and 2015 for full momentum balance). The pressure gradient term is rearranged into a "flux gradient" term that is added to advection $(G R D F)$ and a "slope" term (GRDD) (Shi et al. 2011):

$$
G R D F+G R D D=\frac{\partial}{\partial \xi^{\beta}}\left[J P^{\beta} u_{\alpha}+\frac{1}{2} g\left(\eta^{2}+2 \eta h\right) J L_{\alpha}^{\beta}\right]-g \eta \frac{\partial}{\partial \xi^{\beta}}\left(h J L_{\alpha}^{\beta}\right)
$$

where $\xi^{\beta}$ is the contravariant component of the generalized curvilinear coordinate, $J$ is the Jacobian determinant, $P^{\beta}$ is the contravariant component of volume flux, $u_{\alpha}$ is the Cartesian coordinate of velocity, $L_{\alpha}^{\beta}$ is coordinate transformation matrix between Cartesian coordinates and the generalized curvilinear coordinates.

The advection term $(A D V)$ can be calculated directly using the finite difference:

$$
A D V=\frac{\partial J P^{\alpha} u_{\alpha}}{\partial \xi^{\alpha}}+\frac{\partial J P^{\beta} u_{\alpha}}{\partial \xi^{\beta}}
$$

To obtain the total pressure gradient, Equation 2.8 is subtracted from Equation 2.7 and divided by the Jacobian determinant. The accuracy of the modeled momentum balance terms is evaluated below. 


\subsection{Results}

\subsubsection{Observation-based momentum estimates and model validation}

Momentum balance terms are estimated from the hour-averaged observations of water depth, wave forcing, and currents. Gradients are estimated as the forward difference between sensors seaward of the ebb shoal edge and inside the inlet (Figure 2.1b, $\mathrm{O}$ to $\mathrm{I}_{\mathrm{CH}}$ ), divided by the straightline distance between the sensors $(\partial x \approx 1300 \mathrm{~m})$. The results are qualitatively similar between $\mathrm{O}$ and the sensor midway between $\mathrm{M}$ and $\mathrm{I}_{\mathrm{CH}}$ (Figure 2.1b).

To compare simulations with coincident observations, momentum balance terms are estimated from the model results using the same methods and sensor locations as used for the observations. Modeled velocities and depths were spatially averaged over nine grid points (30 - 50 m radius) surrounding each sensor location to smooth spatial variability. The results are similar without spatial averaging.

Owing to the alongshore (cross-channel) variability in bathymetry and the large horizontal separations between instrument locations $(>500 \mathrm{~m}$ ), alongshore gradients in the momentum terms $(\partial / \partial y)$ cannot be estimated from observations. Thus, the model-data comparison is based on a simplified momentum balance:

$$
\frac{1}{H} \frac{\partial H u}{\partial t}+\frac{1}{H} \frac{\partial H u^{2}}{\partial x}=-g \frac{\partial \eta}{\partial x}-\frac{C_{D} u|U|}{H}-\frac{1}{\rho_{0} H} \frac{\partial S_{x x}}{\partial x}
$$

The observed and simulated bottom stresses are tidally asymmetric (larger on ebb) and correlated with pressure gradients (Figure 2.4, gray and blue curves, and Figures 2.5a, d). Local acceleration (Figure 2.4, red curve) is negligible, except near slack tide. The estimated pressure gradients are, on average, about three times larger on ebb than on flood (Figure 2.4, blue curve, and Figures 2.5a, d), which may be owing to the larger force needed to drive the discharge through the $40 \%$ smaller ebb cross-sectional area. However, the bottom stresses are more tidally asymmetric (have a larger flood-ebb inequality) than the pressure gradients (Figure 2.4, compare gray with blue curve), suggesting other momentum terms also are important. 


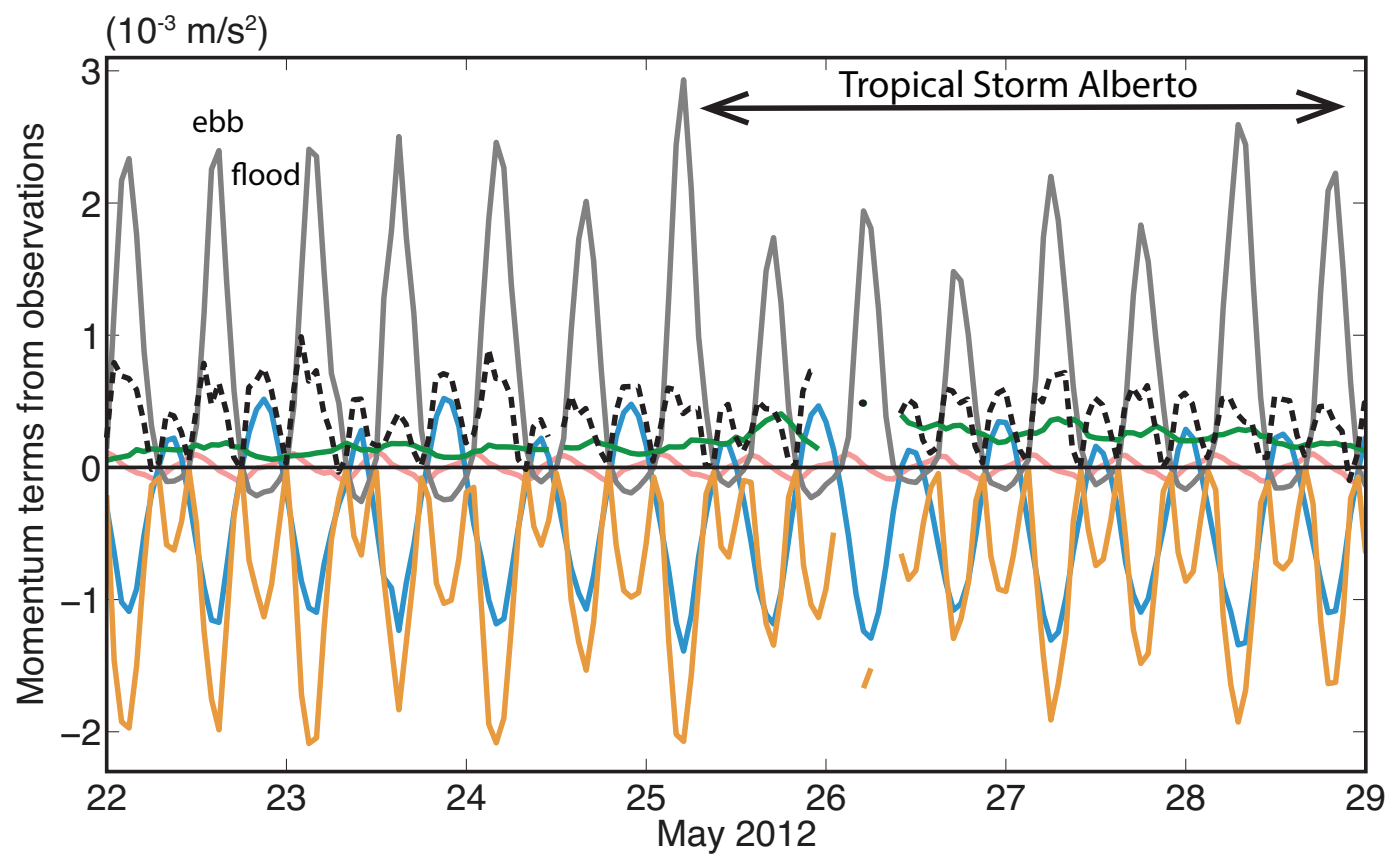

Figure 2.4. Depth-averaged, cross-shore momentum balance terms estimated from the observations versus date time. The terms in the momentum balance are pressure gradient (blue curve), bottom stress (gray curve, positive values indicate offshore-directed flows), wave radiation-stress gradient (green curve), cross-shore advection (orange curve), local acceleration (red curve), and residual (black dashed curve). The squared correlation between bottom stress and pressure is $0.87 \pm 0.06$, and the squared correlation between bottom stress and all the other terms (gray curve versus the sum of all other solid curves) is $0.95 \pm 0.03$. Momentum terms estimated from the simulation qualitatively are similar (not shown).

Cross-shore advection (Figure 2.4, orange curve) arises from spatially decelerating and accelerating flows on ebb and flood, respectively. Without considering advection (Figures 2.5a, d) there are stronger flows (higher bottom stress) than expected given the estimated pressure gradient on ebb (y-axis values are smaller than the 1:1 line), and weaker flows on flood (y-axis values are larger than the 1:1 line). Including advection in the balance (Figures 2.5b, e) increases the magnitude of the observed and modeled y-axis terms on ebb (advection provides a source of momentum), and decreases the magnitudes on flood (advection is a sink of momentum). On flood, cross-shore advection degrades the squared correlation and increases the errors (compare the legend in Figure 2.5a (2.5d) with the legend in Figure 2.5b (2.5e)), possibly owing to the importance of alongshore (cross-channel) advection on flood or to errors in estimating the crossshore advection. 

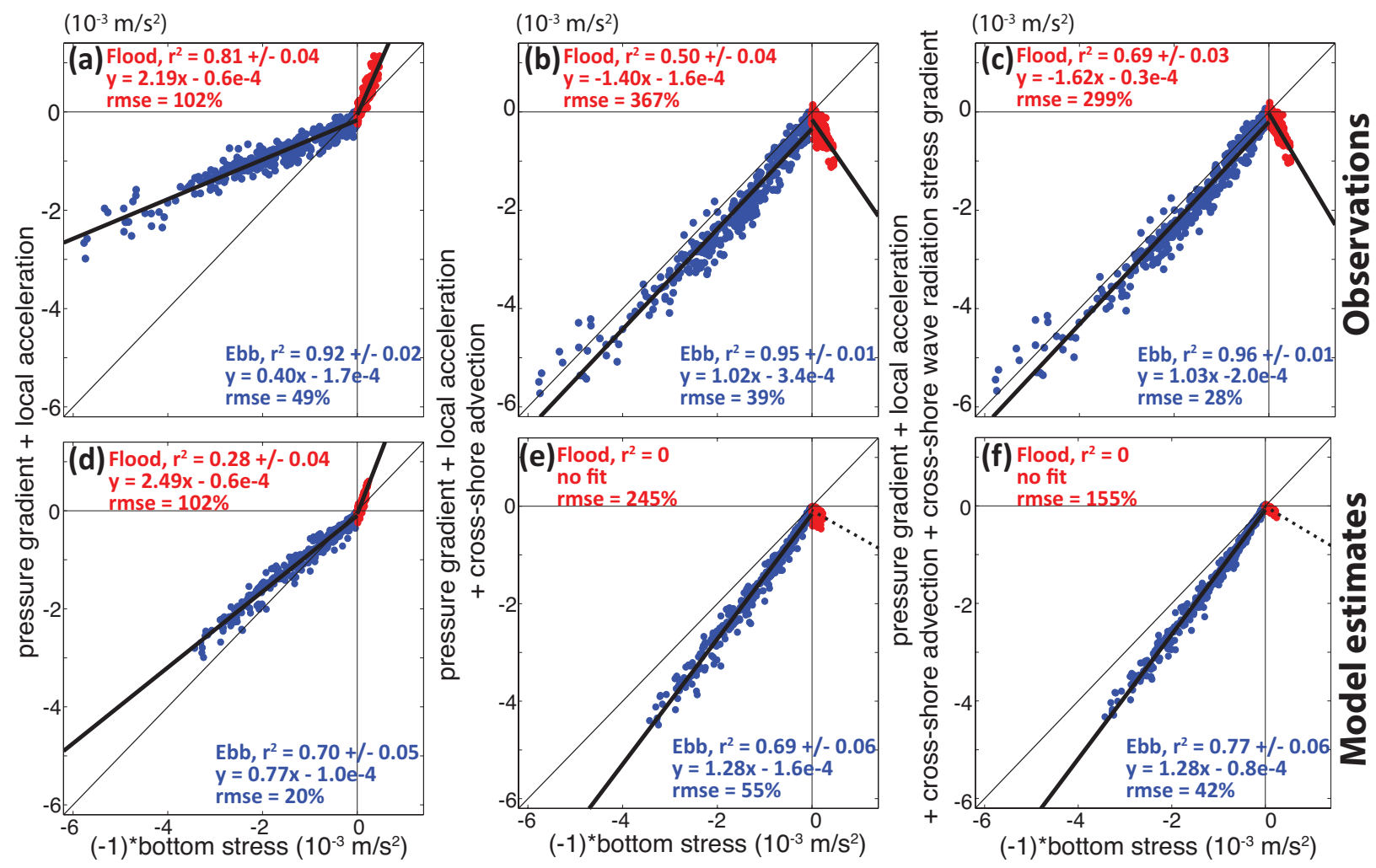

Figure 2.5. Depth-averaged, cross-shore momentum balance terms from $(\mathrm{a}-\mathrm{c})$ observations and $(\mathrm{d}-\mathrm{f})$ model outputs at sensor locations versus negative bottom stress for flood (red circles) and ebb (blue circles). The panels are the sum of (a,d) pressure gradient and local acceleration, (b, e) pressure gradient, local acceleration, and cross-shore advection, and (c, f) pressure gradient, local acceleration, cross-shore advection, and wave radiation-stress gradients. The thin diagonal lines have a slope of 1 , and the thick diagonal lines are the least squares fits (given on each panel, along with the correlation coefficient $r^{2}$ ). The normalized (by bottom stress) root-mean-square error (rmse) is given for flood and ebb. The rmse and mean normalized error (not shown) are similar in magnitude. Model-based results $(\mathrm{d}-\mathrm{f})$ are shown only for times with corresponding observations.

Cross-shore advection estimated from the mid-shoal (Figure 2.1b, M) to inside the inlet (Figure $\left.2.1 \mathrm{~b}, \mathrm{I}_{\mathrm{CH}}\right)$ on flood and ebb is an order of magnitude and $60 \%$ larger, respectively, than that estimated from the offshore (Figure 2.1b, O) to the mid-shoal (Figure 2.1b, M). Thus, the majority of the cross-shore spatial acceleration of flow is concentrated between the mid-shoal and inlet mouth on flood, whereas flows spatially decelerate more steadily across the ebb shoal on ebb. The inequality in advection onshore and offshore of the mid-shoal on flood suggests the first-order forward differencing method (which assumes a constant gradient) poorly estimates the 
gradient at mid-shoal, and thus the cross-shore advection may be overestimated significantly on flood.

Wave radiation-stress gradients (Figure 2.4, green curve) are small, except on flood during storms. Including wave forcing in the momentum balance reduces scatter and enhances flood flows (reduces the negative y-intercepts) (Figures 2.5c, f). Although alongshore wave radiationstress gradients could not be estimated with this observation-based method, these terms are expected to be smaller than the cross-shore wave forcing.

The simulated flood pressure gradient is $50 \%$ smaller than observed, and thus the other simulated terms also are smaller than the corresponding observed terms (compare $\mathrm{x}$ - and $\mathrm{y}$-axis ranges of the symbols in Figures $2.5 \mathrm{a}$ to $\mathrm{c}$ with those in Figures $2.5 \mathrm{~d}$ to $\mathrm{f}$ ). The ebb pressure gradient is $20 \%$ larger in the model than in the observations (compare y-axis values in Figures 2.5a with those in Figure 2.5d). However, the relative importance of the terms estimated from the observations is simulated reasonably well.

The model skill is evaluated by comparing the relationships between simulated bottom stress and terms in the momentum equation (Figures 2.5d-f) with those from the observations (Figures 2.5a-c). The squared correlations are lower in the model-based estimates (legends in Figures $2.5 \mathrm{~d}-\mathrm{f}$ ) than in the observations (legends in Figures 2.5a-c), possibly owing to the method used to average over grid cells near the in situ sensors. The flood and ebb differences in squared correlation (greater on ebb) and the change in squared correlation with the addition of crossshore advection (decrease on flood and little change on ebb) and wave radiation-stress gradient (little change) in the simulations are similar to those for the observations. The least squares fit slopes and normalized errors both suggest that the relative sizes of the terms are simulated well. The least squares fit slopes (the gain error) and y-intercepts (the residual at slack tide) for the model- and observation-based balances are affected similarly by the addition of cross-shore advection (slopes increase on ebb, y-axis values are negative on flood, y-intercepts decrease) and wave radiation-stress gradient (little change in slopes, y-intercepts increase) (Figure 2.5). In the simulations, the root-mean-square, mean (not shown), and standard deviation of the normalized error (not shown) are lower on ebb than on flood, and the normalized error increases with cross- 
shore advection and decreases with wave radiation-stress gradient on flood, and is insensitive to these terms on ebb, similar to the observations.

\subsubsection{Modeled momentum balance}

The observations cannot be used to estimate the alongshore gradients $(\partial / \partial y)$, and, owing to the large horizontal separations between instrument locations $(>500 \mathrm{~m})$, observational estimates of the cross-shore momentum terms are integrals over large areas. Therefore, given the reasonable model-data agreement, the simulated momentum balances are used to examine the dynamics further.

The terms in the simulated momentum balance were averaged over 100-m radius regions to smooth out spatial variability. Results are qualitatively similar without spatial averaging. To estimate depth-averaged terms the simulated depth-integrated momentum terms were divided by the average depth in the 100-m radius region. The modeled advection and wave radiation-stress gradients include both cross- and alongshore contributions. The model was run with and without wave forcing at the offshore boundary (with the same tidal forcing for the same month-long period) to evaluate the effects of waves on the momentum balances.

\subsubsection{Mid-shoal balance}

On ebb, the dominant balance is between pressure gradient, local acceleration, and bottom stress (Figure 2.6a, $r^{2}=0.99 \pm 0.01$, slope $=0.81$ ) on the mid-shoal (Figure 2.1b, M), with advection acting as a small source of momentum (Figure $2.6 \mathrm{~b}, r^{2}=1.00$, slope $=0.99$ ). Wave effects are small and produce some scatter (Figure 2.6b, 13\% scatter is owing to waves because radiationstress gradients are the only missing term on the y-axis), similar to the observation-based estimates (Figure 2.5). Advection has a larger effect on the momentum balance during flood (Figures 2.6a to b, best fit slope decreases from 1.56 to 1.08), consistent with the observationbased estimates (Figures 2.5a and b). Similar to ebb, wave effects on flood produce some scatter (Figure 2.6b). The model balance between pressure gradient, local acceleration, total advection, total wave forcing, and bottom stress does not close perfectly (less than 3\% residual, not shown) owing to other momentum terms (Coriolis acceleration, wind stress, horizontal diffusion, and 3D dispersion effect induced by the vertical variation of horizontal velocities (Putrevu and 
Svendsen, 1999)), conversion from a curvilinear coordinate system, and spatial averaging methods. The similarities between the modeled momentum balance (Figure 2.6), and the observation- and model-based estimates at instrument locations (Figure 2.5) supports the use of the model to investigate the dynamics.

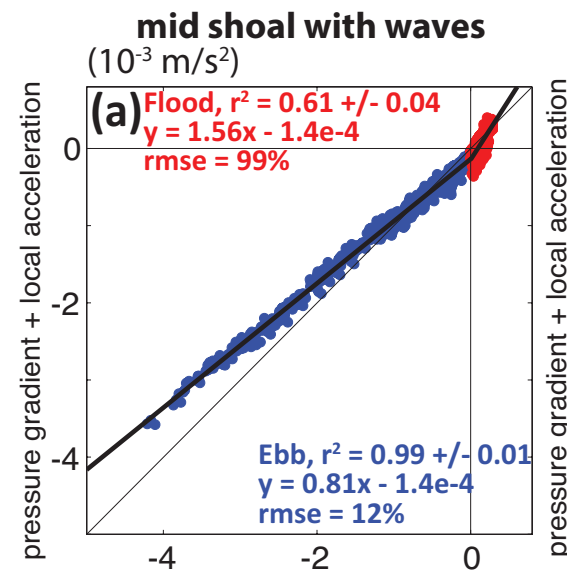

$(-1)^{\star}$ bottom stress $\left(10^{-3} \mathrm{~m} / \mathrm{s}^{2}\right)$

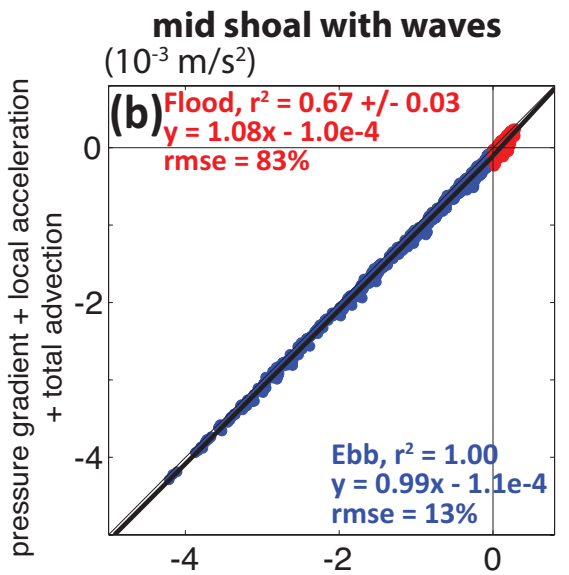

$(-1)^{\star}$ bottom stress $\left(10^{-3} \mathrm{~m} / \mathrm{s}^{2}\right)$

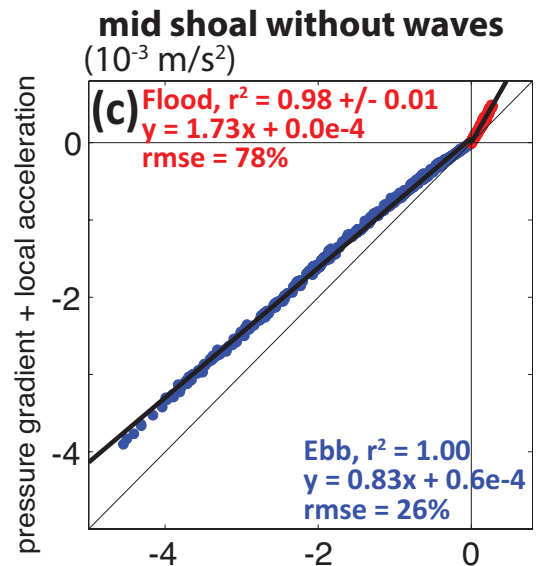

$(-1)^{*}$ bottom stress $\left(10^{-3} \mathrm{~m} / \mathrm{s}^{2}\right)$

Figure 2.6. Depth-averaged, simulated cross-shore momentum balance terms on the mid-shoal (Figure $2.1 \mathrm{~b}, \mathrm{M})$ from runs $(\mathrm{a}, \mathrm{b})$ with waves and (c) without waves versus negative bottom stress for flood (red circles) and ebb (blue circles) for $(a, c)$ pressure gradient and local acceleration and (b) pressure gradient, local acceleration, and total advection The thin diagonal lines have a slope of 1 , and the thick diagonal lines are the least squares fits (equation shown on panels). The normalized (by bottom stress) root-mean-square error (rmse) is given for flood and ebb.

\subsubsection{Cross-shoal variability}

To examine the cross-shore variability in the dynamics and wave effects during storms $\left(H_{\text {sig }}>\right.$ $1.2 \mathrm{~m}$ ) along the southwestern channel from the shoal edge to inside the inlet mouth (Figure 2.7a), the channel is divided into three regions based on tidal and wave-driven dynamics (Figures $2.7 \mathrm{~b}$ and $\mathrm{c}$ ), The shoal edge is roughly defined as where the wave-breaking-induced set-up (Figures 2.7b and c, green curves) is greater than the tidal pressure gradient (Figures 2.7b and c, blue curves), the mid shoal is roughly defined as where the tidal pressure gradient is greater than the set-up, and the inlet is defined as the region onshore of cross-shore distance $=850 \mathrm{~m}$ (Figure 2.7) 

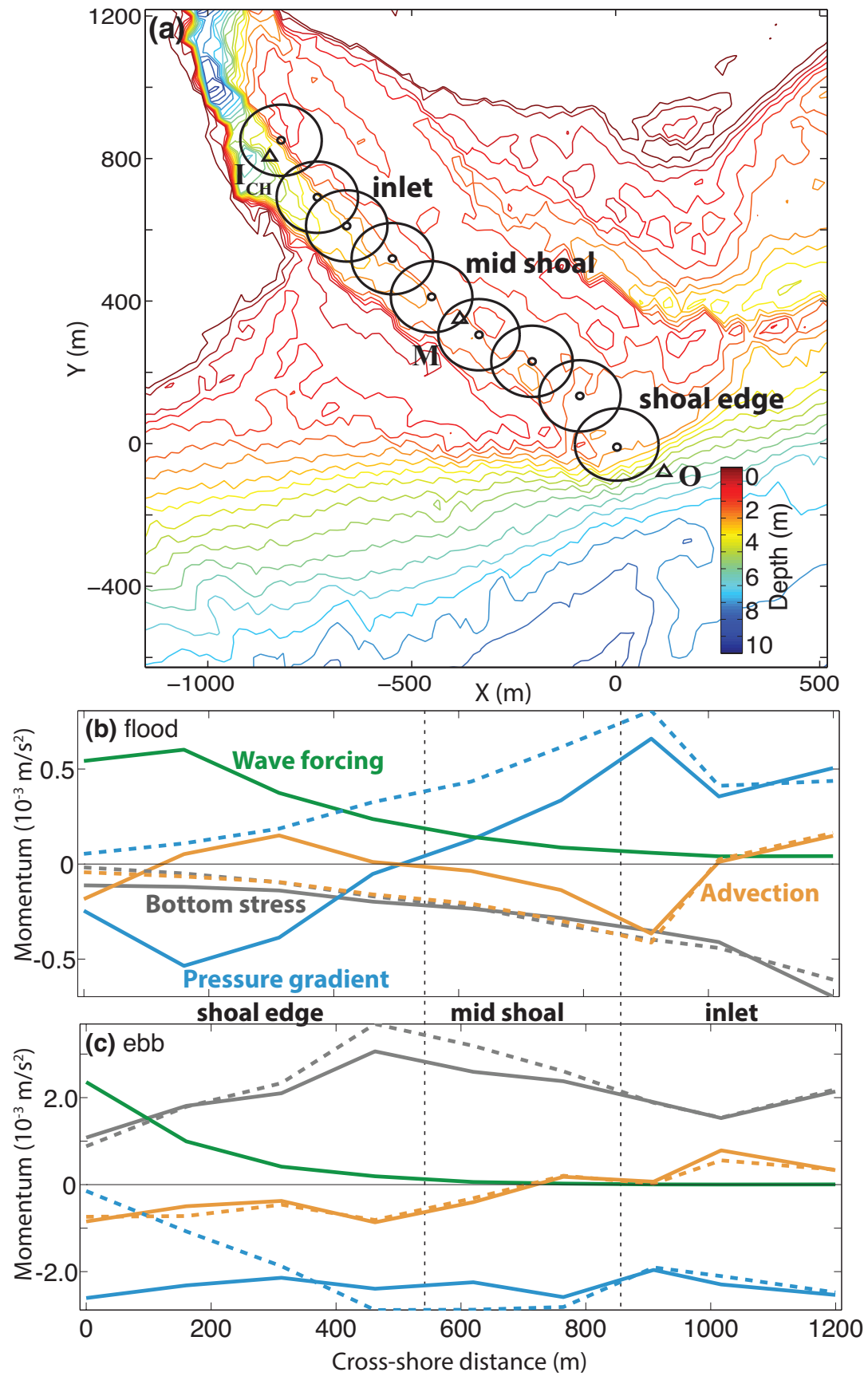

Figure 2.7. (a) Location of simulated momentum outputs overlaid on bathymetry contours (scale on right). Small circles are the center of each 100-m diameter region (large circles). Triangles are the locations of the sensors used in the observation-based momentum estimates (Figure 2.1b, O, $\mathrm{M}, \mathrm{I}_{\mathrm{CH}}$ ). Pressure gradient (blue curves), bottom stress (gray curves, positive values indicate offshore-directed flows), total advection (orange curves), and wave radiation-stress gradients (green curves) averaged over (b) flood and (c) ebb on 26 and 30 May (when observed $H_{\text {sig }}>1.2$ m) for model runs with (solid curves) and without (dashed curves) waves versus cross-shore distance (where $0 \mathrm{~m}$ is near the ebb shoal edge, same as $\mathrm{X}=0$ and $\mathrm{Y}=0$ in panel (a), and distance is positive onshore). Note that offshore is to the right of panel (a) and to the left of panels (b) and (c). 
In the absence of waves, bottom stresses and pressure gradients on the shoal edge are ebbdominated (compare gray and blue dashed curves in Figure 2.7c with those in Figure 2.7b; Figures 2.6c and 2.8c). Advection is similar in magnitude, but opposite in sign to the pressure gradient on flood (Figure 2.7b, dashed orange curve, advection is a sink of momentum). Although advection is small on ebb, it adds to the pressure gradient (Figure 2.7c, dashed orange curve, advection is a source of momentum). There is similar tidal asymmetry without advection at the shoal edge and mid shoal (Figure 2.6c and 2.8c). Advection changes sign inside the inlet (dashed orange curve at cross-shore distance $>1000 \mathrm{~m}$ in Figure $2.7 \mathrm{~b}$ and $>900 \mathrm{~m}$ in Figure $2.7 \mathrm{c})$, possibly owing to changes in channel depth and width.
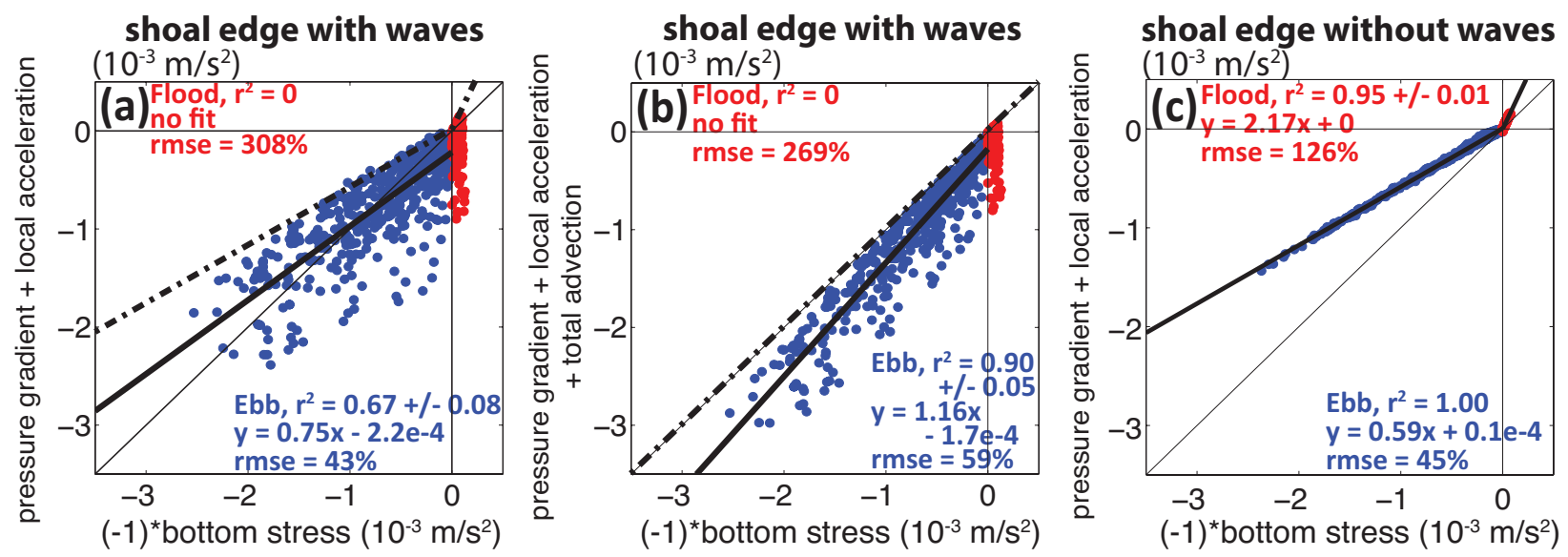

Figure 2.8. Depth-averaged, simulated cross-shore momentum balance terms near the shoal edge (Figure 2.7a, circle just inland of most offshore circle, Figure 2.7b and c, cross-shore distance $=$ $160 \mathrm{~m}$ ) from model runs $(\mathrm{a}, \mathrm{b})$ with and (c) without waves versus negative bottom stress for flood (red circles) and ebb (blue circles) for (a, c) pressure gradient and local acceleration and (b) pressure gradient, local acceleration, and total advection. The thin diagonal lines have a slope of 1 , and the thick diagonal lines are the least squares fits (equation shown on panels). The thick dot-dashed lines are the best-fit slopes to the results for the same model runs, but without waves (thus, the dashed line in panel (a) is the same as the thick solid line in panel (c)). The normalized (by bottom stress) root-mean-square error (rmse) is given for flood and ebb.

The wave radiation-stress gradient is largest at the shoal edge where breaking waves drive set-up (Figures $2.7 \mathrm{~b}$ and c, green curves, wave forcing is positive), resulting in a more negative pressure gradient (compare solid with dashed blue curves in Figures $2.7 \mathrm{~b}$ and c). In addition to driving a set-up, wave forcing drives flows onshore (Figure 2.8b, ebb slope greater than 1), and negative flood bottom stresses (red circles below 0 on y-axis in Figure 2.8a and b) are owing to the wave 
radiation-stress gradient (not included in y-axis of Figure 2.8a and b) driving flows against an adverse tide- and wave-driven pressure gradient.

On ebb, wave forcing decays rapidly over the shoal edge to mid shoal, and is negligible inside the inlet (Figure 2.7c, green curve). Despite the small wave forcing term, the simulations with waves have smaller pressure gradient and bottom stress on the mid shoal than those without waves (compare dashed with solid blue and black curves in Figure 2.7c), suggesting non-local effects (e.g., the setup at the shoal edge) may be important (see Discussion).

On flood, the wave-driven set-up at the shoal edge is larger than the tidal pressure gradient, resulting in an offshore-directed pressure gradient (Figure $2.7 \mathrm{~b}$, solid blue curve is negative for cross-shore distance $<550 \mathrm{~m}$ ). In this region advection changes sign and acts as a source of momentum to the flows (Figure 2.7b, solid orange curve is positive $150<$ cross-shore distance $550 \mathrm{~m}$ ). On the mid shoal, the pressure gradient and advection are smaller for the run with waves than for the run without waves (compare solid with dashed blue and orange curves in Figure 2.7b).

Bottom stresses are ebb dominant across the shoals and into the inlet (compare gray curves in Figure 2.7c with those in Figure 2.7b) for simulations with and without waves. However, the degree of the ebb dominance (relative size of flood and ebb flows) changes with waves (see Discussion).

\subsection{Discussion}

There is cross-shore variability in the response of the flows, water levels, and dynamics to waves along the deep channel. Across most of the ebb shoal, onshore mass transport is enhanced at least partly owing to the wave-induced reduction of ebb dominance of the flows (Figure 2.7c, compare solid with dashed gray curves for $200<$ cross-shore distance $<800 \mathrm{~m}$ ) (Orescanin et al. 2014; Wargula et al. 2014). Bottom stress is a function of flows and water levels, both of which are affected by wave-driven processes. Furthermore, on the ebb shoal, the interactions between tidal processes and the direct (local) and indirect (non-local) wave-driven processes are complex. 
Large waves $\left(H_{\text {sig }}>1.2 \mathrm{~m}\right)$ shoal and break on and just inside the edge of the ebb shoal, driving flows and changing water levels (set-down and set-up) (Figure 2.9a, solid blue and red curves). At the shoal edge, the onshore-directed wave radiation-stress gradient (Figures $2.7 \mathrm{~b}$ and c, green curves, cross-shore distance $<\sim 400 \mathrm{~m}$ ) is partly balanced by the offshore-directed wavebreaking induced set-up (Figures 2.7b and c, solid blue curves, cross-shore distance $<\sim 400 \mathrm{~m}$ ) on both flood and ebb. The wave radiation-stress gradient (compare green curve in Figure 2.7b with green curve in Figure 2.7c) and setup (compare the solid blue curve with the solid red curve for cross-shore distance $<\sim 350 \mathrm{~m}$ in Figure 2.9a) are larger on ebb than flood owing to greater dissipation of wave energy near the shoal edge during ebb (not shown). During ebb, the wave forcing leads to enhanced offshore flows (Figure 2.9b, solid blue curve is negative for $\sim 50<$ cross-shore distance $<\sim 400 \mathrm{~m}$ ). During flood, onshore flows near the shoal edge are enhanced by a wave radiation-stress gradient that is larger than the opposing pressure gradient (Figure $2.7 \mathrm{~b}$, compare green with blue curve for cross-shore distance $<200 \mathrm{~m}$ ) and by onshore-directed flow inertia as the set-up increases and the wave radiation-stress gradient decreases proportionally (Figure $2.7 \mathrm{~b}$, solid blue and green curves add to near-zero for $\sim 200<$ cross-shore distance $<\sim 300 \mathrm{~m}$, near the positive maximum in the orange curve (advection)). These onshore wave-driven flows lead to a reduction in the ebb-dominance of the currents and flux (not shown).

Although the wave radiation-stress gradient and cross-shore wave-driven changes to the pressure gradients are negligible inside the inlet (Figures 2.7b and c, green and blue curves, and Figure 2.9a, solid red and blue curves are flat, cross-shore distance $>900 \mathrm{~m}$ ), there is a reduction in ebbdominance during large waves owing to enhanced onshore mass flux (Orescanin et al. 2014; Wargula et al. 2014) and the partial blocking of the ebb jet (Olabarrieta et al., 2014). Large waves $\left(H_{\text {sig }}>1.2 \mathrm{~m}\right)$ increase the water levels more on ebb (the cross-sectional area inside the inlet is $\sim 200 \mathrm{~m}^{2}$ larger than without waves) than on flood (the cross-sectional area inside the inlet is $\sim 100 \mathrm{~m}^{2}$ larger) (Figure 2.9), decreasing the tidal prism by $\sim 20 \%$.

The wave-induced changes to the simulated flow asymmetry are not consistent with the observations. In particular, the observations suggest flood enhancement in the deep channel (Wargula et al., 2014), whereas the model suggests ebb enhancement in the deep channel (Figure $2.9 \mathrm{~b}$, red and blue curves are negative for $600<$ cross-shore distance $<900 \mathrm{~m}$ ), similar to 
previous modeling studies (Olabarrieta et al., 2011 and 2014). There are several potential sources for this difference, including the smoothing of the observed bathymetry to reduce spurious circulation (the model assumes gradual spatial changes) (Rogowski et al., 2014; Chen et al., 2015), unresolved vertical variability in flows (Spydell et al., 2015), insufficient blocking of the ebb jet (Olabarrieta et al., 2014), an overestimation of set-up inside the inlet (e.g., owing to unresolved exchanges with the ICW), and an underestimation of wave radiation-stress gradients (e.g., owing to incorrectly parameterized dissipation, (Ris and Holthuijsen, 1996)).

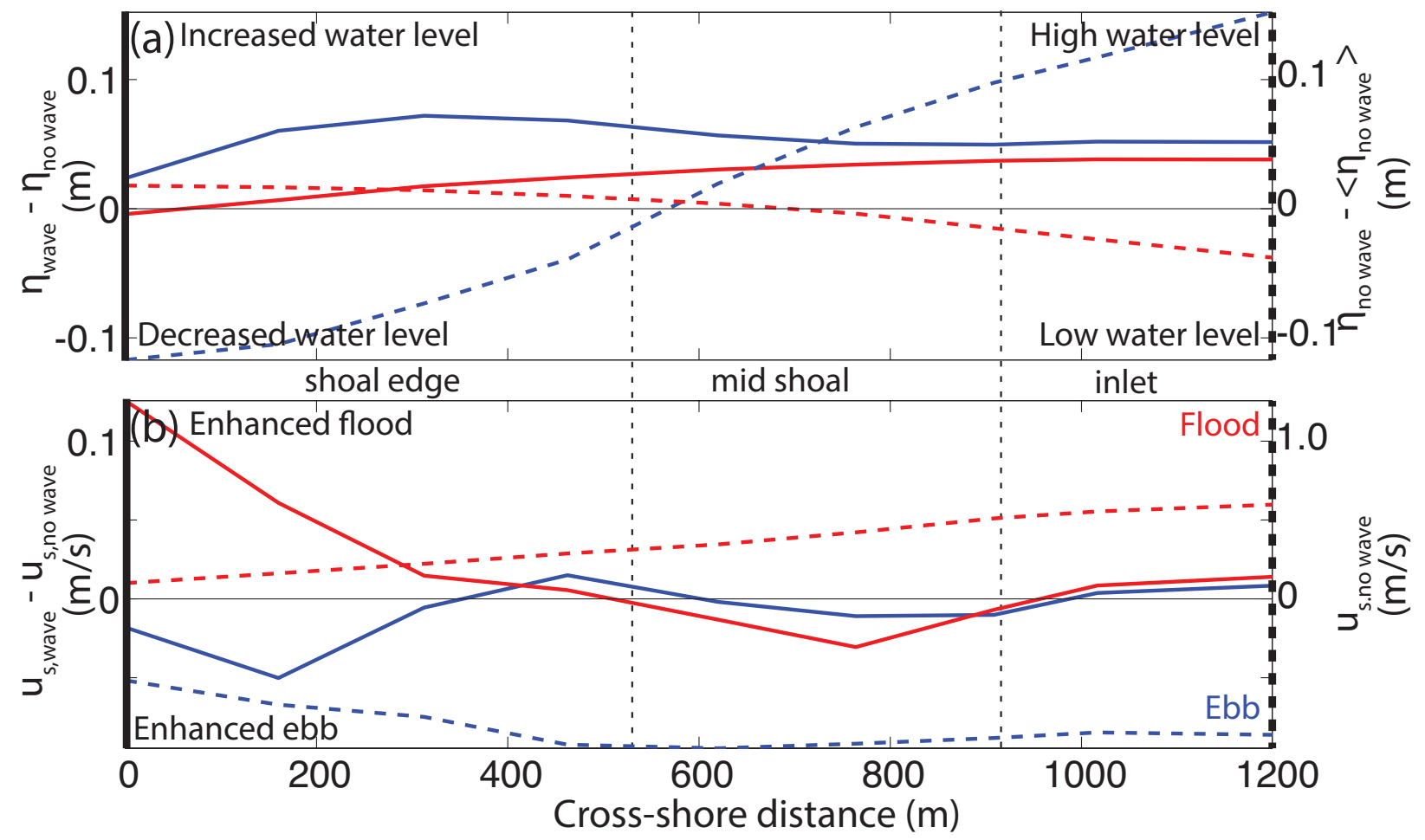

Figure 2.9. (a) Wave-driven change in sea-surface level $\eta_{\text {wave }}-\eta_{\text {no wave }}$ (water levels from the case with waves minus water levels from the case without waves) (solid curves, axis on the left) and tidal sea-surface level $\eta_{\text {no wave }}-\left\langle\eta_{\text {no wave }}\right\rangle$ (de-meaned cross-shore water levels for the case without waves) (dashed curves, axis on the right) and (b) wave-driven cross-shore flows $u_{\text {s, wave - }}$ $u_{s, n o}$ wave (flows from the case with waves minus flows from the case without waves) (solid curves, axis on the left) and tidal cross-shore flows $u_{s, n o}$ wave (flows from the case without waves) (dashed curves, axis on the right) versus cross-shore distance. Results have been averaged over maximum floods (red curves) and ebbs (blue curves) during times with offshore wave heights greater than $1.2 \mathrm{~m}$ (Figure 2.2a). 


\subsection{Conclusions}

Observations of water depths, waves, and currents in and near New River Inlet, NC, were used to investigate tidally asymmetric flows and momentum on the ebb shoal offshore of the inlet mouth. Flows on the shoal are ebb dominant, consistent with prior studies showing inflow and outflow asymmetries at a constriction (Stommel and Farmer, 1952). The observations suggest that the flow asymmetry is reduced during large wave events owing to the relative reduction of ebb flows in the channel crossing the shoal.

Simulations of water depths, waves, and currents from a NearCom-TVD numerical model reproduce the observed momentum balances reasonably well. In particular, the relative importance of model-estimated bed stress, pressure gradient, advection, and wave forcing on the mid-ebb-shoal are similar to those estimated with the observations. Both the observations and simulations suggest the local effects of wave forcing are small on the mid-shoal, that bed stresses and pressure gradients are ebb dominant, and that advection is a sink (source) of momentum on flood (ebb). The simulations suggest waves drive a setup on the outer edge of the shoal and increase water levels inside the inlet, inducing changes to the pressure gradient. The wave radiation-stress gradients enhance onshore mass flux near the shoal edge and inside the inlet, reducing the ebb-dominance of the flows.

\subsection{Appendix: Reynolds stresses and bottom drag coefficient}

Two downward-facing acoustic Doppler velocimeters (ADVs) were deployed $0.8 \mathrm{~m}$ above the seafloor in $2.5 \mathrm{~m}$ depth just offshore of the inlet mouth (Figure 2.1b, black square). The ADVs were separated $1.6 \mathrm{~m}$ horizontally, and were sampled at $16 \mathrm{~Hz}$ from 2 to 22 May for $1140 \mathrm{~s}$ (19 min) starting on the hour and 20 and 40 minutes past the hour. Horizontal velocities were rotated into local principal flow axes $\left(\theta_{p}=-65^{\circ}\right.$, Emery and Thomson, 2001).

Owing to the overlap in frequencies between orbital-wave and turbulent motions, estimates of Reynolds stresses from measurements in shallow water are biased by surface gravity waves (Grant and Madsen, 1986; Trowbridge, 1998). The wave-induced bias was reduced by differencing the spatially separated measurements of horizontal and vertical velocity, assuming that the turbulent and wave motions are not correlated with each other, and that the ADV 
separation is small relative to the wavelength of surface waves, but long relative to the correlation scale of turbulence (Trowbridge, 1998). Wave contamination also was evaluated by comparing the cospectra of the horizontal and vertical velocities with a semi-theoretical model for one-dimensional turbulence (Kaimal et al., 1972; Trowbridge and Elgar, 2003; Gerbi et al., 2009):

$$
\frac{C o_{u w}(k)}{\overline{u^{\prime} w^{\prime}}}=\left[1-\frac{7}{3 \pi} \sin \left(\frac{3 \pi}{7}\right)\right] \frac{1 / k_{0}}{1+\left(\frac{k}{k_{0}}\right)^{7 / 3}}
$$

where $C o_{u w}(k)$ is the cospectrum between the major-axis $(u)$ and vertical velocities $(w)$ as a function of wavenumber $k=2 \pi / \lambda$, where $\lambda$ is a turbulent length scale, $\overline{u^{\prime} w^{\prime}}$ is the covariance of the major-axis and vertical velocity fluctuations, and $k_{0}$ is the "rolloff wavenumber" (the inverse length scale of the dominant flux-carrying eddies). The cospectral peak for the observed velocities was compared with that of the model for each burst.

Frequency-dependent cospectra were transformed to wavenumber spectra using the frozen turbulence hypothesis $(k=2 \pi f / U$, where $f$ is the frequency, and $U$ is the burst-mean speed, Taylor, 1938). The frozen turbulence hypothesis breaks down in the presence of unsteady advection, owing to energetic waves or slow drift (Lumley and Terray, 1983; Gerbi et al., 2009). Thus, bursts with root-mean-square orbital velocities greater than the burst-mean speed ( $22 \%$ of the data, mostly near slack) were discarded. Bursts with rms differences in normalized cospectra and the Kaimal model greater than 0.15 were discarded. The remaining bursts $(46 \%$ of the measured time series) include times with local significant wave heights ranging from 0 to $0.7 \mathrm{~m}$ and currents ranging from -1.2 to $0.6 \mathrm{~m} / \mathrm{s}$.

Reynolds stresses $\left(\overline{u^{\prime} w^{\prime}}\right)$ are estimated by integrating the cross-spectra of the horizontal and vertical velocities from 0.0312 to $8.000 \mathrm{~Hz}$. To extrapolate the measured Reynolds stress estimates to near the seafloor, a linear stress profile $\left(\tau_{b, \max }=\tau_{o b s} H /(H-d)\right.$, where $\tau_{o b s}$ is the measured Reynolds stress, $H$ is the instantaneous depth, and $d=0.8 \mathrm{~m}$ is the measurement 
distance above the bottom) was assumed (i.e., the dominant balance is between a barotropic pressure gradient and vertical stress divergence).

The near-bottom estimates of Reynolds stresses were compared with hourly-averaged major-axis velocity squared (the quadratic drag law for bottom stress, Figure 2.10) to estimate a bottom-drag coefficient of $C_{D}=0.005$, a value similar to previous studies at New River Inlet, NC (Wargula et al., 2014; Chen et al., 2015). Tidal and wave-driven changes to the bottom drag coefficient were negligible. However, 92\% of bursts with local waves greater than $0.5 \mathrm{~m}$ were discarded in quality control, and thus the data may not resolve wave effects on the bottom stress.

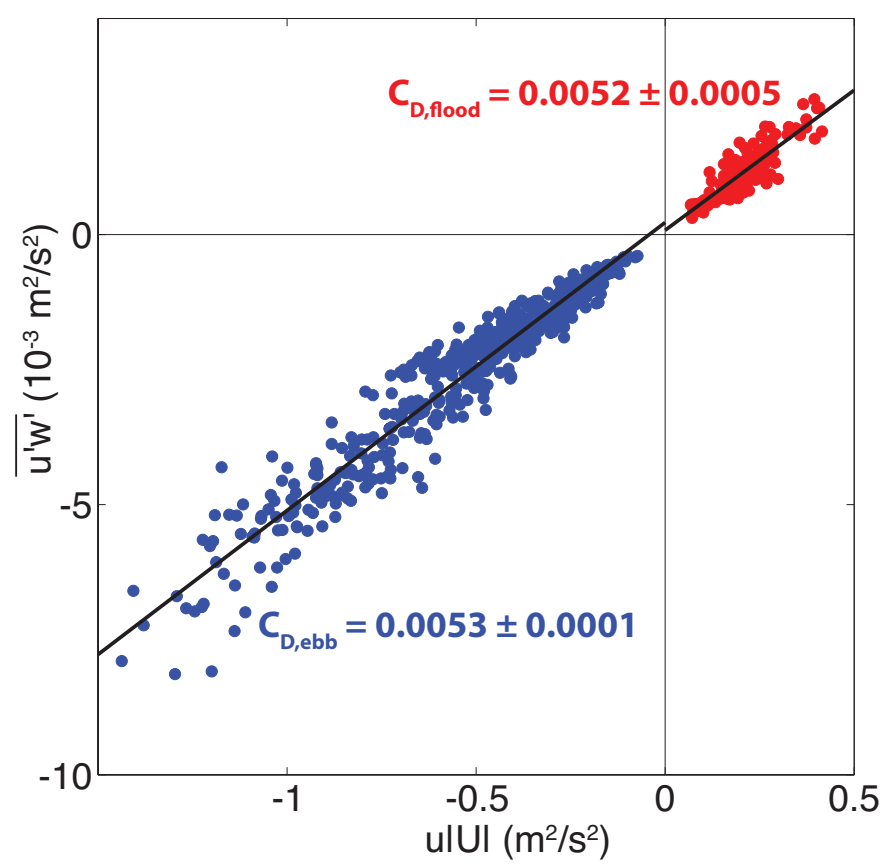

Figure 2.10. Reynolds stress estimates versus major-axis velocity times speed $(u|U|)$ for flood (red circles, slope $=0.0052 \pm 0.0005)$ and ebb (blue circles, slope $=0.0053 \pm 0.0001)$. 


\section{Chapter 3}

\section{Wave-driven along-channel subtidal flows in a well-mixed ocean inlet}

This chapter has been published in Journal of Geophysical Research: Oceans with co-authors Britt Raubenheimer and Steve Elgar and is included with permission (http://dx.doi.org/10.1002/2014JC009839).

\subsection{Abstract}

Observations of waves, flows, and water levels collected for a month in and near a long, narrow, shallow ( $3000 \mathrm{~m}$ long, $1000 \mathrm{~m}$ wide, and $5 \mathrm{~m}$ deep), well-mixed ocean inlet are used to evaluate the subtidal (periods $>30 \mathrm{hrs}$ ) along-inlet momentum balance. Maximum tidal flows in the inlet were about $1.5 \mathrm{~m} / \mathrm{s}$ and offshore significant wave heights ranged from about 0.5 to 2.5 $\mathrm{m}$. The dominant terms in the local (across the km-wide ebb shoal) along-inlet momentum balance are the along-inlet pressure gradient, the bottom stress, and the wave radiation-stress gradient. Estimated nonlinear advective acceleration terms roughly balance in the channel. Onshore radiation-stress gradients owing to breaking waves enhance the flood flows into the inlet, especially during storms.

\subsection{Introduction}

The hydrodynamics of well-mixed tidal inlets, which are transitional regions between bays and the open ocean, have been studied for many years. Numerical simulations suggest that the dominant momentum balance terms governing tidal circulation at well-mixed, shallow tidal inlets depend on the tidal phase (Hench and Luettich, 2003). During maximum ebb or flood, the streamwise tidal balance in the straits of a long, narrow inlet is predicted to be between the pressure gradient and bottom stress (idealized inlet II, Hench et al., 2002). Local advective accelerations may become important offshore of the straits during peak flows, and in the straits near slack tide. In natural inlets, the local momentum balance may be affected by bathymetric variations (Blanton et al., 2002; Hench and Luettich, 2003; Buijsman and Ridderinkhof, 2007). For example, the bed stress becomes increasingly important with decreasing depth (e.g., on the 
shoals and in shallow inlets) and near headlands (Signell and Geyer, 1991; Friedrichs and Madsen, 1992; Buijsman and Ridderinkhof, 2007). In addition, exchange between the different openings of multiple inlet systems may alter the hydrodynamic behavior of each inlet (Boon and Byrne, 1981; Speer and Aubrey, 1985; Aubrey et al., 1993; Chant, 2001; Salles, 2001; Salles et al., 2005; Pacheco et al., 2010).

Subtidal fluctuations also can have a significant effect on the fluxes through inlets and on the momentum balances (Swenson and Chuang, 1983). For example, strong winds can cause pressure gradients that change the direction or strength of the inlet flows (Smith, 1993; Geyer, 1997; Wong and Moses-Hall, 1998; Chant, 2001; Wong and Valle-Levinson, 2002; Cáceres et al., 2003; Waterhouse and Valle-Levinson, 2010; Tutak and Sheng, 2011; Li, 2013). Numerical simulations also suggest that wave forcing may be important along ocean coasts (Piedracoba et al., 2005; Bertin et al., 2009; Malhadas et al., 2009; Olabarrieta et al., 2011; Dodet et al., 2013). However, there are few field-based studies of wave effects on inlet flows.

Along the shoreline on either side of the inlet, cross-shore decreases in the wave momentum flux (radiation stress) owing to wave breaking are balanced by increases in the mean sea level (setup) (Longuet-Higgins and Stewart, 1964; Raubenheimer et al., 2001; Apotsos et al., 2007; Apotsos et al., 2008; and references therein). Near an inlet, model simulations suggest cross-shore radiationstress gradients owing to wave dissipation across the ebb shoal can drive fluxes into the inlet (Bertin et al. 2009; Malhadas et al., 2009), which may result in increased bay water levels (Olabarrieta et al., 2011; Dodet et al., 2013). If the shoals are asymmetric and waves break primarily on one side of an inlet connected to an enclosed bay, flows into the inlet driven by the wave breaking may be balanced by a return flow on the opposite side of the inlet (Piedracoba et al., 2005). In addition, wave-forced flows may constrict the ebb current jet, causing it to narrow and intensify in the main inlet channel. Wave-induced currents near the ebb shoal may be as large as $1 \mathrm{~m} / \mathrm{s}$ (Dodet et al., 2013). If a steady state is not reached or if water is not confined to the bay (e.g., owing to multiple inlets), the onshore radiation-stress gradients may result in onshore-directed mass flux through the inlet, and may be balanced by a combination of friction of the onshore-directed current, an offshore-directed pressure gradient, and advective acceleration (Bertin et al., 2009; Malhadas et al., 2009; Olabarrieta et al., 2011). 
Here, in situ measurements of water levels, currents, and waves at a well-mixed tidal inlet in a system connected to other inlets up and down the coast are used to show that breaking-wave driven along-inlet (cross-shore) radiation-stress gradients significantly affect subtidal flows in the inlet mouth.

\subsection{Field Measurements}

\subsubsection{Site Location}

New River Inlet is roughly $100 \mathrm{~km}$ south of Cape Hatteras, on the coast of North Carolina, USA (Figure 3.1) (Riggs et al., 1995). The inlet width is about $1000 \mathrm{~m}$ at the entrance and tapers to $100 \mathrm{~m}$ about $1000 \mathrm{~m}$ upstream after two sharp $90^{\circ}$ bends. New River extends about $25 \mathrm{~km}$ upstream from the inlet, and the backbay has an area of about $68 \mathrm{~km}^{2}$ (MacMahan et al., 2014). About $3 \mathrm{~km}$ upstream from its mouth the inlet intersects the Intracoastal Waterway (ICW) (Figure 3.1a). The ICW continues north and south from New River, connecting to many additional inlets, including Browns Inlet $12 \mathrm{~km}$ to the north (Figure 3.1) and New Topsail Inlet $36 \mathrm{~km}$ to the south (not shown). Freshwater discharge is minimal, and the water is well mixed in the region seaward of the intersection with the ICW. In late April 2012, salinities measured in the ocean, inlet mouth, and near the ICW intersection were about 36 psu.

The bathymetry was surveyed (relative to NAVD88) five times (April 16-17, May 1-2, 10-11, 17-18, and 25) during the 2012 field program. Overall temporal changes in the sand levels on the ebb shoal and in the inlet mouth typically were less than about $0.3 \mathrm{~m}$, and the results here are not sensitive to which bathymetry is used (elevation changes at the sensors used in the momentum balance analysis were less than $0.1 \mathrm{~m}$ ). Thus, bathymetry from May 10-11, the middle of the study period, is used here. At the mouth of the inlet is a shallow semi-circular ebb shoal ( $\sim 800 \mathrm{~m}$ radius, 1-2 m deep, red-yellow contours in Figure 3.1b). Inside the inlet, there is a 150-m wide, 5-m deep channel (hereinafter referred to as the "channel") on the southwestern edge (blue contours, Figure 3.1b). In April this primary channel was dredged across the ebb shoal to a depth of about $2 \mathrm{~m}$ below the ambient sand level (yellow contours, Figure 3.1b). The northeastern side of the inlet mouth is shallow (2-m deep, hereinafter referred to as the "shoals"), with a remnant channel crossing the ebb shoal (yellow-green contours, Figure 3.1b). 


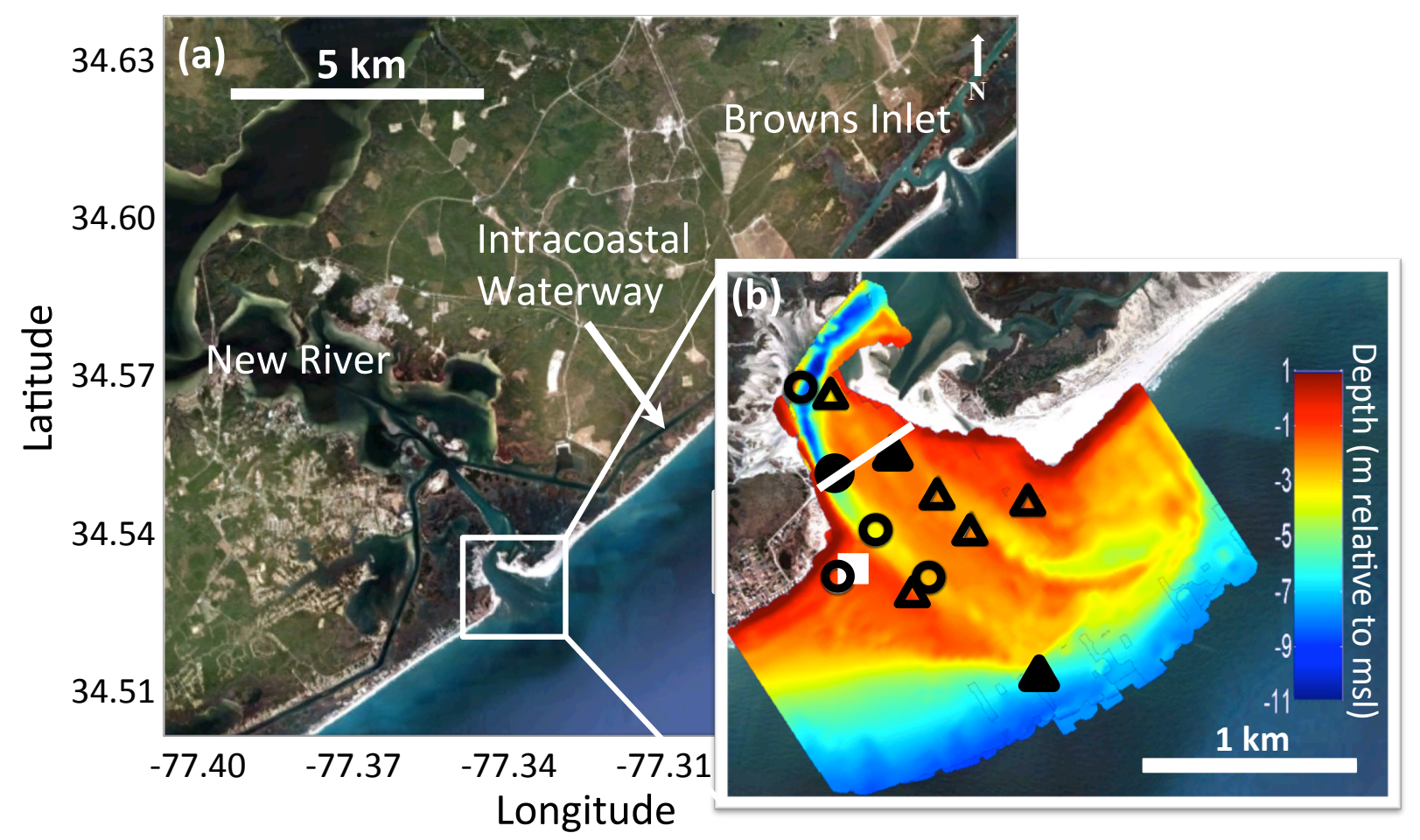

Figure 3.1. (a) Google Earth image of the North Carolina coast (latitude and longitude indicated on axes) showing New River, the Intracoastal Waterway, and Browns Inlet, and (b) close-up view of New River Inlet (square white outline in a) with instrument locations (black circles and triangles are current profilers and current meters, respectively) and bathymetry (color contours, scale on the right, red is shallow, blue is deeper water) superposed. The filled black circle and triangles ("offshore" of the ebb shoal, in the inlet "channel," and on the inlet "shoals") are used for along-inlet balances. Open black circles and triangles are sites of other measurements. The white line between the channel and the shoals sites is a cross-inlet transect surveyed with a boatmounted current profiler (see Appendices A and B). The white square is the location of onsite wind measurements.

\subsubsection{Instrumentation and processing}

Observations were collected nearly continuously during May 2012. Wave heights and tidal elevations were measured at $2 \mathrm{~Hz}$ for $3072 \mathrm{~s}$ starting at the top of each hour with stand-alone pressure gages deployed at 12 sites (black symbols, Figure 3.1b) near and in the inlet mouth. These stand-alone sensors were colocated with either acoustic Doppler velocimeters (ADVs, triangles, Figure 3.1b) or with acoustic Doppler current profilers (ADCPs, circles, Figure 3.1b). At all locations with ADVs, the stand-alone pressure gages were buried about $0.10 \mathrm{~m}$ below the seafloor to avoid dynamic pressure fluctuations (Raubenheimer et al., 2001). At the channel location, the stand-alone pressure sensor initially (April 30, 2012) was mounted on the seafloor and then buried about $0.10 \mathrm{~m}$ below the seafloor on May 4, 2012 (the resulting shift in mean 
pressure was accounted for in the processing so that all pressure data are relative to the survey datum. Retaining the 3 days during which the sensor was unburied does not affect the results).

Atmospheric pressure was measured at ground level about $5 \mathrm{~km}$ inland. Pressure measurements were corrected for atmospheric pressure fluctuations. Water levels were estimated from the nearseafloor pressure measurements assuming hydrostatic pressure and a water density of 1025.6 $\mathrm{kg} / \mathrm{m}^{3}$ (based on salinity of $\sim 36 \mathrm{psu}$ and temperature of $\sim 20^{\circ} \mathrm{C}$ measured near the inlet mouth in late April 2012). Mean water levels $\eta$ were estimated by averaging the data from the buried pressure sensors over each 3072-s record. Water depths $h$ were estimated from the mean water levels and the bathymetry. The water-level fluctuations from the near-bottom pressure sensors were corrected to sea-surface elevation fluctuations using linear theory (Raubenheimer et al., 1998), and significant wave heights $H_{\text {sig }}$ were calculated as 4 times the standard deviation of the sea-surface elevation fluctuations in the wind-wave frequency $(f)$ band $(0.05<f<0.30 \mathrm{~Hz})$. Accounting for wave-current interactions (Smith, 2002) did not significantly affect the wave height or wave forcing estimates.

Flows and wave directions were estimated from measurements with ADVs, which sampled velocity and pressure at $2 \mathrm{~Hz}$ for $3072 \mathrm{~s}$ starting at the top of every hour, and with ADCPs (see below). The locations of the velocity sample volumes and internal pressure gages for the ADVs were about 0.78 and $0.45 \mathrm{~m}$ above the seafloor, respectively. Noisy data from the ADVs (e.g., owing to bio-fouling or bubbles) were removed (Elgar et al., 2001, 2005). The internal pressures from the ADVs are time synced with the velocity, enabling the energy-weighted wave directions in the wind-wave frequency band to be estimated from 3072-s data records (Kuik et al., 1988). Wave directions were rotated to be relative to the along-inlet direction, defined as $-46^{\circ}$ relative to true north based on a straight line between the offshore and channel sites (Figure 3.1b). Mean flows were estimated by averaging data over 3072-s records. At the shoals location, the mean flows are representative of the depth-averaged flows (Wargula et al., 2013).

Wave directions also were estimated from the upward-looking ADCP at the channel location, which sampled near-surface flows and near-bed pressure at $2 \mathrm{~Hz}$ for $1024 \mathrm{~s}$ starting at the top of the hour and the half hour. In addition, this instrument measured currents in 0.50 -m vertical bins 
from about $0.70 \mathrm{~m}$ above the bed to about $0.50 \mathrm{~m}$ below the water surface every minute for 12 minutes ending on the half hour and hour. Upward-looking ADCPs at other, shallower channel locations measured one-minute mean currents in $0.25-\mathrm{m}$ vertical bins from about $0.45 \mathrm{~m}$ above the bed to about $0.25 \mathrm{~m}$ below the water surface. Depth- and time-mean flows at locations with ADCPs were estimated by averaging over the water depth and over the observations in each hour-long period.

Mean flow measurements from ADVs and ADCPs were rotated into along- and across-inlet directions (positive onshore and to the northeast). Principal flow axes were estimated as (Emery and Thomson, 2001):

$$
\theta_{p}=\frac{1}{2} \tan ^{-1}\left[\frac{2 \overline{u_{1}^{\prime} u_{2}{ }^{\prime}}}{\overline{u_{1}^{\prime 2}}-\overline{{u_{2}^{\prime}}^{\prime 2}}}\right]
$$

where $\theta_{p}$ is the principal axis angle relative to north, $u_{1}{ }^{\prime}$ and $u_{2}{ }^{\prime}$ are the de-meaned east-west and north-south velocity fluctuations, and an overbar indicates time averaging.

Onsite winds were measured just southwest of the inlet mouth (white square, Figure 3.1b) about $4.3 \mathrm{~m}$ above mean sea level on a piling located in 2-m water depth (white square, Figure 3.1b) every 5 min until May 21. Additional hourly wind measurements were obtained offshore at about $3 \mathrm{~m}$ above sea level on a buoy in 10-m water depth (NDBC station 41038) $55 \mathrm{~km}$ southwest of New River Inlet. The onsite and NDBC wind measurements were correlated $\left(r^{2} \sim 0.7\right)$ with $95 \%$ confidence. Measured winds were converted to 10-m winds assuming a logarithmic layer, neutral stability, and a roughness length $z_{0}=\alpha u_{*}^{2} / g$ (Charnock, 1955), where $\alpha$ is a free parameter, $u_{*}$ is the friction velocity, and $g$ is gravitational acceleration. The results are not sensitive to variations in $\alpha$ over the range $0.008<\alpha<0.070$ (Kraus, 1972; Smith, 1980; Sempreviva et al., 1990; Peña and Gryning, 2008; Brown and Wolf, 2009).

\subsubsection{Observations}

Tidal currents in the inlet ranged from -1.5 to $1.5 \mathrm{~m} / \mathrm{s}$ (Figure 3.2) and maximum discharge rates

at peak ebb and flood were about 700 to $900 \mathrm{~m}^{3} / \mathrm{s}$ (not shown). Offshore significant wave 
heights ranged from 0.5 to $2.5 \mathrm{~m}$ (Figure 3.3a) and centroidal (energy-weighted over the wind wave band $(0.05<f<0.30 \mathrm{~Hz})$ ) frequencies ranged from 0.11 to $0.18 \mathrm{~Hz}$ (not shown). Offshore centroidal wave directions typically were between $0^{\circ}$ and $20^{\circ}$ relative to shore normal (defined as $-46^{\circ}$ relative to true north, see Section 3.3.2). During the nor'easter (May 15, Figure 3.3) waves approached from about $12^{\circ}$ south of shore-normal and during the tropical storm on May 26 (Figure 3.3) waves approached from about $0^{\circ}$. Refraction resulted in approximately $10^{\circ}$ changes in wave directions around the semi-circular ebb shoal. Wind speeds ranged from 0 to 16 $\mathrm{m} / \mathrm{s}$ (Figure 3.3b) and wind directions were most frequently from the south or southwest (not shown).
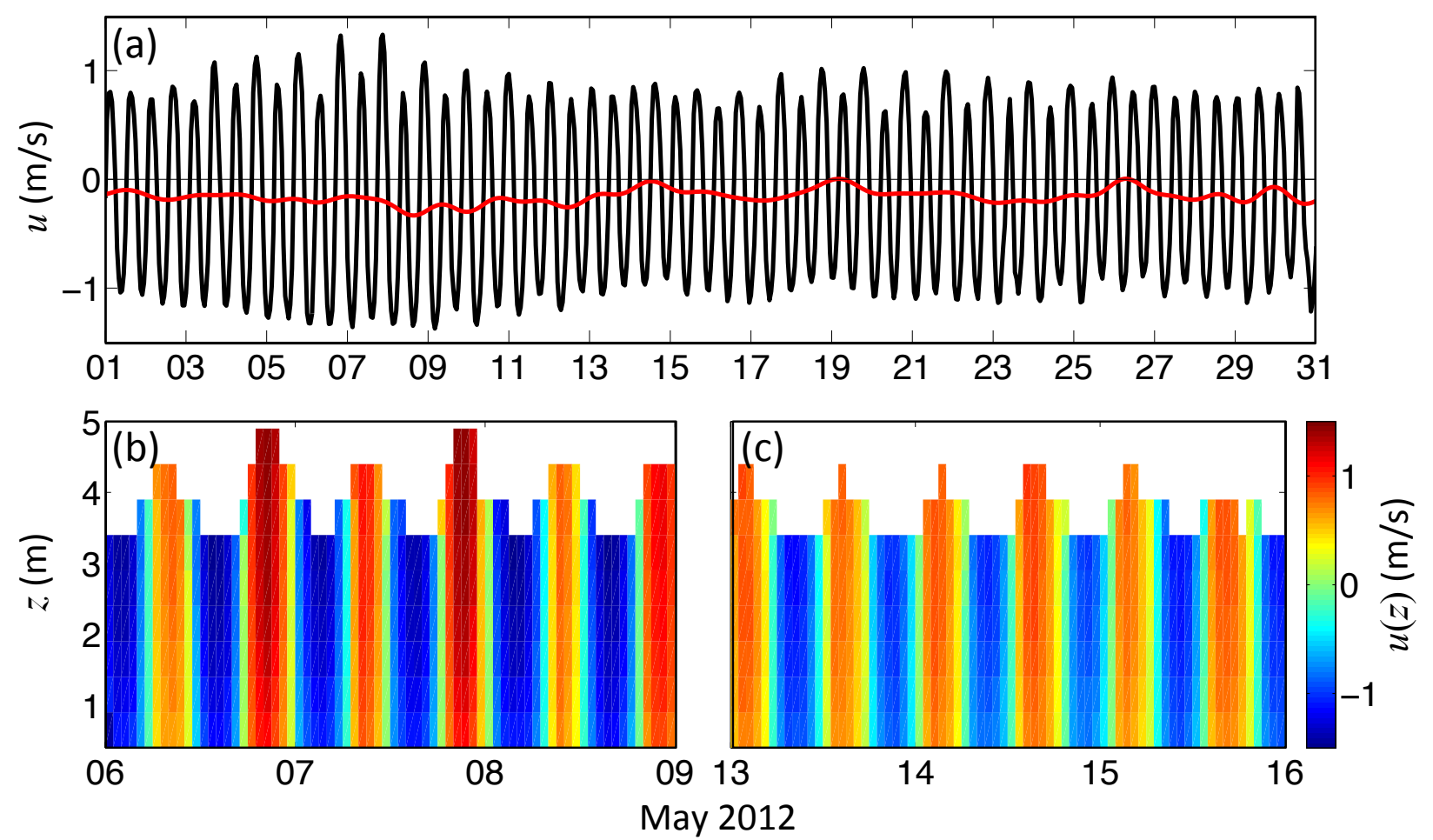

Figure 3.2. (a) Depth-averaged along-inlet currents, $u$ (black curve is unfiltered and red curve is low-pass filtered with the mean retained), and (b) and (c) unfiltered along-inlet currents, $u(\mathrm{z})$ (color contours, scale on the right) at the channel site (black filled circle, Figure 3.1b) as a function of the distance above the bottom, $z$, versus time during (b) spring and (c) neap tides. 


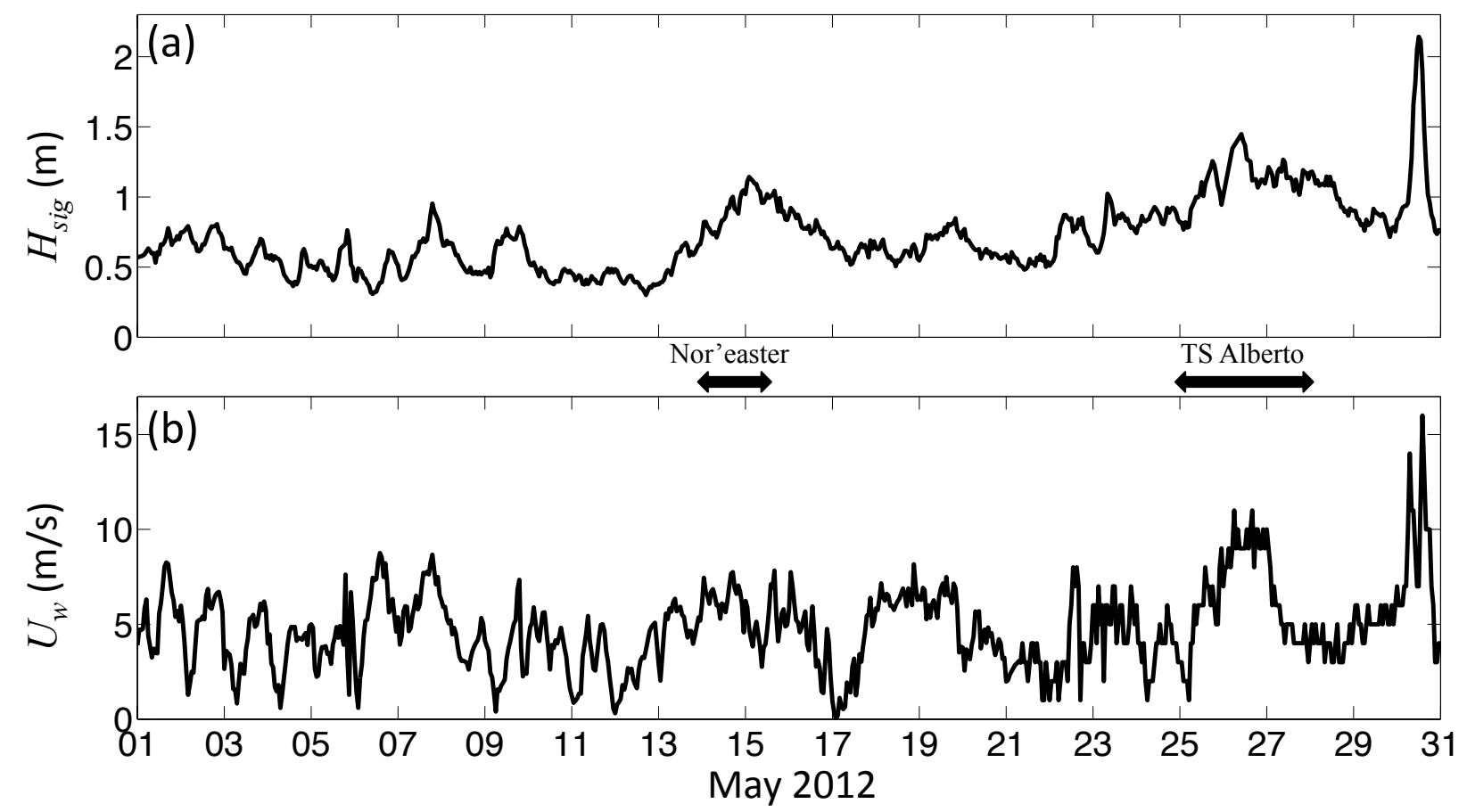

Figure 3.3. (a) Significant wave heights, $H_{s i g}$, at the offshore site (black filled triangle just offshore of the ebb shoal in $5 \mathrm{~m}$ depth, Figure $3.1 \mathrm{~b}$ ), and (b) local wind speed, $U_{w}$, (measured at white square, Figure 3.1b) versus time. Times of a nor'easter and tropical storm Alberto are indicated with black arrows. Centroidal wave periods ranged from 5 to 9 seconds.

The along-inlet flows were nearly depth-uniform above the bottom boundary layer (Figure 3.2b and $\mathrm{c}$ ). The dominant tidal constituent was the $\mathrm{M}_{2}$ (semi-diurnal lunar) tide. Although New River Inlet is a short channel relative to the tidal wavelength (the ratio of channel length to a quarter of a tidal wavelength is about 0.3) (Li and O'Donnell, 2005), the tides are progressive with peak ebbs (floods) occurring within about $30 \mathrm{~min}$ of low (high) water levels (Figure 3.2b and c, and MacMahan et al., in press). Similar to prior observations in curved channels (Waterhouse and Valle-Levinson, 2010), during flood the maximum flows were approximately centered in the primary channel, whereas during ebb the strongest flows were adjacent to the southwestern shore (Figure 3.4). During the flood, water funneled into the mouth with weak, fairly uniform magnitude across the inlet width, converging as the inlet width narrowed, consistent with theory (Stommel and Farmer, 1952). The converging flows led to rapid flood flow accelerations near the mouth of the inlet. During the ebb, water exited the inlet mouth in two distinct jets, one in the deep channel and the other in the shallower remnant channel, with nearly constant flow magnitudes across the ebb shoal. The principal axes (Equation 3.1) of flood and ebb differ by about $10^{\circ}$ to $20^{\circ}$ (Wargula et al., 2013 and Figure 3.4). 


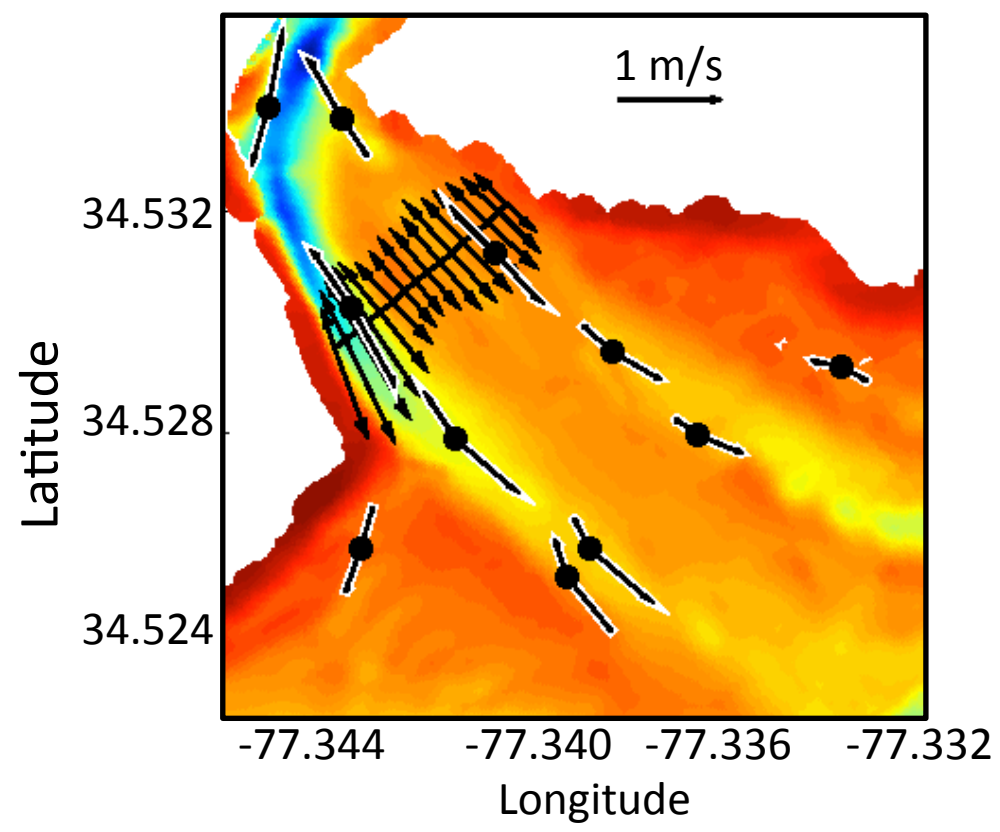

Figure 3.4. Plan view of New River Inlet. Colors are water depth contours (see Figure $3.1 \mathrm{~b}$ for color scale) and arrows are principal axes for flood and ebb flows. The length of each arrow is the average flood or ebb magnitude over the study period (a $1 \mathrm{~m} / \mathrm{s}$ scale arrow is shown near the top center). Black arrows highlighted in white are calculated from in situ sensors located at the corresponding black circle. Black arrows without white highlighting are calculated from boatmounted current profiles (see Appendices A and B) that were depth- and horizontally-averaged over 30-m cross-inlet sections along the black line across the inlet.

Principal flow axes (Equation 3.1) vary along the inlet (cross-shore), as well as across the inlet width (Figure 3.4). Near the inlet mouth the major axis flow direction varies from about $-30^{\circ}$ to $60^{\circ}$, depending on tidal stage and location. The results are not sensitive to changes in the definition of the along-inlet direction for $-60^{\circ}<\theta<-15^{\circ}$ (Wargula et al., 2013).

\subsection{Theory: momentum balance}

The effects of wave forcing on along-inlet flows at New River Inlet were examined by analyzing the dominant terms in the depth-integrated momentum balance (Lentz et al., 1999; Cáceres et al., 2003; Hench and Luettich, 2003):

$$
\frac{\partial(h u)}{\partial t}+\frac{\partial\left(h u^{2}\right)}{\partial x}+\frac{\partial(h u v)}{\partial y}-F h v=-\frac{h}{\rho_{0}} \frac{\partial P_{b}}{\partial x}+\frac{\tau^{s x}}{\rho_{0}}-\frac{\tau^{b x}}{\rho_{0}}-\frac{1}{\rho_{0}} \frac{\partial S_{x x}}{\partial x}-\frac{1}{\rho_{0}} \frac{\partial S_{x y}}{\partial y}
$$


where $t$ is time, $x$ and $y$ are the along- and across-inlet coordinates, $h$ is water depth, $u$ and $v$ are the along- and across-inlet components of the depth-averaged velocity, $F$ is the Coriolis parameter, $\rho_{0}$ is water density, $P_{b}$ is the bottom pressure (which is simplified by the constantdensity hydrostatic equation $P_{b}=\rho_{0} g \eta$, where $\eta$ is the mean water level), $\tau^{s x}$ is wind stress (approximated by $\rho_{a} C_{w} u_{w}\left|U_{w}\right|$ where $C_{w}$ is the wind drag coefficient (Large and Pond, 1981), $u_{w}$ is the along-inlet wind speed and $\left|U_{w}\right|$ is the total wind speed at 10-m above the water surface, and $\rho_{a}$ is the air density), and $\tau^{b x}$ is bottom stress (approximated by $\rho_{0} C_{D} u|U|$, where $C_{D}$ is the bottom drag coefficient calculated from the data (see Results and Figure 3.7) and $|U|$ is the total velocity magnitude $\sqrt{u^{2}+v^{2}}$ )). The results are not sensitive to the small (less than 5\%) changes in water depth $h$ owing to the (neglected) erosion and accretion at the sensor locations. The cross-shore and diagonal wave radiation-stresses $S_{x x}$ and $S_{x y}$ are approximated as (LonguetHiggins and Stewart, 1964; Raubenheimer et al., 2001; Apotsos et al., 2008):

$$
\begin{gathered}
S_{x x}=E_{w}\left[\left(\cos ^{2} \theta_{b}+1\right) \frac{c_{g}}{c}-\frac{1}{2}\right] \\
S_{x y}=E_{w} \cos \theta_{b} \sin \theta_{b} \frac{c_{g}}{c}
\end{gathered}
$$

where $\theta_{b}$ is the centroidal wave direction, $c_{g}$ and $c$ are the group velocity and phase speed (estimated from the centroidal frequency and the water depth), and $E_{w}$ is the wave energy, calculated as:

$$
E_{w}=\frac{1}{16} \rho_{0} g H_{\text {sig }}^{2}
$$

The results are not sensitive to the small differences (roughly 10-15\% overestimation during large wave events) between radiation stresses estimated using the bulk formulas above and radiation stresses estimated using a frequency-dependent directional moment technique (Herbers and Guza, 1990; Elgar et al., 1994; Raubenheimer et al., 2001; Feddersen, 2004). 
To focus on how wave forcing (rather than tidal processes) affects the flows, all momentum balance terms were de-meaned (see Discussion) and low-pass filtered (e.g., red curve in Figure 3.2a) using a discrete Fourier transform filter (cutoff period of $30 \mathrm{hr}$ ) with three transition band samples (Table X, Rabiner and Gold, 1975). The results are not sensitive to cutoff periods ranging from about 26 to $40 \mathrm{hr}$. Owing to ringing artifacts (Gibbs phenomenon) associated with filtering, roughly 24 hours of data were removed from the beginning and end of the time series. The conclusion that waves affect the flows in the inlet is not sensitive to the removal of these data. The subtidal pressure and flow measurements include astronomically forced fortnightly tidal fluctuations and fluctuations at subtidal frequencies driven by nonlinear interactions between higher-frequency tidal processes (Fortunato et al, 1999; MacMahan et al., 2014). Stormdriven fluctuations at tidal frequencies, which can result from short period changes in the forcing or from nonlinear interactions between the forcing processes (e.g., waves, winds) and the tidal flows (Brown et al., 2012) are neglected. Thus, the effects of storm processes may be underestimated.

Coriolis acceleration is neglected because the Rossby number is large at the inlet. Subtidal temporal changes in flux and alongshore gradients of wave radiation stress (the first and last terms in Equation 3.2, $O\left(10^{-5}\right) \mathrm{m}^{2} / \mathrm{s}^{2}$, Figure 3.5) were significantly smaller than the other terms and also are neglected. Remote and local winds may cause subtidal motions at inlets (Wong and Moses-Hall, 1998; Wong and Valle-Levinson, 2002). The effects of large-scale wind forcing, which likely is important to the flows in the inlet (Geyer, 1997; Brown et al., 2013; Li, 2013), are included in the forcing. At New River Inlet, local wind stress is weakly correlated with the measured pressure gradients, which include setup and surge owing to local and remote winds. However, observation-based estimates suggest that local wind stresses $\left(O\left(10^{-5}\right) \mathrm{m}^{2} / \mathrm{s}^{2}\right.$, pink curve, Figure 3.5) over the km-wide ebb shoal are uncorrelated with the bottom stress, and, consistent with prior surfzone studies (Lentz et al., 1999) are an order of magnitude smaller than the wave forcing term $\left(O\left(10^{-4}\right) \mathrm{m}^{2} / \mathrm{s}^{2}\right.$, blue curve, Figure 3.5$)$. Sensitivity tests indicate that local radiation-stress gradients are much larger than local wind stresses for a range of sea-surface roughnesses (Brown and Wolf, 2009, $0.008<\alpha<0.070)$ and wind drag coefficients $(0.0010<$ $\left.C_{w}<0.0025\right)$. Previous models have shown that inlet dynamics differ between the channel and shoals (Cáceres et al., 2003; Buijsman and Ridderinkhof, 2007; Waterhouse and Valle-Levinson, 
2010; Olabarrieta et al., 2011), and thus the channel and shoal momentum balances are examined separately.

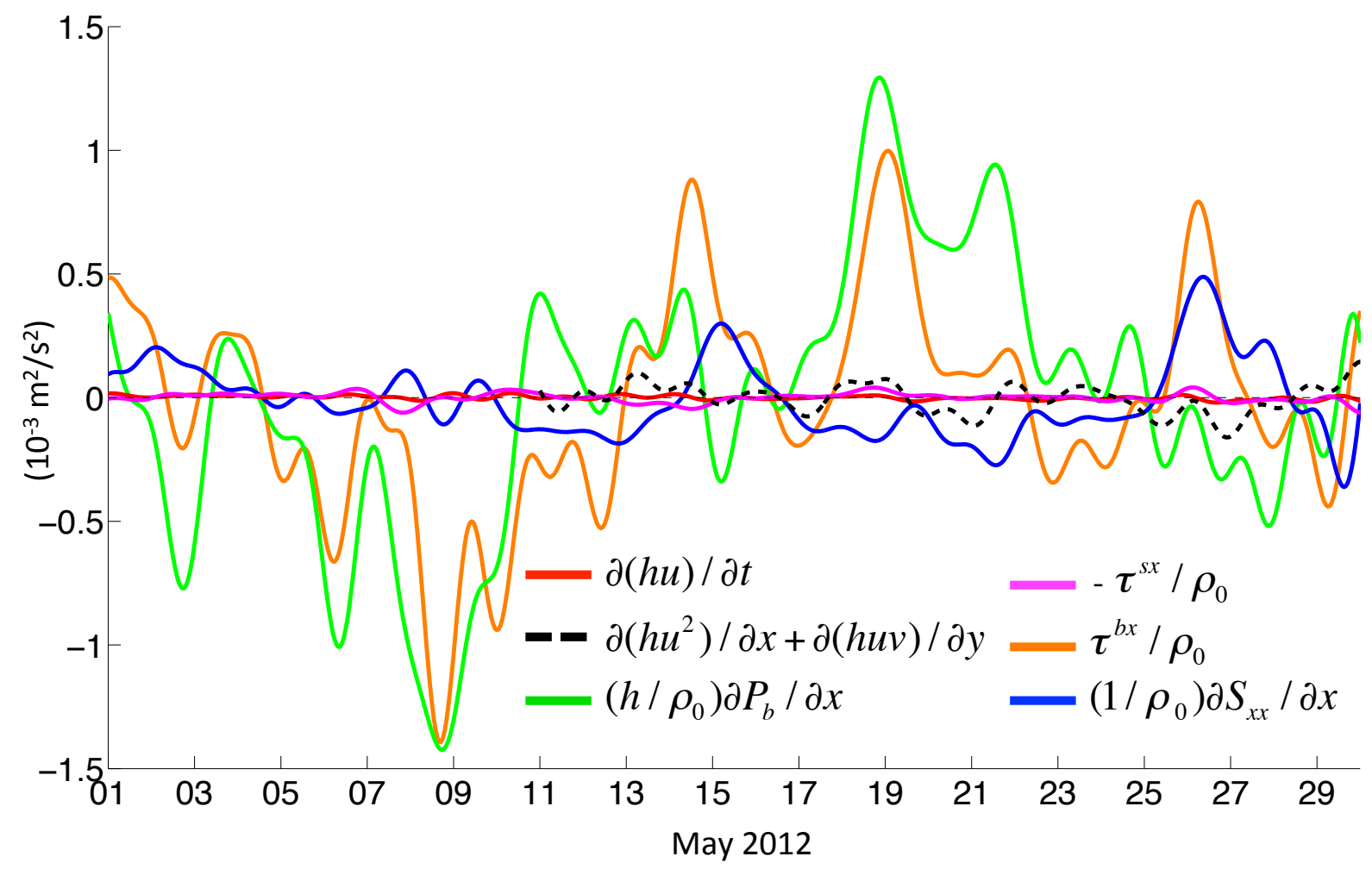

Figure 3.5. Subtidal, de-meaned channel momentum balance terms (Equation 3.1): temporal change in flux (red curve), advective acceleration (black dashed curve, Figure 3.6), pressure gradient (green curve), local wind stress (pink curve), bottom stress (orange curve), and wave radiation stress gradient (blue curve) versus time.

Accelerations of the inlet flows between the offshore and inlet sites (Figure 3.4) could affect the subtidal momentum balance via the advective acceleration terms (Hench et al., 2002; Cáceres et al., 2003; Hench and Luettich, 2003; Li and O'Donnell, 2005; Winant, 2008; Waterhouse and Valle-Levinson, 2010; Tutak and Sheng, 2011). However, consistent with prior modeling studies in well-mixed, shallow, tidal estuaries, rough estimates suggest the two horizontal advection terms in the channel partially cancel (see Appendix A), and their sum (black dashed curve, Figure 3.5 and 3.6) appears to be small $\left(O\left(10^{-5}\right.\right.$ to $\left.\left.10^{-4}\right) \mathrm{m}^{2} / \mathrm{s}^{2}\right)$ compared with the dominant $\left(O\left(10^{-3}\right) \mathrm{m}^{2} / \mathrm{s}^{2}\right)$ momentum balance terms (Jay, 1991; Olabarrieta et al., 2011). Furthermore, addition of these terms to the subtidal momentum balance does not change the overall correlations between the momentum balance terms ( $r^{2}$ changes less than $2 \%$, see Results) or the best-fit value of the drag coefficient ( $C_{D}$ changes are order $2 \%$, see Figure 3.7 and Section 3.6.3). 
Also consistent with prior studies (Li and O'Donnell, 2005; Winant, 2008; Waterhouse and Valle-Levinson, 2010; Olabarrieta et al., 2011), depth-averaged lateral advection was smaller on the shoals than in the channel (Appendix A and Figure 3.12). Estimates of the advective terms are less accurate at the shoals location, owing to their relatively smaller magnitudes and to curvature of the remnant channel. When crude calculations of the advective terms on the shoals are added to the momentum balance, the overall correlation and drag coefficient are reduced by about $10 \%$ and $20-25 \%$, respectively. However, these reductions do not change the conclusions, and thus, these terms are neglected here.

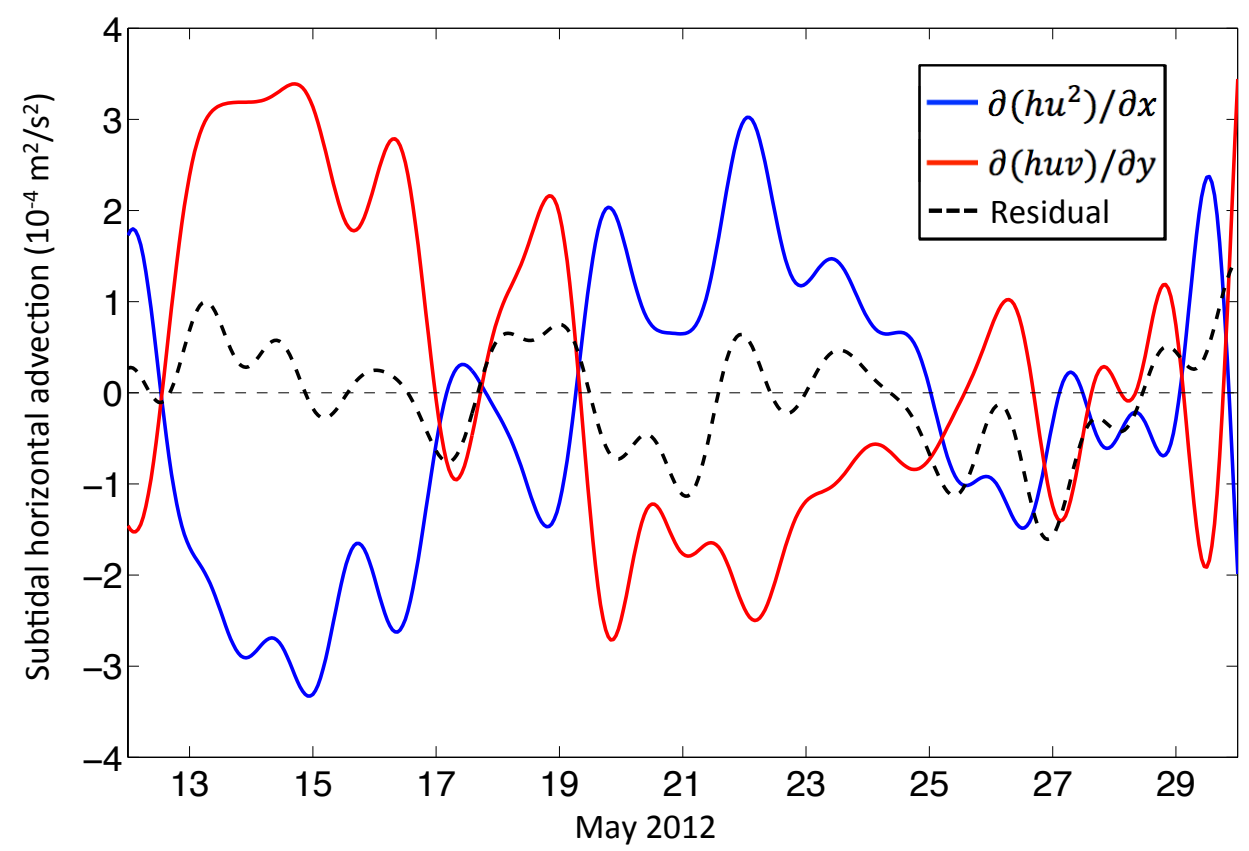

Figure 3.6. Subtidal horizontal advection terms (second (blue curve) and third (red curve) terms in Equation 3.2) and the sum of the two terms (dashed black curve) in the channel versus time. See Appendix A for methods.

The simplified, subtidal, along-inlet, depth-integrated momentum balance becomes:

$$
C_{D} u|U| \approx \frac{\tau^{b x}}{\rho_{0}}=-g h \frac{\partial \eta}{\partial x}-\frac{1}{\rho_{0}} \frac{\partial S_{x x}}{\partial x}
$$

The water depth $h$ was approximated as $5 \mathrm{~m}$ at the channel and $2 \mathrm{~m}$ on the shoals. The rootmean-squared subtidal changes in mean water level $\partial \eta$ between the offshore site and the channel and the shoals were $0.02 \mathrm{~m}$ and $0.01 \mathrm{~m}$, respectively. Root-mean-squared subtidal flows were 
$0.17 \mathrm{~m} / \mathrm{s}$ in the channel (red curve, Figure 3.2a) and $0.10 \mathrm{~m} / \mathrm{s}$ on the shoals. Spatial gradients were calculated using a forward derivative with $\partial x$ the measured distance between the offshore location and the channel or shoals site (approximately $1000 \mathrm{~m}$, Figure 3.1b). The difference between the distance from the shoals to $5 \mathrm{~m}$ depth in the along-inlet direction and the distance from the shoals to the offshore sensor is about $30 \mathrm{~m}$ (less than 3\%) and does not affect the results. Computing the gradients in the momentum balance using a forward difference assumes that the terms vary linearly between the two sensors. The simple balance (Equation 3.6) is similar for centered differences using observations collected farther upstream (not shown), supporting this assumption.

The sensor array used here can resolve large-scale $(O($ few-hundred $\mathrm{m}))$ forcing and circulation patterns, but not small-scale $(O(<100 \mathrm{~m}))$ features that may be caused by unresolved bathymetric variations, or by small-spatial and short-temporal fluctuations in the radiation stresses. For example, visual observations during the field study, and preliminary results from remote sensing (Jessup et al., 2012) and drifting instruments (Zippel and Thomson, 2012) suggest that wave dissipation was spatially variable. Although these small-scale fluctuations may contribute to scatter in the simple momentum balance used here, their inclusion would not change the conclusion that wave forcing contributes significantly to the observed flows.

\subsection{Results}

Between the offshore and the deep channel locations (Figure 3.1b), subtidal bottom stress is primarily balanced by subtidal pressure gradients $\left(r^{2}=0.96 \pm 0.02\right.$, Figure $\left.3.7 \mathrm{~b}\right)$, similar to the tidal balance expected in the straits of long-narrow inlets (Hench et al., 2002). The pressure gradient fluctuations (green curve, Figure 3.8a and 3.9a) may result from fortnightly oscillations, remote- or large-scale-wind forcing, and other subtidal motions in the ocean that propagate into the inlet and the ICW and from subtidal motions that are generated in the inlet via nonlinear interactions between tidal constituents (Chant, 2001; MacMahan et al., 2014). 

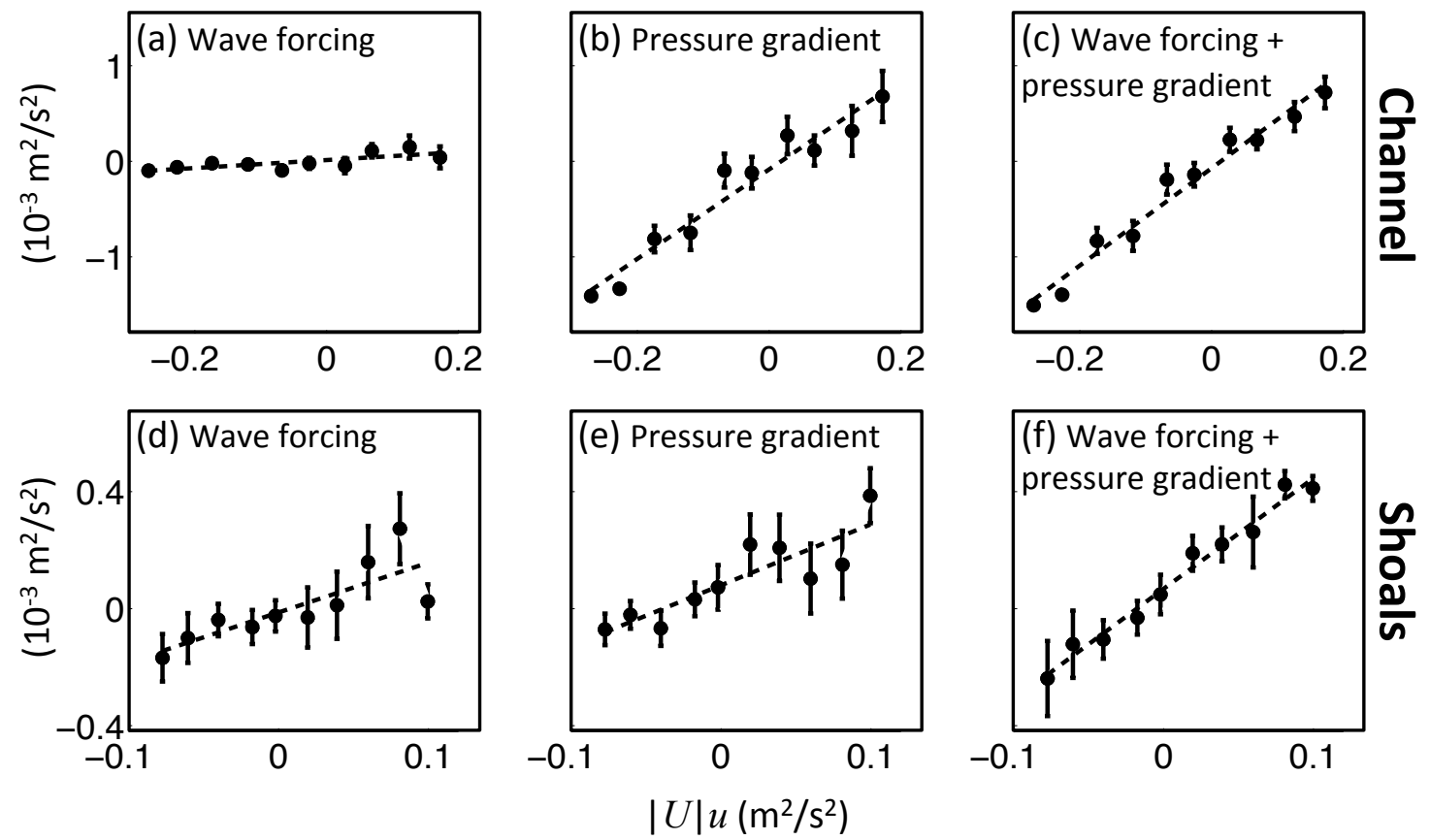

Figure 3.7. Binned means (circles) and standard deviations (vertical bars) of along-inlet (a, d) wave radiation-stress gradients, (b, e) pressure gradients, and (c, f) sum of along-inlet wave radiation-stress and pressure gradients versus inlet flow $(|U| u)$ in the channel (a-c) and on the shoals (d-f). The dashed lines are least squares linear fits to the binned values. Drag coefficients $C_{D}$ calculated from the linear fits are 0.005 in the channel (c) and 0.004 on the shoals (f). Note the vertical ranges are larger for the channel (a-c) than for the shoals (d-f).

In the main channel, wave forcing is an order of magnitude smaller than the pressure gradient (Figs. 7a, 7b, and 8a) and does not improve the overall balance significantly when summed with the pressure gradient (compare $r^{2}=0.98 \pm 0.01$, Figure 3.7c, with $r^{2}=0.96 \pm 0.02$, Figure 3.7b), although the standard deviations in each bin are reduced. However, even though wave forcing usually was relatively small, during big wave events the radiation-stress gradient term became larger than the pressure gradient (see black arrows indicating nor'easter and tropical storm Alberto, Figure 3.8a), and was needed to balance the bottom stress (Figure 3.8b).

Between the offshore and shallow shoals sites (Figure 3.1b), wave radiation-stress and pressure gradients have similar magnitudes (Figs. 7d, 7e, and 9a) and each are correlated with bottom stress $\left(r^{2}=0.65 \pm 0.13\right.$, Figure $3.7 \mathrm{~d}$, and $r^{2}=0.75 \pm 0.10$, Figure 3.7e). Including both improves the correlation between forcing and bottom stress significantly $\left(r^{2}=0.98 \pm 0.01\right.$, Figure $\left.3.7 \mathrm{f}\right)$. 
Discrepancies between the estimated bottom stress and the sum of the forcing terms (Figs. 8b and $9 \mathrm{~b}$ ) could be owing to neglected processes (e.g., wind stress and nonlinear advection), threedimensional effects (e.g., eddies), estimation techniques (e.g., forward differences and filter errors), and measurement errors.

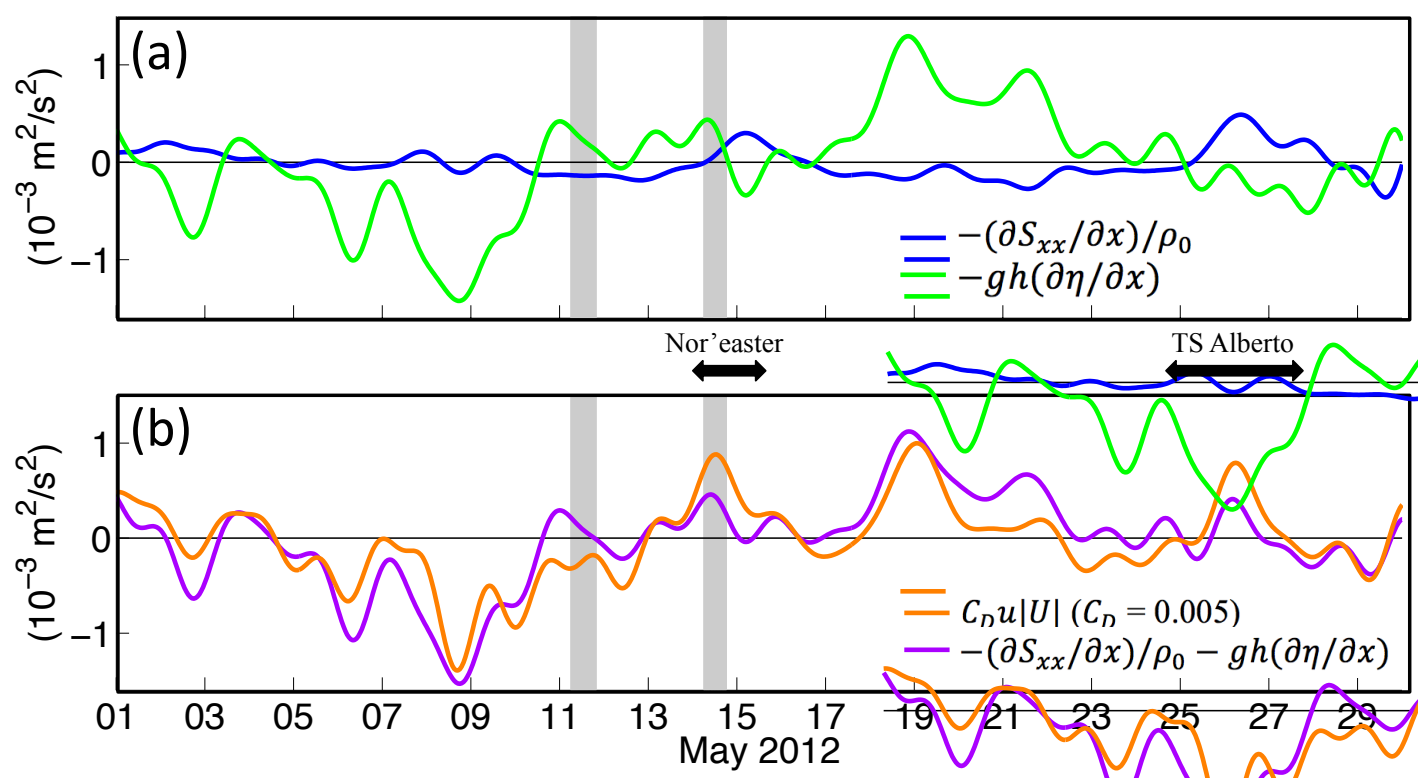

Figure 3.8. Subtidal, de-meaned channel (a) wave forcing $-\left(\partial S_{x x} / \partial x\right) / \rho_{0}$ (blue curve) and pressure gradient $-g h(\partial \eta / \partial x)$ (green curve) and (b) bottom stress (orange curve, $C_{D}=0.005$, from Figure 3.7c) and wave radiation-stress plus pressure gradients $-\left(\partial S_{x x} / \partial x\right) / \rho_{0}-g h(\partial \eta /$ $\partial x)$ (purple curve) versus time. The two curves in $(b)$ are correlated $\left(r^{2} \sim 0.68\right)$ at $95 \%$ confidence levels. Gray vertical stripes are times of cross-inlet transects (white line, Figure 3.1b) with the boat-mounted current profiler (see Appendix B). Times of a nor'easter and tropical storm Alberto are indicated with black arrows.

During storms (black arrows at May 15 and May 25-27 in Figs. 8b and 9b), the wave forcing term enhances the flood flows into the inlet (bottom stress is positive) against an adverse (negative) pressure gradient. Local flows $(u|U|)$ at in situ sensors upstream and downstream of the locations used in the momentum balance calculations also showed enhanced flood flows during times with bigger waves (Figure 3.10). Additionally, the tidally averaged discharge (not shown) measured by a boat-mounted current profiler across the inlet width (white line, Figure $3.1 b$ ) is consistent with the result that wave forcing enhances flood flows (see Appendix B). 


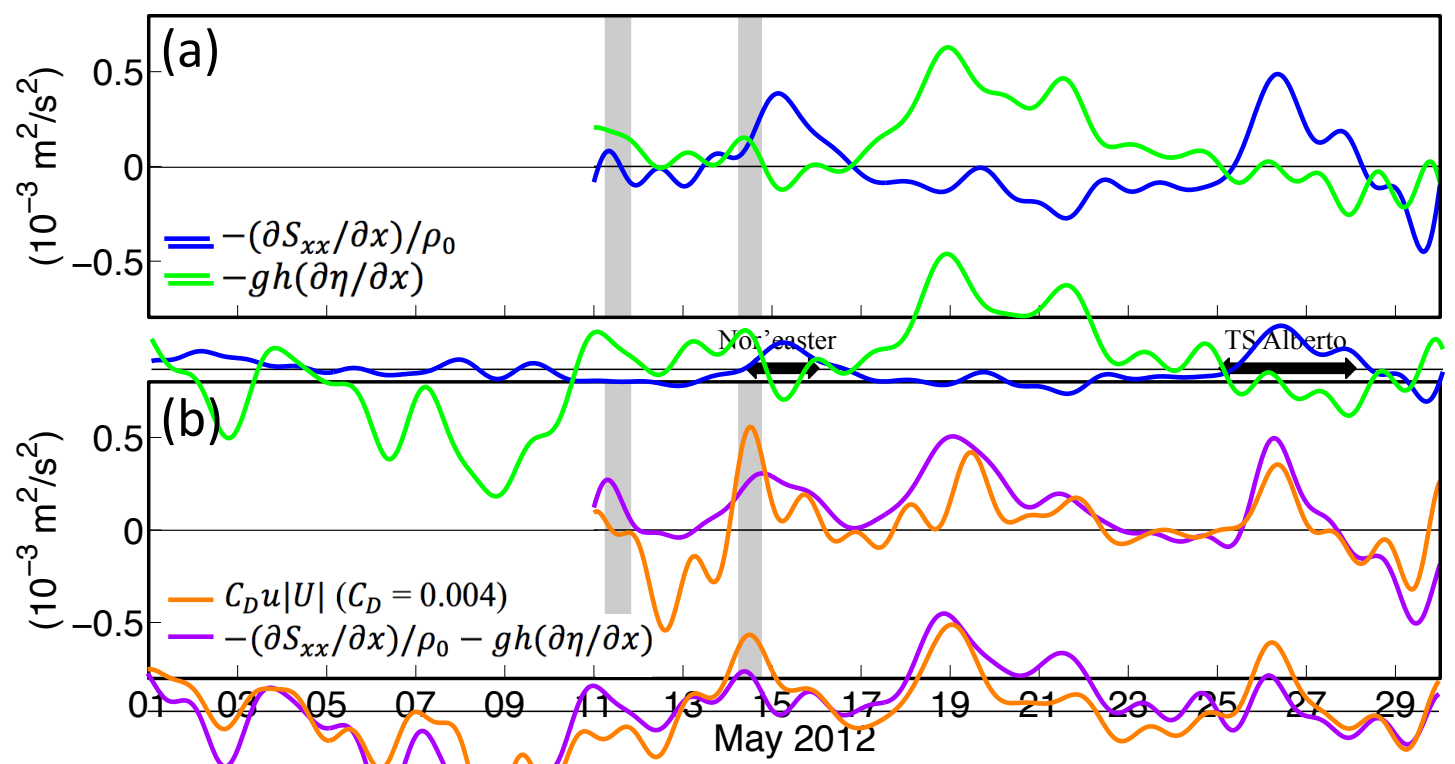

Figure 3.9. Subtidal, de-meaned shoals (a) wave forcing - $\left(\partial S_{x x} / \partial x\right) / \rho_{0}$ (blue curve) and pressure gradient $-g h(\partial \eta / \partial x)$ (green curve) and (b) bottom stress (orange curve, $C_{D}=0.004$, from Figure 3.7f) and wave radiation-stress plus pressure gradients $-\left(\partial S_{x x} / \partial x\right) / \rho_{0}-g h(\partial \eta /$ $\partial x)$ (purple curve) versus time. The two curves in (b) are correlated $\left(r^{2} \sim 0.45\right)$ at $95 \%$ confidence levels. Gray vertical stripes are times of cross-inlet transects (white line, Figure 3.1b) with the boat-mounted current profiler (see Appendix B). Times of a nor'easter and tropical storm Alberto are indicated with black arrows. 


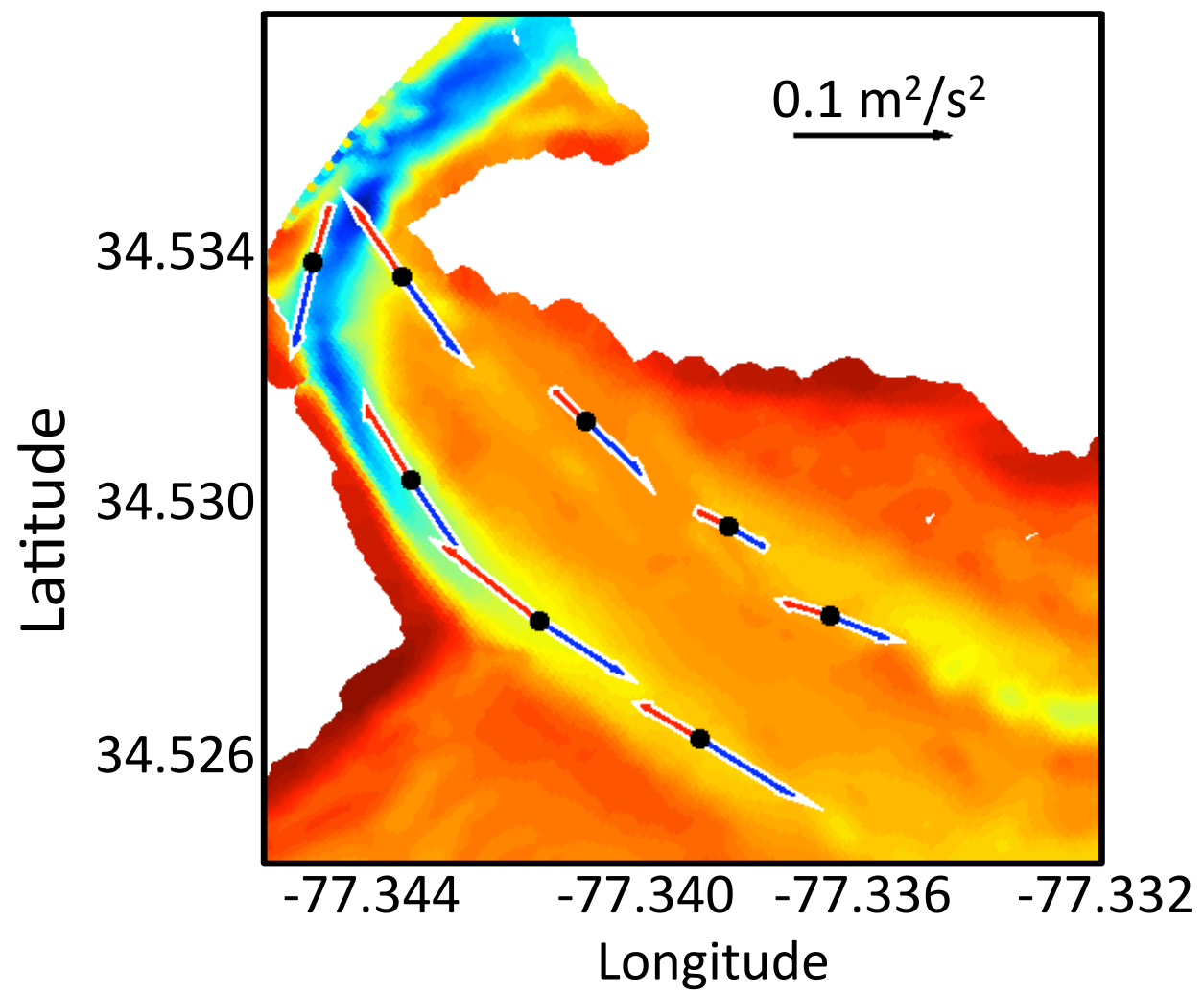

Figure 3.10. Plan view of New River Inlet. Colors are water depth contours (see Figure 3.1b for color scale) and arrows are directions and magnitudes of demeaned subtidal $u \mid U l$ at in situ sensors, averaged over times with significant wave heights less than (blue arrows) and greater than (red arrows) $1 \mathrm{~m}$. A $0.1 \mathrm{~m}^{2} / \mathrm{s}^{2}$ scale arrow is shown near the top right.

\subsection{Discussion}

\subsubsection{Wave-enhanced fluxes in the inlet}

These observation-based estimates of wave-enhanced onshore (flood) flows are consistent with prior model simulations of Óbidos Inlet and Lagoon, Portugal (Bertin et al., 2009; Malhadas et al., 2009) and of the shoals and shallow channels at Ría de Ribadeo, Spain (Piedracoba et al., 2005) and Willapa Bay Inlet, WA, USA (Olabarrieta et al., 2011). However, at Ría de Ribadeo the ebb flows were enhanced on the western side of the channel during large waves, and at Willapa Bay the ebb jet in the main channel was narrowed and intensified by the action of the waves. The enhancement of the flood flows seen in the main channel at New River Inlet could be owing to differences in the inlet geometry (e.g., asymmetric wave breaking patterns at Ría de Ribadeo and Willapa Inlet), or to the time needed to reach a steady state. 
The Ría de Ribadeo is a closed system with a relatively large inlet (width $\sim 1 \mathrm{~km}$ and depth $\sim 17$ $\mathrm{m}$ ) connected to a small embayment (area $\sim 8.5 \mathrm{~km}^{2}$ ). During storms, wave breaking over the shoals on the eastern side forces flows into the inlet. The small embayment quickly reaches a steady state, and a circulation pattern is initiated with the onshore fluxes balanced by enhanced ebb flows on the western side of the inlet (Piedracoba et al., 2005). Willapa Bay (area $\sim 260$

$\mathrm{km}^{2}$ ) also is a closed system that has a large inlet (width about $10 \mathrm{~km}$ ) with a deep ( $\sim 24 \mathrm{~m}$ ) main channel on the northern side and shoals interrupted by several shallow channels on the southern side. Wave breaking over the extensive shoals is predicted to drive flows into the inlet, causing an $11.8 \%$ increase in bay volume (Olabarrieta et al., 2011). As a steady state is approached (with wave forcing balanced at least partly by the setup in the bay), the enhanced flows into the inlet over the shoals (e.g., red and yellow areas in Figure 14 in Olabarrieta et al. (2011)) may be balanced by reduced flood and enhanced ebb flows in the main channel (e.g., blue areas in Figure 14 in Olabarrieta et al. (2011)). Similar to Ría de Ribadeo, the asymmetry of the wave forcing over the spatially nonuniform Willapa Bay shoal-channel system, in combination with local conservation of mass across the inlet, may contribute to the spatial variability of the flows. Although Óbidos lagoon (area $\sim 7 \mathrm{~km}^{2}$ ) also is a closed system, the inlet is narrow $(\sim 25 \mathrm{~m})$ and shallow ( $\sim \mathrm{m}$ ) (Malhadas et al., 2009), possibly restricting the wave-driven flux of water into the lagoon and increasing the time during which there is a net mass flux into the bay, allowing inflow across the entire width of the inlet. New River Inlet is an open system, connected to other inlets via the ICW (Figure 3.1a), and with relatively symmetric wave forcing around the semicircular ebb shoal (Figure 3.1b). The additional inlets along the ICW allow for water mass exchange and leakage. Thus, roughly uniform wave forcing during storms may enhance net flood flows throughout the inlet without local conservation of mass or asymmetric intensification of flows.

\subsubsection{Tidally averaged flows}

Here, "residual" flows are estimated crudely by averaging over all full tidal cycles in the time series. The results are not significantly different (less than $0.01 \mathrm{~m} / \mathrm{s}$ change) from those obtained by subtracting the astronomically forced tidal motions estimated with a harmonic analysis from the full time series and averaging over the experiment period. These longer period, tidally averaged motions underlying the subtidal fluctuations analyzed above may be owing to nonlinear 
interactions between tidal motions, to inlet processes with periods greater than a few days (Brown et al., 2012), or to exchanges with other inlets connected via the ICW.

At New River Inlet, tidally averaged (over 18 to 30 days) flows are ebb-dominant $(O(-0.1 \mathrm{~m} / \mathrm{s}))$ at both the channel and shoals locations within the inlet mouth (Figure 3.4). However, farther upstream, near the first $90^{\circ}$ bend and where the width of the inlet narrows (Figure 3.1b), the tidally averaged flows on the shoals become flood dominant (Lippmann et al., 2013, and compare length of flooding and ebbing arrows in Figure 3.4 at the most upstream location on the shoals).

The tidally averaged flows are not included in the momentum balance analysis above (Sections 3.4 and 3.5). Combining the tidally averaged and subtidal flows shows that, during storms, wave forcing retarded or reversed the offshore-directed "non-tidal" flows at all locations. In the main channel, flows were reversed to onshore-directed near the $90^{\circ}$ bend, retarded to nearly zero inside the inlet mouth (filled black circle, Figure 3.1b), and retarded to a smaller, though still offshore-directed, magnitude in locations offshore of the mouth and across the ebb shoal. A similar along-inlet gradient in flow response during large wave events was observed on the shoals. However, the location of flow retardation to near zero was farther offshore than that in the main channel (between the filled triangle inside the inlet and the open triangle just offshore, Figure 3.1b). The onshore (or less offshore) directed "non-tidal" flow at all locations in the channel and on the shoals during storm events supports the result that waves enhanced flows into the inlet.

\subsubsection{Estimated drag coefficients}

The $95 \%$ confidence limits on $C_{D}$ estimated using a least squares fit are small $(<0.0001)$. However, shortening or lengthening the section of data used in the analysis and changing the bin sizes (Figure 3.7) can change the estimate of $C_{D}$ by as much as \pm 0.002 , possibly owing to errors and neglected processes associated with the filtering technique (Brown et al., 2012) or to temporal variations in the bottom stress or other processes. For example, previous studies have suggested that waves may increase or decrease the apparent bed roughness, depending on the wave and current directions, water depth, and the wave amplitude (Grant and Madsen, 1979; 
Olabarrieta et al., 2010). At inlets with significant wave forcing, storm-related variations in wave conditions and tidal-modulation of currents, wave heights, and wave breaking may lead to a temporally varying bottom stress (Kang and Di Iorio, 2006). Drag coefficient values fitted separately to ebb and flood conditions suggest that the bottom drag is smaller during floods and larger during ebbs. Using these different $\mathrm{ebb}$ and flood $C_{D}$ values slightly improves the correlations between the bottom stress and forcing on the shoals. Temporal variations in these bulk estimates of $C_{D}$ based on the simplified momentum balance also could be owing to changes in flow patterns and migrating bedforms, or to neglected processes such as time-varying wave breaking induced turbulence (Feddersen et al., 2004), lateral mixing and eddies (Geyer et al., 2000), and unresolved advection (Brown and Trask, 1980; Geyer et al., 2000).

Despite these limitations in the estimates and the uncertainties in the value of the drag coefficients, the $C_{D}$ on the shoals is lower than the $C_{D}$ in the channel irrespective of the length of time series used, the combination or separation of ebb and flood, or the fitting to binned or unbinned momentum terms. Gravel and bedforms larger in the channel than on the sandy shoals (Traykovski, pers. comm.) may contribute to the higher $C_{D}$ in the channel. The different $C_{D}$ estimation techniques do not change the qualitative results that wave forcing enhances flood flows in the inlet.

\subsection{Conclusions}

Observations of tides, waves, and currents in both a 5-m deep main channel and a shallower, 2-m deep remnant channel on the neighboring shoals at New River Inlet, North Carolina, USA indicate that wave forcing is a significant contribution to the subtidal along-channel momentum balance. Within the main inlet channel, the primary force balance is between the pressure gradient and bottom stress, with wave radiation stresses significant only during storms. On the shallower shoals, wave radiation-stress and pressure gradient forcing contribute equally to the balance with bottom stress. Wave forcing tends to enhance the flood flows at the inlet, both in the channel and on the shoals. 


\subsection{Appendix}

\subsubsection{Appendix A: Advection terms}

The magnitudes of the two subtidal advection terms (second and third terms in Equation 3.2) are estimated crudely using the in situ data (Figure 3.6). The along-inlet gradient $\partial\left(h u^{2}\right) / \partial x$ (blue curve, Figure 3.6) is estimated by a forward difference between $h u^{2}$ at the offshore and the channel or shoals sites (black filled circle and triangles, Figure 3.1b) divided by the distance between the sites. The cross-inlet gradient $\partial(h u v) / \partial y$ in the channel (red curve, Figure 3.6) is estimated by a forward difference between huv at the channel and shoals sites divided by the distance between them. The two terms are correlated $\left(r^{2}=0.91\right)$ with $95 \%$ confidence, but are out of phase, and thus roughly balance each other. In particular, the sum of the two advection terms is smaller than the dominant forcing terms (compare black dashed curve with the orange, green, and blue curves, Figure 3.5).
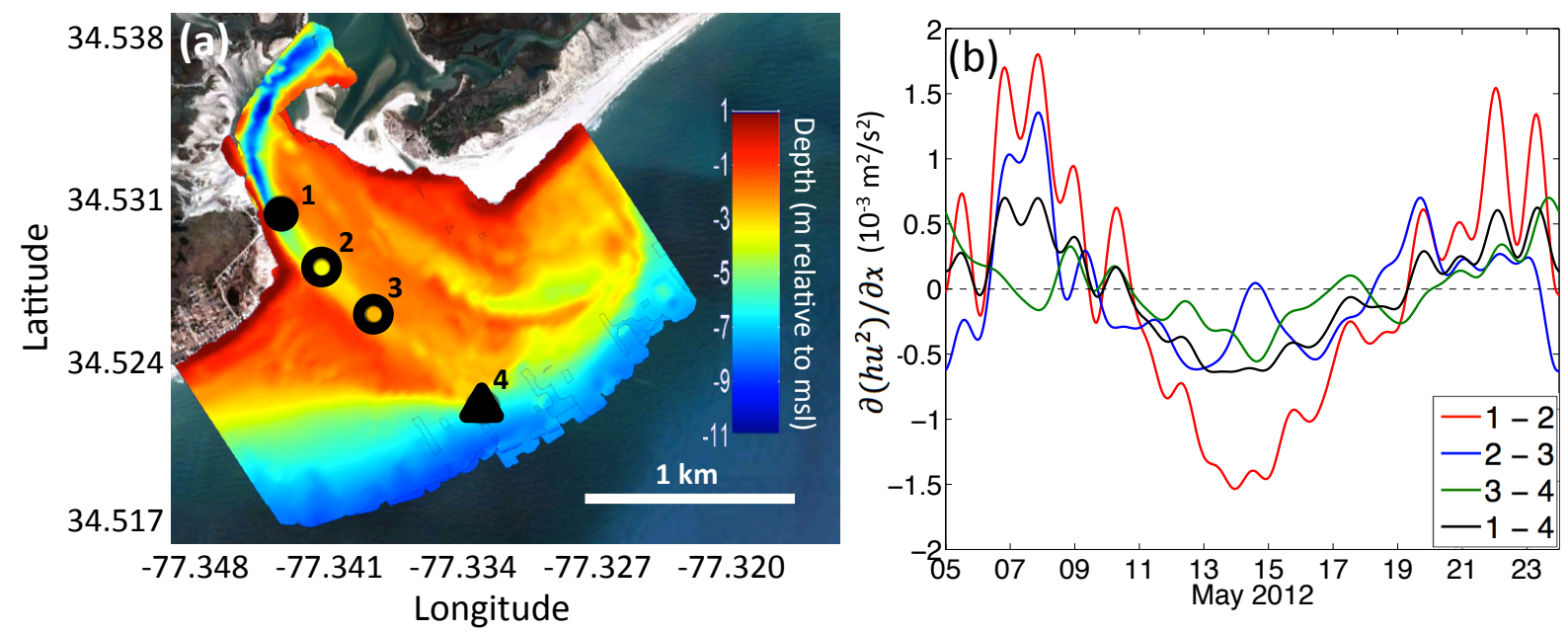

Figure 3.11. (a) Locations of instruments (latitude and longitude indicated on axes) used to form sensor pairs to estimate (b) the subtidal along-inlet gradient of along-inlet advection $\partial\left(h u^{2}\right) / \partial x$ (second term in Equation 3.2) as a function of time. Filled circle and triangle are "channel" and "offshore" sites. Pair 1-4 (black curve in b) was used in the final advection calculation (blue curve, Figure 3.6).

The accuracy of the advection estimates, which are based on spatially sparse measurements, is evaluated using additional in situ measurements spanning the ebb shoal, and using high-spatial resolution boat-mounted current profiler-transect measurements (white line, Figure 3.1b). Estimates of the subtidal along-inlet gradient $\partial\left(h u^{2}\right) / \partial x$ in the channel between different 
instrument pairs along the inlet $(1-2,2-3,3-4$, Figure 3.11a) shows that the magnitude of the advective term increased onshore. All estimates showed a similar structure in time (Figure 3.11b), suggesting that the estimates are plausible. Although using the channel (sensor 1, Figure 3.11a) and offshore (sensor 4, Figure 3.11a) locations may result in underestimation of the advective term by about a factor of 3 (compare 1-4 with 1-2, Figure 3.11b), these sensors were used in the analysis to be consistent with estimates of the other momentum terms.

Boat-mounted profiler transects suggest that the underestimation of the along-inlet term $\partial\left(h u^{2}\right) / \partial x$ may be balanced by similar underestimation of the cross-inlet term $\partial(h u v) / \partial y$. Current profile transects (white line, Figure 3.1b) were conducted hourly for 14 hours on May 11 and 14 to sample the change in flows over a complete tidal cycle. The downward-facing transducer was positioned $0.20 \mathrm{~m}$ below the water surface and sampled at $1 \mathrm{~Hz}$ with vertical bins from 0.02 to $0.50 \mathrm{~m}$ and blanking distances of 0.20 to $0.50 \mathrm{~m}$, depending on the water depth (measured by a separate vertical acoustic beam) and velocity conditions. Boat velocity and position were measured by GPS with real-time kinematic corrections. The current profile transects were depth-averaged and horizontally averaged over 20-m (Figure 3.12) or 30-m (Figure 3.4) cross-inlet sections. The cross-inlet advection term estimated from these high-spatial resolution transects is maximum in the channel and small over the shoals (Figure 3.12), consistent with prior studies (Li and O'Donnell, 2005; Winant, 2008; Waterhouse and ValleLevinson, 2010; Olabarrieta et al., 2011). In particular, in the channel (cross-inlet distance -20 to $100 \mathrm{~m}$, Figure 3.12) the advection term is large $\left(O\left(10^{-4}\right.\right.$ to $\left.\left.10^{-3} \mathrm{~m}^{2} / \mathrm{s}^{2}\right)\right)$ and negative for both ebbing and flooding flows. On the shoals, the cross-inlet term fluctuates between positive and negative, but always is small. The signs and relative magnitudes of the crude estimates from the in situ sensors are consistent with the transect-based estimates. However, the in-situ-based estimates (Figure 3.6) are more than a factor of 4 smaller than the local estimates from the transect data owing primarily to the poor spatial resolution of the in situ measurements, which average the terms between the instrument locations (between the symbols in Figure 3.12).

\subsubsection{Appendix B: Tidally-averaged discharge}

Discharge was calculated by spatially integrating the boat-mounted current profile transects (see Appendix A) over the inlet cross-section (white line, Figure 3.1b). To calculate the tidally 
averaged discharge during specific periods, the hourly discharge data were interpolated using a spline fit and integrated in time.

The tidally averaged discharge measured on May 11 and 14 by the boat-mounted current profiler across the inlet width is consistent with the result that wave forcing enhances flood flows (see Results). On May 11, during calm conditions ( $H_{\text {sig }}=0.5 \mathrm{~m}$ and light northerly winds $\sim 4 \mathrm{~m} / \mathrm{s}$ (Figure 3.3) from $\sim 0^{\circ}$ ), the averaged discharge was out of the inlet (ebbing). However, on May 14 , during an approaching storm $\left(H_{\text {sig }}=1.0 \mathrm{~m}\right.$ and moderate southerly winds $\sim 6 \mathrm{~m} / \mathrm{s}$ (Figure 3.3 ) from $\sim 170^{\circ}$ ), the averaged discharge was into the inlet (flooding). In addition to wave forcing, the southerly winds may have contributed to the residual flooding discharge. Note that the subtidal pressure gradient was similar on both days (green curves in Figs. 8a and 9a).

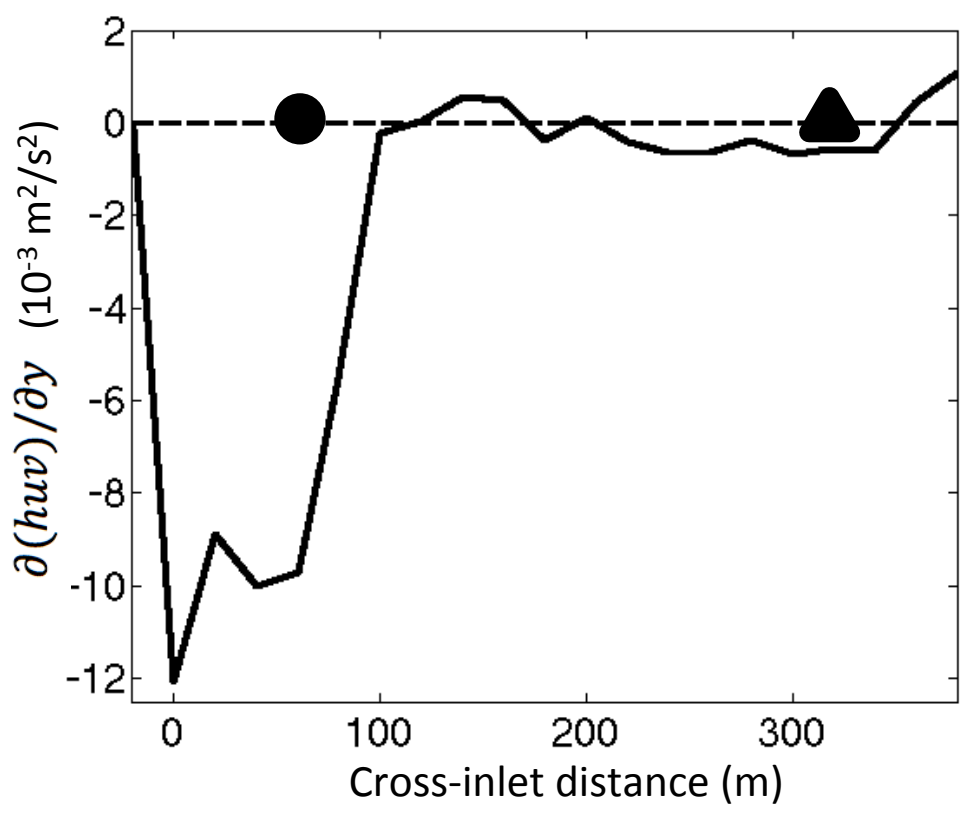

Figure 3.12. The tidally averaged cross-inlet gradient of along-inlet advection $\partial(h u v) / \partial y$ (third term in Equation 3.2) calculated from 20-m horizontally binned flows and water depths measured by the boat-mounted current profiler across the inlet width (white line, Figure 3.1b) versus cross-inlet distance. The origin $(0 \mathrm{~m})$ of the cross-inlet distance was set at the deepest point in the channel. The black circle and triangle on the dashed line at advection $=0$ are the locations of the channel and shoals in situ sensors (Figure 3.1b). 


\section{Chapter 4}

\section{Curvature- and wind-driven cross-channel flows at an unstratified tidal bend}

\subsection{Abstract}

Observations of flows, water levels, winds, and bathymetry collected for a month at an unstratified, narrow $(150 \mathrm{~m})$, shallow $(8 \mathrm{~m})$, 90-degree, tidal inlet bend are used to evaluate an analytical model for curvature-driven flow and the effects of local wind on the cross-channel circulation. Along-channel flows range -1.0 to $1.4 \mathrm{~m} / \mathrm{s}$ (positive is inland) and cross-channel flows are roughly 0.1 to $0.2 \mathrm{~m} / \mathrm{s}$ (positive is to the west) at a profiler near the outer bank of the bend. High-resolution observations across the channel suggest tidal asymmetry and lateral variability in the sea surface tilts and flows. The depth-averaged dynamics suggest the importance of local deviations of the pressure gradient on ebb from the large scale (shore-toshore) pressure gradient. The two-layered cross-channel flows during weak winds are consistent to first order with a one-dimensional depth-varying balance between centrifugal acceleration, bottom stress, and diffusion. Low-passed (to remove tides) surface and bottom cross-channel flows were correlated $\left(r^{2}=0.5\right.$ to 0.7$)$ with cross-channel wind velocity, suggesting that winds enhance and degrade the local-curvature-induced, two-layer flow, and driving three-layer flow. This flow response to the wind is larger than that expected from a one-dimensional balance, suggesting that two- and three-dimensional processes are important.

\subsection{Introduction}

Cross-channel flows laterally redistribute water properties and momentum, affecting alongchannel dynamics (Lerczak and Geyer, 2004), longitudinal dispersion (Seim and Gregg, 1997; Lacy and Monismith, 2001), and bay-ocean exchange (Smith, 1976). Curvature-driven crosschannel flows (e.g., at a bend or headland) have been studied for many years (Boussinesq 1868; Thomson 1876; Rozovskii, 1957; Kalkwijk and Booij, 1986; Geyer 1993). However, the 
modification of these dynamics in unstratified tidal bends with complex geometry and strong winds is not understood well.

At an unstratified bend, centrifugal forcing of flow causes helical particle motions with a primary along-channel (streamwise) flow and secondary cross-channel (stream-normal) flow towards the outside of the bend at the surface and towards the inside of the bend near the bed (Kalkwijk and Booij, 1986). Field and laboratory studies suggest that upstream geometry (e.g., an upstream headland or bend) can cause tidal asymmetry in the development of cross-channel flows inside a bend (Vennell and Old, 2007), as well as flow decelerations and adverse sea surface tilts at the outer bank of a downstream bend (Blanckaert, 2010). Tidal asymmetry of cross-channel flows has been identified as a major driver of residual estuarine circulation in stratified systems (Chant and Wilson, 1997; Lerczak and Geyer, 2004; Becherer et al., 2015). However, the importance of tidal asymmetry and lateral variability in flows and geometry to the cross-channel dynamics in an unstratified inlet are not well understood.

Winds can drive subtidal changes to inlet circulation over large scales (Wong, 1994) and on local scales (Wong and Valle-Levinson, 2002). Numerical and observational studies suggest that although local wind effects occur over a small area, they can influence overall dynamics substantially by driving flows (Csanady, 1973; Hearn et al., 1987; Mathieu et al., 2002; Huijts et al., 2009; Li and Li, 2012) and pressure gradients (Hinata et al., 2010), modifying circulation patterns (Ponte et al., 2012), increasing shear (MacVean and Lacy, 2014), and enhancing sediment transport and morphological evolution (Chen et al., 2009). Many studies have demonstrated the indirect effects of wind on cross-channel dynamics either via Ekman dynamics (Winant, 2004; Sanay and Valle-Levinson, 2005) or by driving lateral phase lags in alongchannel flows, which generate cross-channel flows via differential advection or cross-channel baroclinic forcing (Wong, 1994; Chen et al., 2009; Waterhouse and Valle-Levinson, 2010; Li and Li, 2012; Xie et al., 2017). However, the direct effects of local wind on cross-channel flows in shallow (e.g., less than Ekman depth), unstratified systems are generally neglected. 
Here, in situ measurements of water levels, currents, wind, and bathymetry at an unstratified tidal inlet bend are used to evaluate a laboratory-tested analytical model for curvature-driven flow (Kalkwijk and Booij, 1986) and the effects of local wind on the cross-channel circulation.

\subsection{Theory}

A streamwise coordinate system is adopted (hereafter called along- and cross-channel directions, Figure 4.1a, coordinate system labeled $s$ and $n$ ), such that the depth-averaged cross-channel flows are always zero. In contrast to prior studies (Geyer, 1993; Nidzieko et al., 2009), the sign of the along-channel flow is retained (positive (negative) during flood (ebb)) to avoid artificial M4 (6.2 h period overtide) frequency fluctuations in the time series and artificial M2 (12.4 h period lunar tide) fluctuations in the wind when rotated into the same reference frame. The crosschannel momentum balance at an unstratified bend in streamwise coordinates is (Kalkwijk and Booij, 1986; Geyer, 1993; Nidzieko et al., 2009):

$$
\frac{\partial u_{n}}{\partial t}+u_{s} \frac{\partial u_{n}}{\partial s}+u_{n} \frac{\partial u_{n}}{\partial n}-\frac{u_{s}^{2}}{R}+F u_{s}=-g \frac{\partial \eta}{\partial n}+\frac{\partial}{\partial z}\left[A \frac{\partial u_{n}}{\partial z}\right]
$$

where $t$ is time, $s$ and $n$ are the along and cross-channel coordinates (positive into the inlet and to the western bank, Figure 4.1a, coordinate system), $u_{s}$ and $u_{n}$ are the along- and cross-channel velocities, $R$ is the radius of curvature, $F$ is the Coriolis parameter, $\eta$ is the water level, and $A$ is the vertical eddy viscosity. Advection owing to cross-channel gradients in flow curvature, vertical advection, and horizontal diffusion (not shown in Equation 4.1) are assumed to be small (Kalkwijk and Booij, 1986; Hench et al., 2002).

The left hand side of Equation 4.1 is made up of acceleration terms (from left to right): local acceleration owing to time rate of change in cross-channel flows, along-channel advective acceleration owing to spatial adjustment of the cross-channel flows, cross-channel advective acceleration of the cross-channel flows, centrifugal acceleration owing to channel curvature, and Coriolis acceleration owing to rotation. These accelerations are balanced by a cross-channel pressure gradient owing to a sea surface tilt and vertical diffusion (Equation 4.1, left to right of the right hand side). 

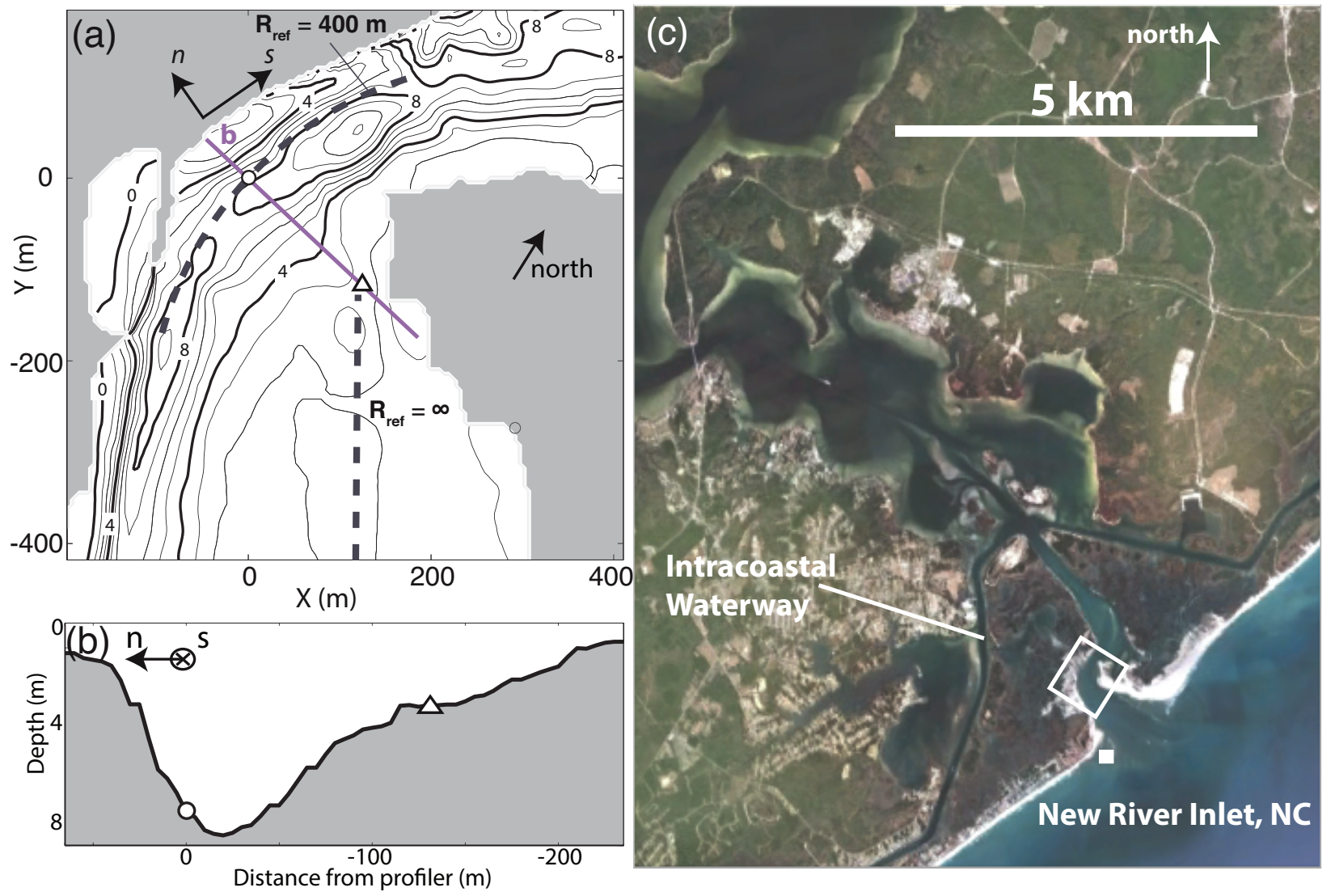

Figure 4.1 (a) Contour lines of bathymetry ( $1 \mathrm{~m}$ depth increments $(0,4$, and $8 \mathrm{~m}$ contours are thick and labeled)) overlaid with locations of the colocated profiler and pressure gage (black open circle) and the pressure gage (black open triangle). Gray dashed curves of $400 \mathrm{~m}$ and $\infty$ (straight) radii included for reference. Positive along- and cross-channel directions are indicated with black arrows labeled $s$ and $n$. Gray regions correspond to no bathymetry data (see panel (c) for true coastline). (b) Bathymetry versus cross-channel distance from the profiler (positive to the left (west)) along the purple line labeled $\mathbf{b}$ in panel (a). Instrument locations are indicated by the black open circle and triangle. Flood and positive cross-channel flow directions (positive $s$ and $n$ ) are into the page and to the left. (c) Google Earth image of the North Carolina coast showing New River Inlet and the Intracoastal Waterway. The white open square shows the location of panel (a). The white filled square is the location of onsite wind measurements.

The depth-averaged (indicated by the overbars) momentum balance (Equation 4.1) is:

$$
\overline{u_{s} \frac{\partial u_{n}}{\partial s}}+\overline{u_{n} \frac{\partial u_{n}}{\partial n}}-\overline{\frac{u_{s}^{2}}{R}}+F \overline{u_{s}}=-g \frac{\partial \eta}{\partial n}+\overline{\frac{\partial}{\partial z}\left[A \frac{\partial u_{n}}{\partial z}\right]}
$$

By definition, $\overline{u_{n}}=0$ (thus, the depth-averaged local acceleration is zero). 
The depth-average of vertical diffusion (Equation 4.2) is defined as the difference between the surface (wind) and bottom boundary stress conditions (Kalkwijk and Booij, 1986):

$$
\overline{\frac{\partial}{\partial z}\left[A \frac{\partial u_{n}}{\partial z}\right]}=\frac{1}{H} \int_{h}^{\eta} \frac{\partial}{\partial z}\left[A \frac{\partial u_{n}}{\partial z}\right] d z=\frac{\tau^{s n}}{\rho_{0} h}-\frac{\tau^{b n}}{\rho_{0} h}
$$

where $h$ is the water depth and $\tau^{s n}$ and $\tau^{b n}$ are the surface $(z=\eta)$ and bottom $(z=h)$ boundary conditions, the cross-channel components of wind and bottom stress, respectively. The wind stress is parameterized as $\tau^{s n}=\rho_{a} C_{w} w_{n}|W|$, where $\rho_{a}$ is the density of air, $C_{w}$ is the wind drag coefficient (Large and Pond, 1981), $w_{n}$ is the cross-channel component of wind velocity, and $|W|$ is the total wind speed at $10 \mathrm{~m}$ above the water surface. The bottom stress is approximated as $\tau^{b n}=\rho_{0} C_{D} u_{n, b}\left|U_{b}\right|$, where $C_{D}$ is the bottom drag coefficient, $u_{n, b}$ is the near-bottom (defined here as velocity at $z=0.8 \mathrm{~m}$, the measurement lowest in the water column) cross-channel velocity, and $\left|U_{b}\right|$ is the near-bottom total velocity magnitude $\left(\left|U_{b}\right|=\sqrt{u_{s, b}^{2}+u_{n, b}^{2}}\right)$.

Following previous studies, we obtain the depth-varying cross-channel momentum balance by subtracting Equation 4.2 from Equation 4.1 and substituting in Equation 4.3:

$$
\begin{aligned}
\frac{\partial u_{n}}{\partial t}+ & \left(u_{s} \frac{\partial u_{n}}{\partial s}-\overline{u_{s} \frac{\partial u_{n}}{\partial s}}\right)+\left(u_{n} \frac{\partial u_{n}}{\partial n}-\overline{u_{n} \frac{\partial u_{n}}{\partial n}}\right)-\frac{u_{s}^{2}-\overline{u_{s}{ }^{2}}}{R}+F\left(u_{s}-\overline{u_{s}}\right) \\
= & \frac{\partial}{\partial z}\left[A \frac{\partial u_{n}}{\partial z}\right]-\frac{\tau^{s n}}{\rho_{0} h}+\frac{\tau^{b n}}{\rho_{0} h}
\end{aligned}
$$

Slack tide, the $\sim 30$ minute transition period between flood and ebb, is neglected in the momentum balance analysis. The local acceleration is neglected because it is small $\left(O\left(10^{-5}\right)\right.$ $\mathrm{m} / \mathrm{s}^{2}$ ), except near slack. Coriolis acceleration is neglected because the Rossby number (Ro = $U /(F R) \sim 50$, Nidzieko et al., 2009) is large inside the inlet owing to the sharp curvature, and the term is small compared to other terms $\left(O\left(10^{-5}\right)\right.$ to $\left.O\left(10^{-4}\right) \mathrm{m} / \mathrm{s}^{2}\right)$. Wind stress is small $\left(O\left(10^{-5}\right)\right.$ to $O\left(10^{-4}\right) \mathrm{m} / \mathrm{s}^{2}$ ) compared other terms and the dynamics analysis (Sections 4.5.1 and 4.5.2) will 
focus on low wind days. Bottom stress is also small $\left(O\left(10^{-4}\right) \mathrm{m} / \mathrm{s}^{2}\right)$ compared other depthaveraged terms (Nidzieko et al., 2009).

The nonlinear advection terms (Equation 4.4, second and third parenthesis on left hand side) are neglected in the steady-state analytical model (Kalkwijk and Booij, 1986) by assuming the length scales of flow adaptation are short compared with the length scale of variability in the curvature along the channel. Assuming a bottom drag coefficient $C_{D}$ of 0.005 (Wargula et al., 2014; Chen et al., 2014), the adaptation length scale is $L_{\text {adapt }}=11 \mathrm{~h}$ (Kalkwijk \& Booij, 1986), roughly 100 $\mathrm{m}$. This suggests that the cross-channel flows are fully adapted to the curvature near the midpoint of the $\sim 400 \mathrm{~m}$ long bend (Figure 4.1a, black open circle). Thus, advection may be neglected in local dynamics, however, advection may be important in regions with varying depth, width, or curvature owing to the non-local (e.g., downstream or cross-gradient) adjustment of flows to variable geometry and flows (Signell and Geyer, 1991; Geyer, 1993; Nidzieko et al., 2009; Blanckaert, 2011).

The rearranged depth-averaged (simplified Equation 4.2) and depth-varying momentum balances (simplified Equation 4.4) are (Kalkwijk and Booij, 1986):

$$
\begin{gathered}
-\frac{\overline{u_{s}{ }^{2}}}{R}=-g \frac{\partial \eta}{\partial n} \\
-\frac{u_{s}^{2}-\overline{u_{s}{ }^{2}}}{R}=\frac{\partial}{\partial z}\left[A \frac{\partial u_{n}}{\partial z}\right]+\frac{\tau^{b n}}{\rho_{0} h}
\end{gathered}
$$

\subsection{Field observations}

\subsubsection{Site location}

New River Inlet is roughly $100 \mathrm{~km}$ south of Cape Hatteras, on the coast of North Carolina. The inlet width is $1000 \mathrm{~m}$ at the mouth and tapers to $200 \mathrm{~m}$ about $800 \mathrm{~m}$ inland from the mouth, where two sharp $90^{\circ}$ bends form the shape of a reversed ' $\mathrm{S}$ ' (Figure 4.1c). New River extends about $25 \mathrm{~km}$ upstream from the inlet, and the backbay has an area of about $68 \mathrm{~km}^{2}$ (MacMahan et al., 2014). Approximately $3 \mathrm{~km}$ upstream from its mouth, the inlet intersects the Intracoastal 
Waterway, which continues north and south from New River, connecting to many additional inlets, including Browns Inlet (located $12 \mathrm{~km}$ to the north) and New Topsail Inlet (located $36 \mathrm{~km}$ to the south).

The bathymetry was surveyed (relative to NAVD88) five times (16 to 17 April; 01 to 02,10 to 11, 17 to 18, and 25 May) during the 2012 field program. Temporal changes in the sand levels near the profiler (Figure 4.1a, black open circle) inside the inlet channel were less than $0.2 \mathrm{~m}$, and the results here are not sensitive to which bathymetry survey is used. For this study, we use the bathymetry surveyed from 10 to 11 May, located during the middle of the study period.

There are two channels inside the inlet mouth that converge at the bend: a western channel (hereafter referred to as the "deep channel") (50 to $100 \mathrm{~m}$ wide; $10 \mathrm{~m}$ deep near the bends and shoals to approximately $5 \mathrm{~m}$ near the inlet mouth) and an eastern channel on the shallow shoals (hereafter referred to as the "shoals channel") (2 to $3 \mathrm{~m}$ deep). The western channel was dredged in April 2012.

The radius of curvature $R$ is defined as the change in angle along a streamline $R=-\partial s / \partial \theta$, where $s$ is the along-streamline coordinate and $\theta$ is the angle of the streamline (Hench et al., 2002). Typically, a radius of curvature is estimated using the arc between the inflection points in

a channel bend along the centerline of either the channel or thalweg (the deepest part of the channel) (Elston, 2005). However, the local radius of curvature can be spatially and tidally variable owing to changes in the local geometry and deviations of the flow. The shoals channel is nearly straight (Figure 4.1a, vertical dashed line). The deep channel has a "bend-scale" (from bend inlet to outlet) curvature of $400 \mathrm{~m}$, which aligns with the local contours near the profiler reasonably well (Figure 4.1a, compare contours near black open circle with dashed curve).

\subsubsection{Water level and flow observations}

Observations of water levels and flows were collected at the bend (Figure 4.1a, symbols) nearly continuously during May 2012. Water levels were measured at $2 \mathrm{~Hz}$ for $3072 \mathrm{~s}$ starting at the top of each hour with stand-alone pressure gages (Figure 4.1a, symbols). On the shoals (Figure 4.1a, black open triangle), the pressure gage was buried about $0.10 \mathrm{~m}$ below the seafloor to avoid 
dynamic pressure fluctuations (Raubenheimer et al., 2001), whereas the pressure gage in the deep channel was mounted on the seafloor (Figure 4.1a, black open circle). Pressure gage elevations were adjusted as needed to maintain roughly constant elevation with respect to sand level. These shifts in vertical location are accounted for in processing. Pressure measurements were corrected for atmospheric pressure fluctuations, measured at ground level about $5 \mathrm{~km}$ inland. Water depths were estimated from the near-seafloor pressure measurements assuming hydrostatic pressure and a water density $\rho_{0}$ of $1024 \mathrm{~kg} / \mathrm{m}^{3}$ (the time-averaged measured density). Mean water levels $\eta$ were estimated from the mean water depths $H$ averaged over each 3072-s record) and the bathymetry. The cross-channel pressure gradient (Equation 4.5) estimated between the standalone pressure gages (Figure 4.1b, symbols) was referenced to a flat datum by assuming a flat water surface across the channel at slack tide (i.e., when the dominant centrifugal forcing is zero; Nidzieko et al., 2009). Results without this correction are qualitatively the same (Appendix).

The pressure sensor in the deep channel (Figure 4.1a, black open circle) was colocated with an upward-looking acoustic Doppler current profiler. Currents were measured in $0.50 \mathrm{~m}$ vertical bins from about $0.80 \mathrm{~m}$ above the bed to about 1.0 to $1.5 \mathrm{~m}$ below the water surface every minute for 12 min ending on the half hour and hour. Measured currents were averaged over hourly periods and extrapolated to the bed using a logarithmic fit assuming a no-slip condition and to the surface using a parabolic fit assuming a no-shear condition (Geyer et al., 2000). As a result, near-bottom velocities may be under- or overestimated owing to uncertainty in the shape of the bottom boundary layer and wind effects on currents may be underestimated near the surface. Near-surface wave orbital velocities and sea-surface elevation fluctuations were measured at the offshore bend at $2 \mathrm{~Hz}$ for $1024 \mathrm{~s}$ starting at the top of the hour and the half hour.

Flows were rotated to streamwise and stream-normal directions (Section 4.3; Figure 4.1a, coordinate system). There may be small errors in the rotation angle owing to inaccuracies in velocity measurements or extrapolation schemes. However, the results are not sensitive to $O\left(10^{\circ}\right)$ changes in rotation. Temporal fluctuations in the along-channel angle were generally less than $+/-10^{\circ}$ off the principal axis of the flows (14.9 ${ }^{\circ}$ east of north; Emery and Thomson, 2001), and results are not sensitive to using temporally-varying versus fixed coordinate systems. 
Boat-mounted transects near the profiler were conducted hourly for $10 \mathrm{~h}$ on 21 May (Figure 4.1a, black open circle) to sample the lateral variability in water levels and current profiles from before max flood to after max ebb. Boat velocity, position, and altitude above mean sea level (water levels) were measured at $1 \mathrm{~Hz}$ by GPS with real-time kinematic corrections. The downward-facing transducer was positioned $0.20 \mathrm{~m}$ below the water surface and sampled flows at $1 \mathrm{~Hz}$ with vertical bins from 0.02 to $0.50 \mathrm{~m}$ and blanking distances of 0.20 to $0.50 \mathrm{~m}$, depending on the water depth (measured by a separate vertical acoustic beam) and velocity conditions. The water levels and depth-averaged current profile transects were averaged in time every 6 seconds (an equivalent of horizontally averaging over roughly $5 \mathrm{~m}$ ). Water levels were also smoothed with a 30 -point moving average.

\subsubsection{Wind and density observations}

Winds were measured ( 5 min means) from April 28 to May 21 with an anemometer about $4.3 \mathrm{~m}$ above NAVD88 in $2 \mathrm{~m}$ water depth southwest of the inlet mouth (Figure 4.1c, white filled square). Hourly offshore winds from a buoy in $10 \mathrm{~m}$ water depth $55 \mathrm{~km}$ southwest of New River Inlet (NDBC station 41038, location not shown) were used to extend the dataset. The onsite and NDBC wind measurements were correlated $\left(r^{2} \sim 0.7\right)$ with $95 \%$ confidence. Measured winds were converted to $10 \mathrm{~m}$ winds assuming a logarithmic layer, neutral stability, and a roughness length $z_{0}=\alpha u_{*}^{2} / g$ (Charnock, 1955) where $\alpha$ is an empirical parameter, $u *$ is the friction velocity, and $g$ is gravitational acceleration. The results are not sensitive to variations in $\alpha$ over the range $0.008<\alpha<0.070$ (Kraus, 1972; Smith, 1980; Sempreviva et al., 1990; Peña and Gryning, 2008; Brown and Wolf, 2009).

Typical (not including major storms) wind speeds ranged from 0 to $8 \mathrm{~m} / \mathrm{s}$ and were most frequently from the south or southwest. During two tropical storms, TS Alberto and TS Beryl (Figure 4.2, 26 and 30 May), the wind speeds were $10 \mathrm{~m} / \mathrm{s}$ from the northeast (to the southwest) and $15 \mathrm{~m} / \mathrm{s}$ initially from the southeast before rotating to be from the northwest, respectively. The local wind velocity at the bend may veer $O\left(10^{\circ}\right)$ from those measured at the inlet mouth (pers. comm. D. Ortiz-Suslow). However, the comparisons of cross-channel winds and currents presented below are not sensitive to $+/-20^{\circ}$ variations in the local wind direction. 


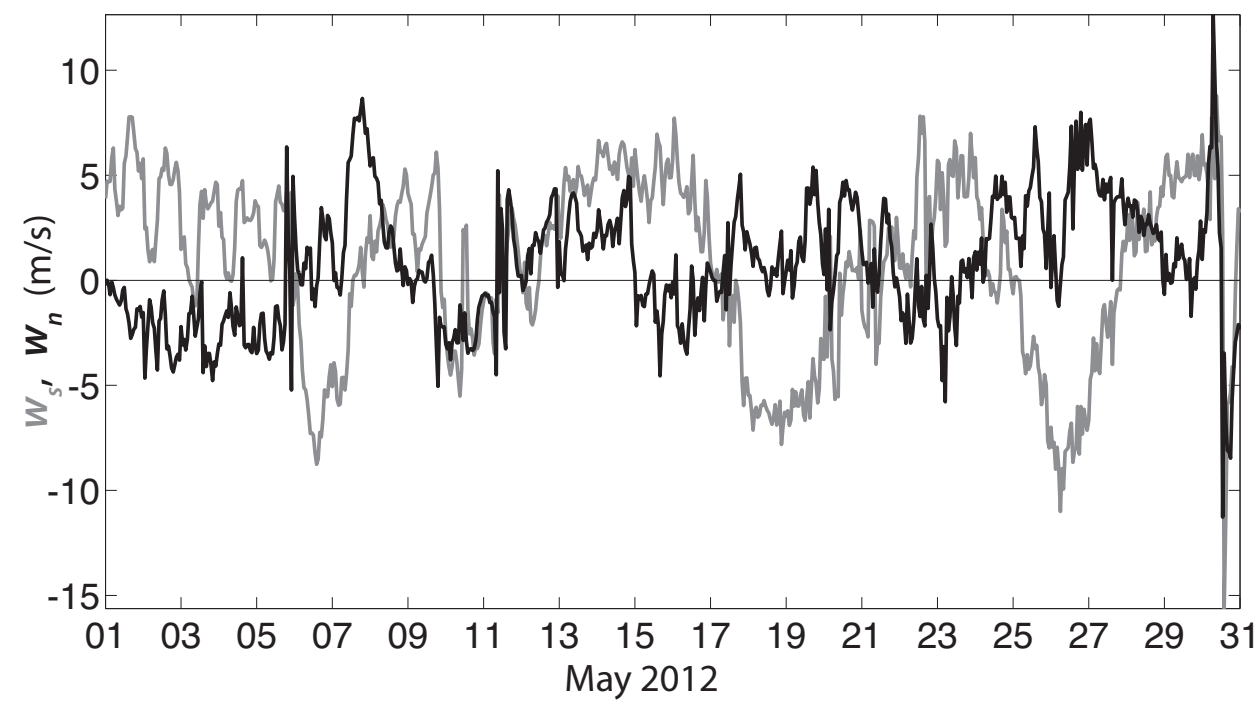

Figure 4.2. The local (Figure 4.1c, white square) along-channel (gray curve) and cross-channel (black curve) wind speeds $\left(w_{s}, w_{n}\right)$ versus time.

Temperature and salinity were measured with a conductivity-depth-temperature (CTD) sensor on 21 cross-channel transects near the bend (Figure 4.1a, black open circle) at different tidal stages (flood/ebb/slack, spring/neap) from 01 to 20 May. Instrument noise is $O\left(0.1 \mathrm{~kg} / \mathrm{m}^{3}\right)$ (pers. comm. T. Lippmann).

Depth- and cross-inlet-averaged water density varied in time from roughly 1023 to $1025 \mathrm{~kg} / \mathrm{m}^{3}$. Cross-channel changes in density were typically small (less than $\sim 0.2 \mathrm{~kg} / \mathrm{m}^{3}$, which is only slightly larger than the instrument accuracy) and vertical density variations usually were smaller than horizontal variations. The baroclinic pressure gradient is small (less than $O\left(10^{-4}\right) \mathrm{m} / \mathrm{s}^{2}$ ), except near slack (not shown). Richardson numbers estimated from the velocity measurements in the deep channel (Figure 4.1a, black open circle) and from 52 density profiles collected within $50 \mathrm{~m}$ of the current profiler were less than 0.25 (not shown), except during slack tide, suggesting that mixing may dominate over stratification and stratification should have little influence on the vertical structure of the flow (Geyer, 1993). Transient, larger horizontal gradients in density may occur in New River Inlet owing to occasional export of brackish water from the southern arm of the Intracoastal Waterway (pers. comm. J. MacMahan). Thus, baroclinicity may have a transitory contribution to the dynamics that is not resolved with the available dataset. The inlet is considered unstratified and effects from density variations are neglected. 


\subsection{Results and discussion}

\subsubsection{Depth-averaged flows and dynamics}

Depth-averaged along-channel tidal currents in the deep channel (Figure 4.1a, black open circle) were flood-dominated, and ranged from -1.0 to $1.4 \mathrm{~m} / \mathrm{s}$ (Figure $4.3 \mathrm{a}$ ). The dominant tidal constituent was the M2 (semidiurnal lunar) tide. The dominant overtide was the M4, which had an amplitude nearly $14 \%$ that of the M2 tide. Although New River Inlet is a short channel relative to the tidal wavelength (the ratio of channel length to a quarter of a tidal wavelength is about 0.3) (Li and O'Donnell, 2005), the tides are progressive with peak ebbs (floods) occurring within about $30 \mathrm{~min}$ of low (high) water levels (MacMahan et al., 2014) (Figure 4.3, compare panels). The difference between flood and ebb water levels varied from 0.7 to $1.4 \mathrm{~m}$ (the latter during spring tides, Figure 4.3b, 07 May).
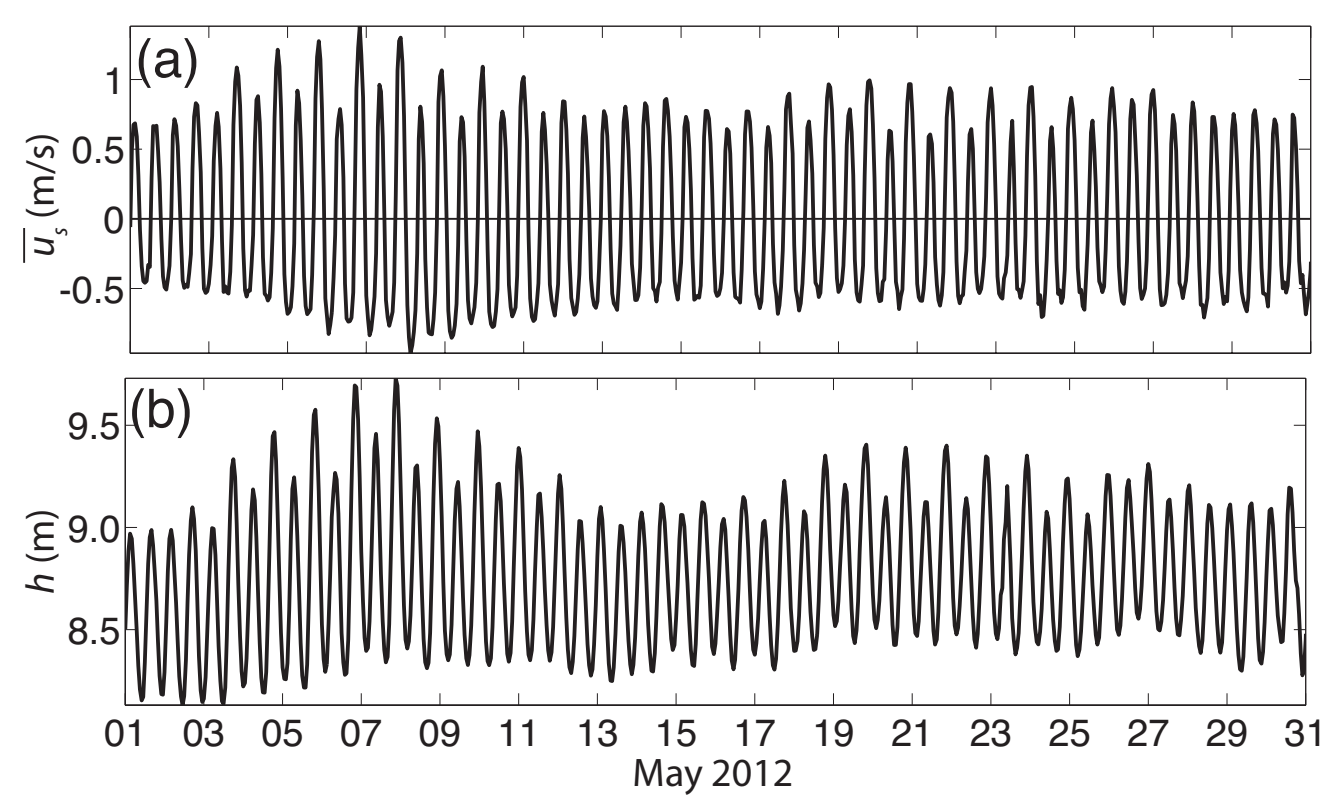

Figure 4.3. (a) Depth-averaged, along-channel flows $\overline{u_{s}}$ (the depth-averaged cross-channel currents are zero by definition) and (b) water depth $h$ in the deep channel (Figure 4.1a, black open circle) versus time.

Boat-mounted cross-channel transects on 21 May show similar cross-sectional-averaged maximum flows on flood and ebb ( 0.6 and $-0.8 \mathrm{~m} / \mathrm{s}$, respectively) but a tidal asymmetry in the horizontal flow structure (Figures $4.4 \mathrm{a}$ and $\mathrm{c}$ ). On flood, the flows are divided into two converging "jets" located in the deep channel (Figure 4.4a, along-transect distance $\approx 0 \mathrm{~m}$, red 
curves; Figure 4.4c, "Flood channel jet") and in the shoals channel (Figure 4.4a, along-transect distance $\approx-120 \mathrm{~m}$, red curves; Figure 4.4c, "Flood shoals jet"). On ebb, there is one jet in the deep channel (Figure 4.4a, along-transect distance $\approx-50 \mathrm{~m}$, blue curves; Figure 4.4c, "Ebb channel jet") and weaker, divergent flow at the outer and inner banks. The depth-averaged flows at the profiler are less than $10 \%$ different from and $50 \%$ smaller than the maximum channel jet flows on flood and ebb, respectively (Figure 4.4c, compare black arrows with nearby maximum red and blue arrows).
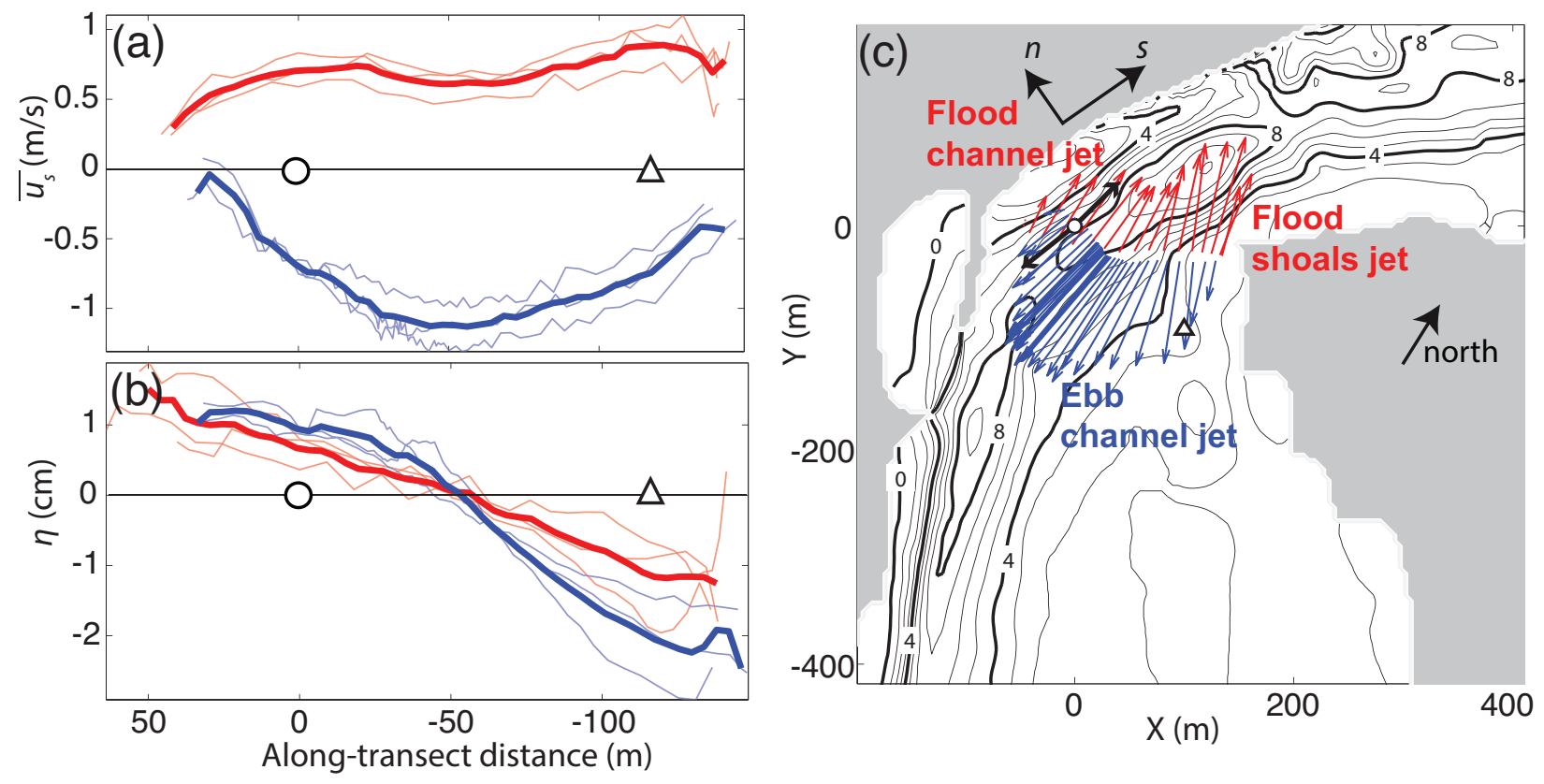

Figure 4.4. (a) Depth-averaged streamwise flows $\overline{u_{s}}$ (rotated to the local streamwise axis) and (b) the along-transect-mean-subtracted water levels $\eta$ on 21 May just before, during, and just after maximum flood and ebb (thin red and blue curves, respectively; thick curves are the average) versus along-transect distance (positive to the left (west)). (c) Boat-mounted (red and blue arrows) and fixed (black arrows) measurements of depth-averaged flows during max flood (red) and max ebb (blue) on 21 May superimposed on bathymetry ( $1 \mathrm{~m}$ depth increments $(0,4$, and $8 \mathrm{~m}$ contours are thick and labeled)). Locations of the colocated profiler and pressure gage and the single pressure gage are indicated with the black open circle and triangle, respectively.

The channel-scale (Figure 4.4b, symbols) cross-channel sea surface tilt estimated from the GPS altitude of the boat (the "GPS estimate") is steeper on ebb compared with flood during 21 May, similar to that estimated with the fixed pressure gages (the "fixed estimate") (Figure 4.5, compare peaks of black curve near the words "flood" and "ebb"). However, there is more scatter on flood compared with the ebb (the ranges in GPS estimates are 15\% smaller to $87 \%$ larger than 
and $29 \%$ to $46 \%$ larger than the fixed estimates on flood and ebb, respectively (not shown)), potentially owing to along-channel (Figure $4.4 \mathrm{c}$, note that the boat transect is not along the axis connecting the fixed measurements (symbols)) and temporal variability in the pressure gradient on the flood.

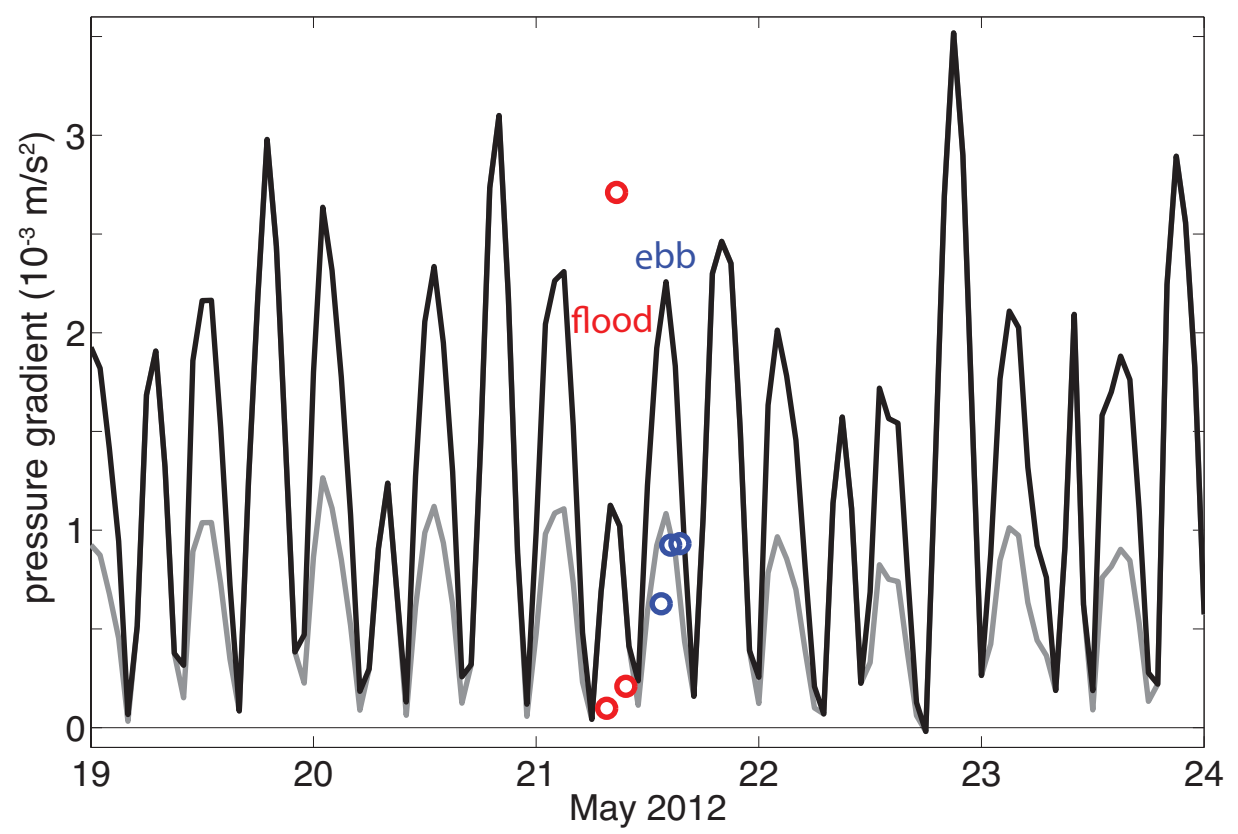

Figure 4.5. Cross-channel pressure gradient versus time. The circles are the GPS estimates of the pressure gradient near the profiler (Figure 4.4b, $17<$ along-transect distance $<-15 \mathrm{~m}$ ) during flood (red) and ebb (blue). The curves are estimates between fixed pressure gages (Figure 4.4c, symbols) unweighted (black curve) and weighted (gray curve) by the GPS estimates (circles).

There is tidal asymmetry in the lateral structure of the water levels (Figure 4.4b). On ebb, the sea surface tilt is steep over the ebb jet and inner bank (Figure 4.4b, thick blue curve, $-20<$ alongtransect distance $<-120 \mathrm{~m}$ ) and levels off over the weak flows on the outer bank (Figure 4.4b, thick blue curve, along-transect distance $\approx 0 \mathrm{~m}$ ), while, on flood, the average sea surface tilt is roughly constant across the channel (Figure $4.4 \mathrm{~b}$, thick red curve). The weaker flows and tilt near the outer bank on ebb are similar to those observed in a laboratory study and may be owing to the upstream bend (Figure 4.4c, S-curve bend at the edge of the white open square), which induces centrifugal acceleration that drives momentum away from the outer bank of the downstream bend (not shown) (Blanckaert, 2010). To correct for the lateral variability in pressure gradient on ebb (the "weighted pressure gradient"), the fixed pressure gradient estimate was reduced by $52 \%$ (Figure 4.5 , gray curve), which is the average difference between the fixed 
and the GPS estimates of the pressure gradient near the profiler (Figure 4.4b, $17<$ along-transect distance $<-15 \mathrm{~m}$; Figure 4.5, compare blue symbols with the black curve). On flood, no correction could be made, owing to the significant scatter in the GPS estimate of the pressure gradient near the profiler (Figure 4.5, compare red symbols with the black curve).

The squared correlation with centrifugal acceleration $(R=400 \mathrm{~m})$ using the weighted pressure gradient (Figure 4.5, gray curve) $\left(r^{2}=0.86 \pm 0.06\right)$ is higher than with the unweighted pressure gradient (Figure 4.5 , black curve) $\left(r^{2}=0.65 \pm 0.13\right)$. The weighted pressure gradient is, on average, $20 \%$ and $26 \%$ larger than the centrifugal acceleration $(R=400 \mathrm{~m})$ during max ebbs and floods, respectively. This residual may partially be owing to the uncertainty in the radius of curvature estimate (Figure 4.6, linear regressions (red and blue lines) suggest radii of curvature of $320( \pm 15) \mathrm{m}$ on flood and $350( \pm 14) \mathrm{m}$ on ebb).

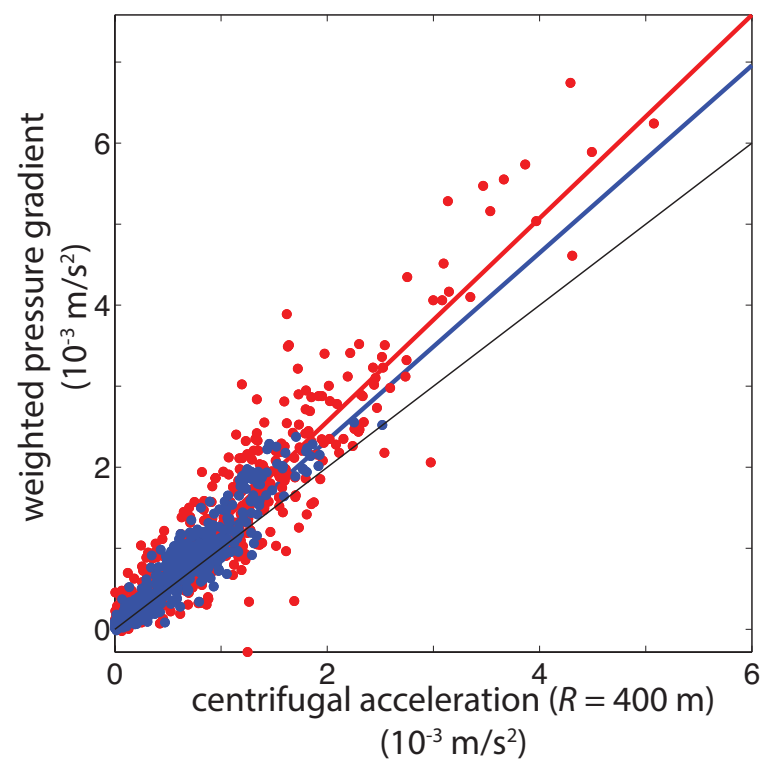

Figure 4.6. Weighted pressure gradient versus centrifugal acceleration $(R=400 \mathrm{~m})$ during ebb (blue circles, slope of red best-fit line $=1.16 \pm 0.04$ ) and flood (red circles, slope of blue best-fit line $=1.25 \pm 0.06$ ). The black line indicates the 1:1 line.

The weighted pressure gradient is less than (greater than) the driving centrifugal acceleration as the along-channel flows increase (decrease) on flood and ebb (not shown), suggesting temporal variability in the momentum balance, potentially owing to time-varying differences in the local pressure gradient or the importance of non-local effects (such as along- or cross-channel 
advection (Equation 4.4, second and third parenthesis on left hand side)) as the flows develop (Nidzieko et al., 2009; Blanckaert, 2010). However, along-channel gradients $\partial / \partial s$ could not be resolved owing to the large distance (roughly $400 \mathrm{~m}$ ) between in situ velocity measurements (not shown) relative to the horizontal length scales over which nonlinearity is expected to be important (Section 4.3, 100 m) (Vennell and Old, 2007; Fong et al., 2009; Nidzieko et al., 2009). In addition, cross-channel gradients $\partial / \partial n$ could not be resolved owing to the noise in velocity measurements along the boat transect. Additional measurements are needed to resolve the importance and temporal variability of nonlocal effects (i.e., advection).

\subsubsection{Depth-varying flows and dynamics}

The along-channel flows were unidirectional (Figure $4.7 \mathrm{a}$, red and blue curves), while the roughly 0.1 to $0.2 \mathrm{~m} / \mathrm{s}$ cross-channel flows typically had a two-layered vertical structure, with near-surface flows directed toward the outside of the bend (Figure 4.7b, positive direction) and near-bottom flows directed toward the inside of the bend (Figure 4.7b, negative direction). Sometimes the cross-channel flow structure was three-layered, with flow towards the inside of the bend (negative direction) at the surface, above the classical two-layered vertical structure (Figure 4.7b).

The vertical structure of the cross-channel flows at maximum flood and ebb (Figure 4.7b) was quantified using empirical orthogonal functions (EOFs, Emery and Thomson, 2001) (not shown). The cross-channel flows were converted into depth-normalized vertical coordinates (sigma layers), $\sigma$ (defined as $\sigma=z / h$, where $z$ is the vertical coordinate (positive upwards) and $h$ is the instantaneous profile depth) (Kierfve, 1975; Giddings et al., 2014). Flows were divided into 10 full sigma layers and two half-sigma layers at the surface and bottom of the profile where flows are extrapolated (Kjerfve, 1975). The resulting full sigma layer sizes range from 0.71 to $0.85 \mathrm{~m}$.

The first EOF mode, which accounted for $52 \%$ of the variance, had a root-mean-square (rms) magnitude of $0.17 \mathrm{~m} / \mathrm{s}$ overall $(0.20 \mathrm{~m} / \mathrm{s}$ and $0.13 \mathrm{~m} / \mathrm{s}$ on $\max$ flood and ebb, respectively) and a two-layered vertical structure. The surface (bottom) flows of the first mode were towards the outside (inside) of the bend $94 \%$ of the time, consistent with curvature-driven flow theory. The second EOF mode, which accounted for $20 \%$ of the variance, had a rms magnitude of $0.06 \mathrm{~m} / \mathrm{s}$ 
overall (with the same magnitude on flood and ebb) and three-layered vertical structure. The circulation represented by the second mode changed sign in time, with surface flows in the same direction as the cross-channel wind $66 \%$ of the time (wind effects on the subtidal flows are examined further in Section 4.5.3).
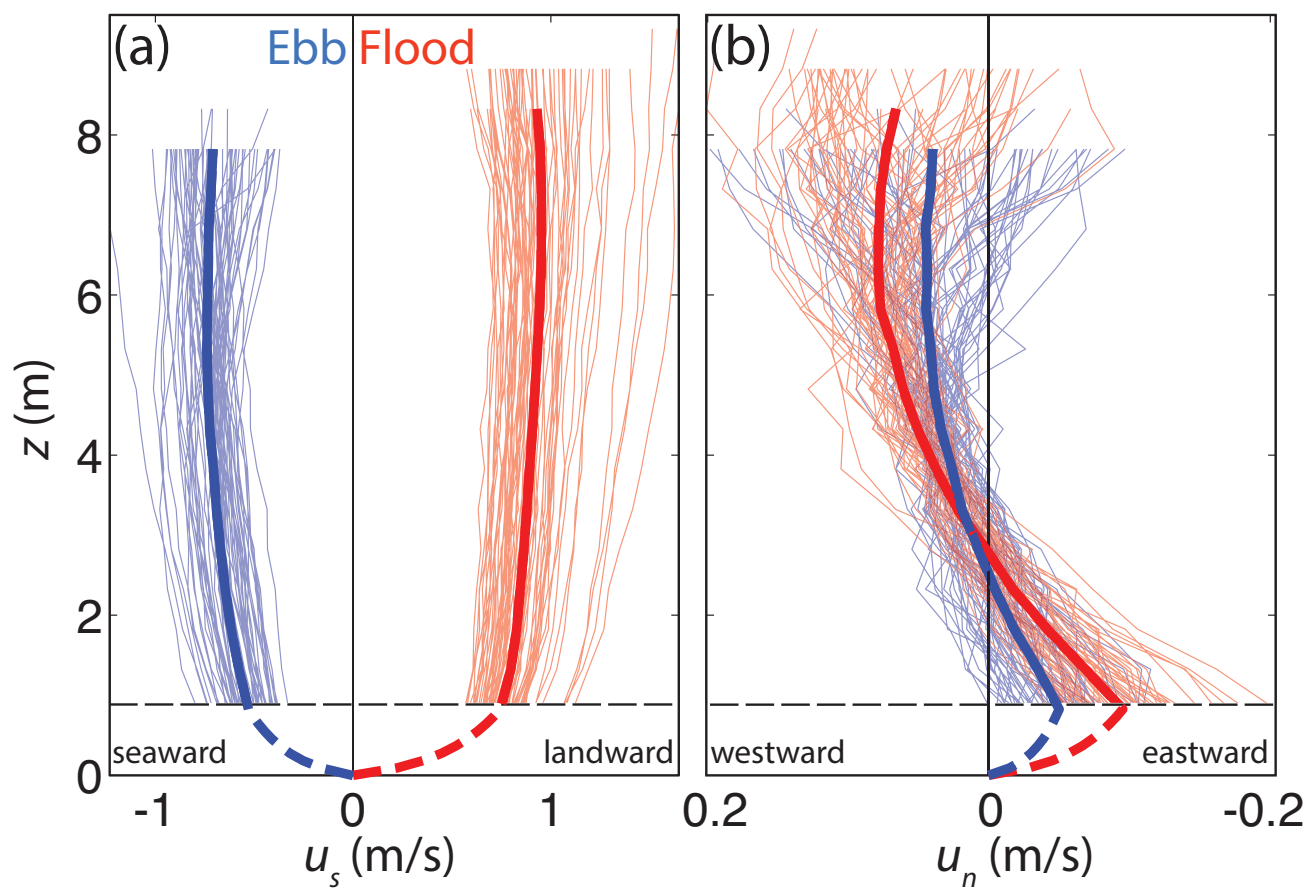

Figure 4.7. Distance above bottom $z$ versus (a) along-channel $u_{s}$ and (b) cross-channel $u_{n}$ currents during maximum flood (red curves) and ebb (blue curves) in the deep channel (Figure 4.1a, black open circle). The positive directions are inland (flood) and to the western bank (towards the outside of the bend; note that positive is to the left in panel (b)). The average profiles for all maximum flood and ebb are shown with the thick solid red and blue curves, respectively. The horizontal dashed line indicates the lower limit of measurements (examples of extrapolated flows shown in dashed curves).

The analytical model for curvature-driven flows (Kalkwijk and Booij, 1986) was evaluated by comparing model estimates of two-layer flow with observed two-layer flows during maximum flood and ebb corresponding to weak winds (cross-channel winds less than $2 \mathrm{~m} / \mathrm{s}$ ). In particular, along-channel flows in the analytical model are assumed to have a logarithmic profile proportional to the depth-averaged velocity $\overline{u_{s}}$ and bottom drag coefficient $C_{D}$ (Kalkwijk and Booij, 1986): 


$$
u_{s, \log }=\overline{u_{s}}\left[1+\frac{\sqrt{C_{D}}}{\kappa}\left(1+\ln \left(1+\frac{z}{h}\right)\right)\right]
$$

where $\kappa$ is the von Kármán constant. The bottom drag coefficients $C_{D}$ that best resolved the average along-channel flows above $z=0.8 \mathrm{~m}$ (i.e., measured flows) were 0.002 on flood and 0.005 on ebb (Figure 4.8a, gray curve; Figure 4.8c, black curve). The ebb drag coefficient is consistent with previous studies in other parts of New River Inlet (Wargula et al., 2014; Chen et al., 2015). These bottom drag coefficients result in eddy viscosities $A$ of $0.03 \mathrm{~m}^{2} / \mathrm{s}$ and $0.04 \mathrm{~m}^{2} / \mathrm{s}$ on flood and ebb, which are consistent with the magnitude expected in unstratified systems (Geyer and MacCready, 2014).

Assuming zero surface stress (no wind), steady state, negligible advective acceleration, and a parabolic eddy viscosity, the cross-channel flows may be analytically derived:

$$
u_{n, \log }=\frac{2\left|\overline{u_{s}}\right| h}{\kappa^{2} R} f_{b}\left(\frac{z}{h}, \frac{\sqrt{C_{D}}}{\kappa}\right)
$$

where $f_{b}$ is a function of $z / h$ and $\sqrt{C_{D}} / \kappa$ (see Equations 17, 24, and 25, Kalkwijk and Booij, 1986). Using a radius of curvature of $400 \mathrm{~m}$ (Figure 4.1a) and the best-fit drag coefficients, the cross-channel flows were similar to the analytical model (Figures $4.8 \mathrm{~b}$ and d, compare thick red and blue curves with gray and black curves), suggesting that a one-dimensional balance between centrifugal acceleration, diffusion, and bottom stress governs the cross-channel flows to first order. In addition, the agreement between the observations and analytical model of the crosschannel flows is similar for different drag coefficients above the bottom boundary layer. Nearbottom flow measurements would be needed to precisely resolve drag coefficient. 

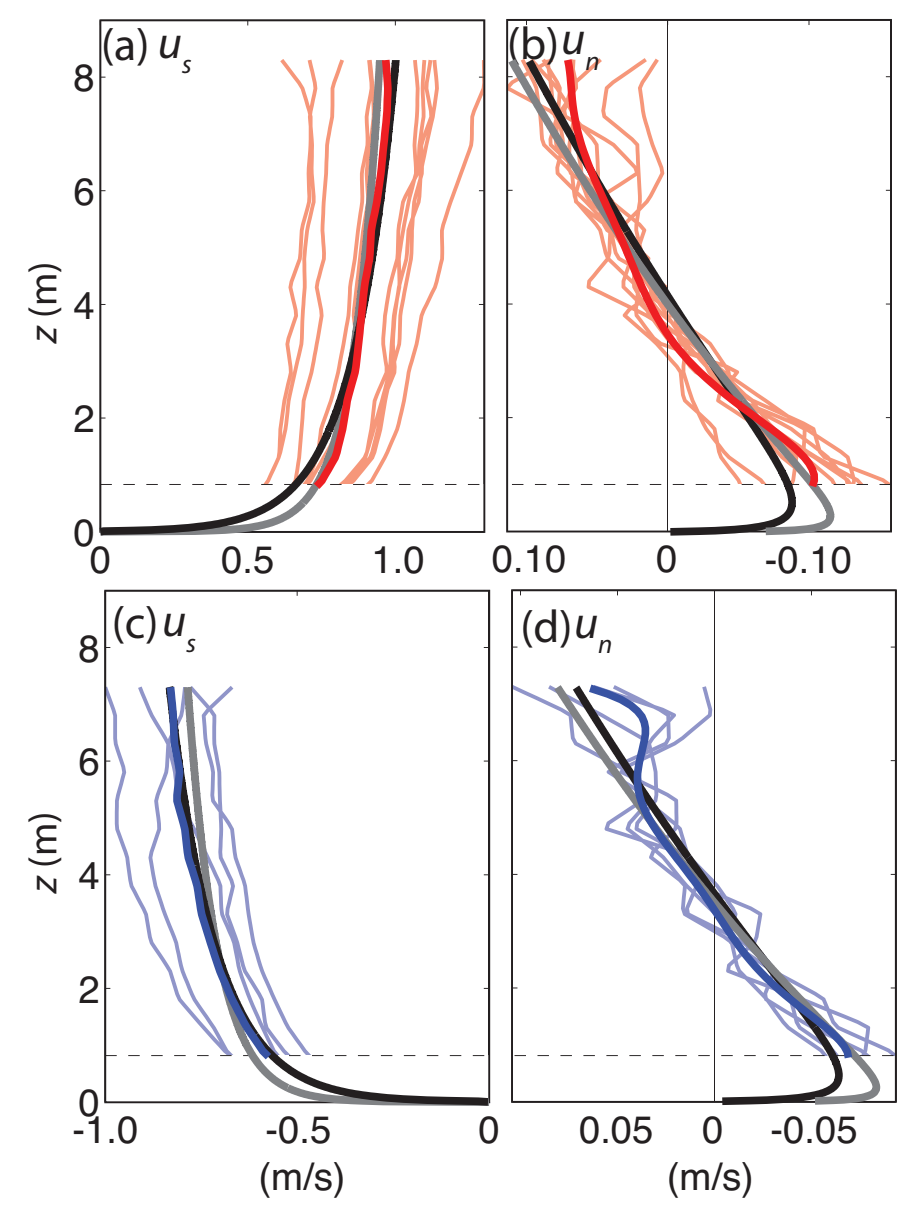

Figure 4.8. Distance above bottom $z$ versus (a, c) along-channel flows $u_{s}$ and (b, d) crosschannel flows $u_{n}$ for $(\mathrm{a}, \mathrm{b})$ flood and $(\mathrm{c}, \mathrm{d})$ ebb. Thin curves are observations during maximum flood (red) and ebb (blue) corresponding to weak cross-channel winds $(<2 \mathrm{~m} / \mathrm{s})$ and two-layer cross-channel flows. Thick red and blue curves are the average (the average in panels $(b, d)$ are smoothed with a 6th order polynomial fit). The dashed horizontal black line indicates the lower limit of measurements. The results for the Kalkwijk and Booij (1986) model assuming $R=400$ $\mathrm{m}$ and $C_{D}=0.002$ or $C_{D}=0.005$ (Equations 4.7 and 4.8) are shown in the gray and black curves, respectively.

There is some vertical variability in the cross-channel flows that is not captured in the analytical model, particularly on flood. The near-bottom (near-surface) velocities and shear are larger (smaller) in the observations than in the model (Figure 4.8b, compare red and gray scale curves at $z \approx 1$ and $8 \mathrm{~m}$ ). This vertical variability suggests the importance of other processes not present in the analytical model, such as a non-parabolic eddy viscosity profile (Vennell and Old, 2007) or nonlocal processes, such as advective acceleration owing to downstream adjustment of crosschannel flows to curvature (Nidzieko et al., 2009) and cross-channel gradients in cross-channel flows (Blanckaert, 2010). 


\subsubsection{Subtidal wind-driven flows}

Even weak winds were found to drive vertical variability in the cross-channel flows. To evaluate this effect, the sigma-layer cross-channel flows and winds were detrended and low-pass filtered using a discrete Fourier transform filter (cutoff period of $30 \mathrm{~h}$ ) with three transition band samples (Rabiner and Gold, 1975, Table X). Results are not sensitive to cutoff periods ranging from about 25 to $40 \mathrm{~h}$. The trends were added back to the cross-channel flows and winds after filtering. Lowpass filtered cross-channel flows were correlated with lowpass filtered crosschannel wind speed (Figure 4.9, $r^{2}=0.5$ to 0.7 ) at most sigma levels (except in the mid-water column where flows change sign, and nearest the seafloor). Positive (westward) cross-channel winds corresponded to enhanced cross-channel circulation (stronger surface and near-bottom flows, Figure 4.9, 06 to 08 May) and negative (eastward) winds tended to weaken surface and bottom flows (Figure 4.9, 18 May) or drive opposing (negative/eastward direction) flows on top of the curvature-driven two-layered flow (Figure 4.7b; Figure 4.9, 02 to 05 May).

Subtidal along-channel flows were weakly correlated to the cross-channel wind velocity at the 95\% confidence level ( $r^{2}=0.3$ to 0.5 ), with surface flows generally positive/inland (bottom flows negative/seaward) directed for negative/eastward cross-channel winds (not shown). Ekman transport is unlikely to account for this effect, owing to the direction of change in the alongchannel flows relative to that of cross-channel wind (to the left of the wind at the surface) and the large Ekman number $(\mathrm{Ek} \approx O(5)$, which suggests that friction dominates over Coriolis).

Neither subtidal along-channel nor cross-channel flows were correlated to the along-channel component of wind at the $95 \%$ confidence level. 


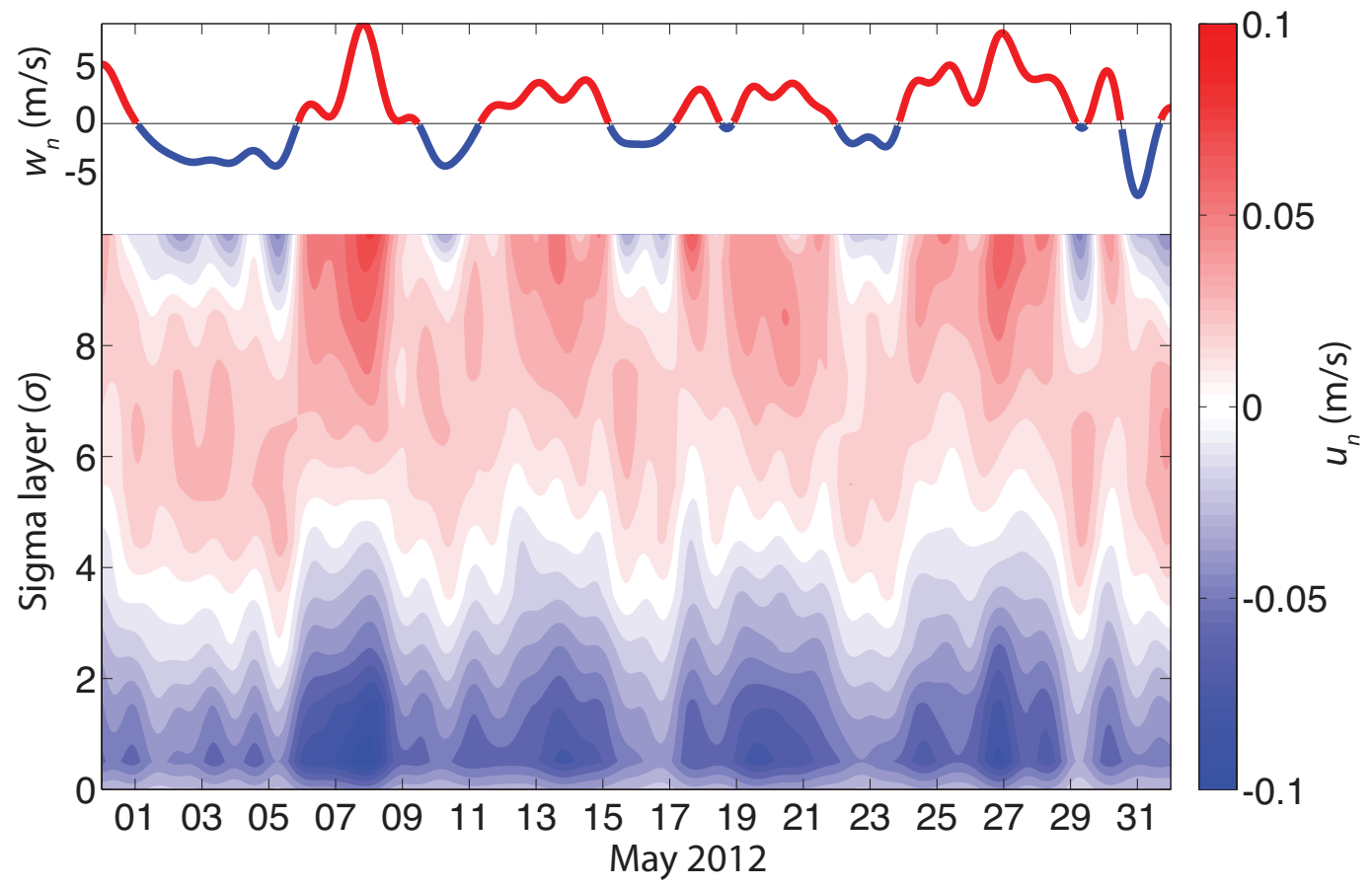

Figure 4.9. Lowpass filtered cross-channel currents $u_{n}$ (color contours, scale on the right) in the deep channel (Figure 4.1a, black open circle) as a function of sigma layers (lower y-axis scale), and lowpass filtered cross-channel wind speed $w_{n}$ (red and blue curve) (upper left hand y-axis scale), versus time.

One idealized numerical study suggests that cross-channel wind-driven change to cross-channel currents in a straight, $3-\mathrm{km}$ wide, stratified channel may be scaled by a one-dimensional balance between wind stress and vertical diffusion (Huijs et al., 2009):

$$
u_{n, \max } \approx \frac{\tau^{s n} h}{4 \rho_{0} A_{0}}
$$

However, using the measured wind stress, tidal water depth, and $A_{0}=0.03 \mathrm{~m}^{2} / \mathrm{s}$ (Section 4.5.2), the $u_{n, \max }$ expected from this formula is, on average, nearly an order of magnitude smaller than the observed near-surface lowpass-filtered cross-channel flows. Although a one-dimensional balance resolves the cross-channel flows well to first order during low winds (Section 4.5.2), a one-dimensional balance may not explain the wind-driven change in cross-channel flows at New River Inlet. 
There are several differences between New River Inlet and the Huijts et al. (2009) model that may play a role in wind-driven circulation, including the curvature $\left(R_{\text {New } R i v e r} \approx 400 \mathrm{~m}\right.$ versus $R_{\text {Huijs }}=\infty$ (straight)), the channel width (fetch) $\left(B_{\text {New River }} \approx 200 \mathrm{~m}\right.$ versus $B_{\text {Huijs }}=3 \mathrm{~km}$ ), and eddy diffusivity $\left(A_{0, \text { New River }} \approx 0.03 \mathrm{~m}^{2} / \mathrm{s}\right.$, suggesting well mixed conditions, versus $A_{0, \text { Huijts }}=0.004$

$\mathrm{m}^{2} / \mathrm{s}$, suggesting stratification). Other numerical simulations showed minimal cross-channel flow response to winds of any direction in an idealized straight channel without other sources (e.g., baroclinicity, curvature, Coriolis terms) of cross-channel flow forcing (Hinata et al., 2010). At New River, the effects of cross-channel winds on cross-channel flows may be enhanced by the underlying curvature-induced flows, for example, by reducing the effective water depth. Additional measurements of vertical and temporally varying Reynolds stresses and density (to estimate eddy diffusivity and stratification with more accuracy), local wind stress, and better resolution of the along- and cross-channel advection are needed to quantify the interactions between cross-channel wind stress, stratification, and channel geometry.

\subsection{Summary}

Depth-averaged along-channel flows measured near the outer bank of an unstratified, narrow $(150 \mathrm{~m})$, shallow $(8 \mathrm{~m}), 90$-degree tidal inlet bend are stronger on flood compared with ebb, owing to a horizontal shift in the location of the channel jet. High-resolution observations of water levels across the channel suggest tidal asymmetry and lateral variability in the sea surface tilt. Accounting for the local decrease in the sea surface tilt on ebb closed the depth-averaged momentum balance with centrifugal acceleration.

Two- and three-layered cross-channel flows were observed at the bend. The two-layered crosschannel flows during weak winds are consistent to first order with a one-dimensional balance between centrifugal acceleration, bottom stress, and diffusion. Cross-channel wind modifies cross-channel circulation, enhancing and weakening the two-layered curvature-driven flow as well as driving opposing flows on top of the curvature-driven two-layered flow (three-layered flow). These wind-driven changes are an order of magnitude larger than those expected from a one-dimensional balance between wind stress and vertical diffusion, suggesting the importance of two- and three-dimensional processes. 


\subsection{Appendix: Pressure gradient}

There is uncertainty in the relative vertical locations of the pressure gages (Figure 4.1b, symbols) owing to uncertainty in the positions of the gages relative to the seafloor at initial deployment and the time-varying vertical movement of the pressure gage on the shoals (Figure 4.1b, black open triangle). This error (potentially along with a real signal) is removed partially by assuming that the cross-channel pressure gradient is zero during slack (when the dominant driving force, centrifugal acceleration, is near-zero, Nidzieko et al, 2009) (Figure 4.5, black curve). However, this process also may remove a real signal.

The uncorrected cross-channel pressure gradient has significant low frequency fluctuations $\left(O\left(10^{-3}\right) \mathrm{m} / \mathrm{s}^{2}\right.$ (4 to $\left.8 \mathrm{~cm}\right)$, Figure 4.10). Although some of the fluctuations coincide with changes in cross-channel wind direction (not shown), the lowpass filtered wind and uncorrected crosschannel pressure gradient are not correlated. Thus, the variability in the pressure gradient likely is owing to a combination of subtidal forcing (e.g., wind stress) and measurement error owing to vertical adjustment, burial and un-burial (whether by divers or by "natural" causes such as moving bedforms), and fouling of the pressure gages (shells were found inside the cap of the pressure gage on the shoals). Major jumps in water level measurements $(\sim 60 \mathrm{~cm})$ owing to known burial events (the pressure gage on the shoals was buried by divers on May 6, corrected in Figure 4.10) were corrected to within a few centimeters by comparing the mean pressure levels before and after the burial. However, because the subtidal sea surface tilt signal also varies on the order of a few centimeters, the error cannot be removed completely.

However, the main results of momentum balance analysis are qualitatively the same with and without correcting the pressure gradient. 


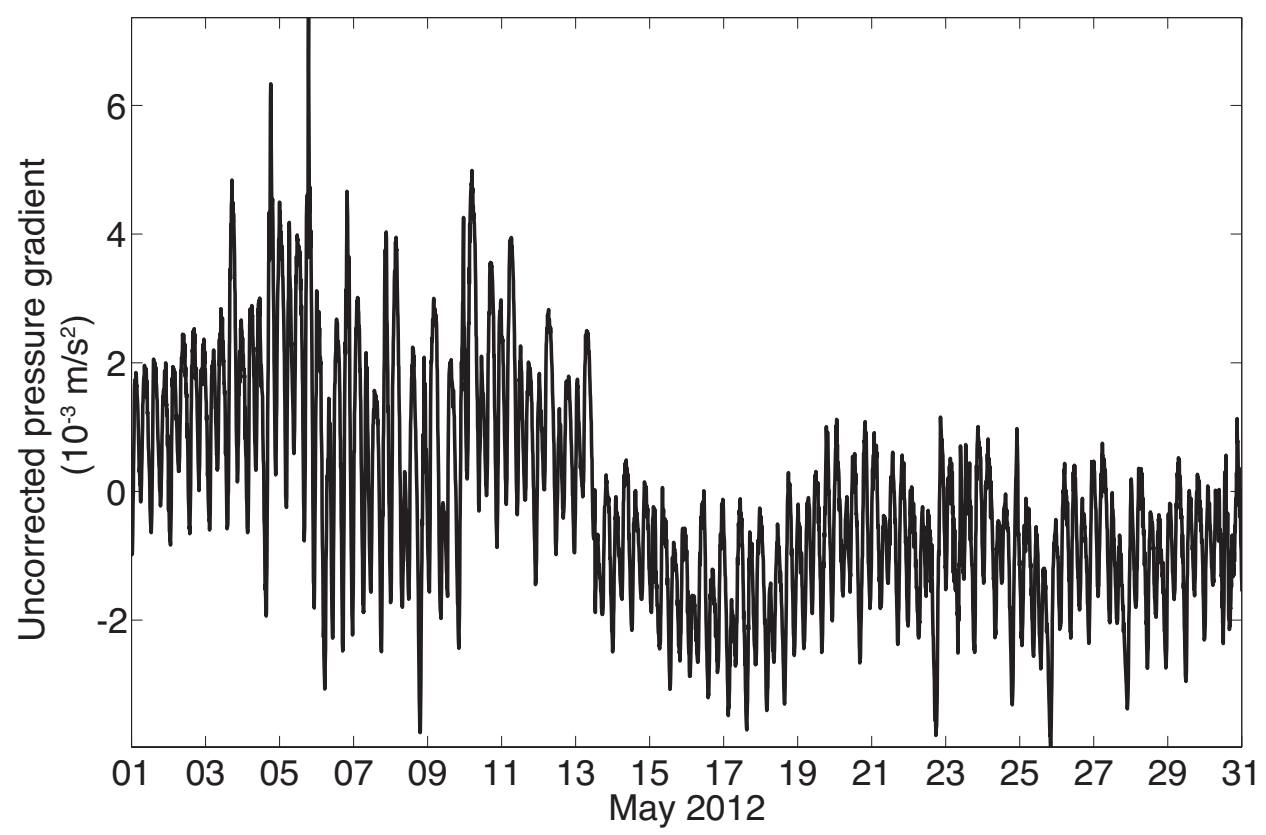

Figure 4.10. Uncorrected (except for large shift in mean between May 1 to 6 (unburied) and May 6 to 31 (buried)) barotropic pressure gradient across the channel (Figure 4.1a, circle to triangle) versus time. 


\section{Chapter 5}

\section{Conclusions and future work}

\subsection{Conclusions}

The effects of waves and wind on tidal and subtidal hydrodynamics at unstratified, shallow New River Inlet, NC, are evaluated using field observations and numerical simulations. Here, it is shown that waves and wind drive changes to inlet circulation. In particular:

- Waves have a local and nonlocal effect on flows and water levels at an inlet. Local gradients in wave energy over the ebb shoal drive an onshore-directed mass flux, which increase water levels inside the inlet. The shoaling and breaking of waves near the offshore edge of the ebb shoal induce local setdown and setup in the water levels which, in combination with the increased inlet water levels, induce nonlocal changes to the pressure gradient on the ebb shoal. On flood, nonlocal wave effects on the pressure gradient are dominant, reducing flows into the inlet inside the main channel. On ebb, the local wave forcing at the offshore edge of the shoal is dominant, blocking the jet and reducing the ebb flows. Overall, the tidally-driven ebb-dominance in the flows was reduced owing to the relatively larger reduction of ebb versus flood flows, leading to enhanced flow into the inlet on subtidal time scales during large waves (Wargula et al., 2014).

- Cross-channel wind modifies cross-channel circulation at a sharp bend, enhancing and weakening the curvature-driven two-layered flow and sometimes driving three-layered flow. The two-layered cross-channel flows during low winds are consistent, to first order, with a local, one-dimensional balance between centrifugal acceleration, bottom stress, and diffusion. However, the wind-driven change to the flows is an order of magnitude larger than that expected from a one-dimensional balance, suggesting two- and threedimensional processes are important. 


\subsection{Future work}

This work has improved understanding of the role of waves and winds in driving circulation at a natural inlet. However, this work also raises a number of new questions.

In Chapter 2, large waves were shown to drive changes in the circulation patterns near the inlet mouth. However, questions remain regarding the sensitivity of the circulation response to factors, such as the presence and bathymetry of an ebb shoal and the alongshore processes on the coasts adjacent to the inlet mouth. For example, a shallow ebb shoal may concentrate wave forcing to the outer edge, owing to depth-limited breaking. Further observations at deeper inlets or inlets without ebb shoals are needed to understand how wave effects on circulation change with different inlet mouth bathymetries. In addition, it is not well understood how wave- and pressuregradient-driven alongshore currents contribute to the change in circulation on the ebb shoal during large wave events.

In Chapter 3, breaking waves were shown to enhance fluxes into the inlet on subtidal time scales. This excess water may be stored in several parts of the New River system: inside the inlet mouth, upstream in the large backbay, or in the marsh. In addition, the wave-driven fluxes may be lost to the system through other inlets along the Intracoastal Waterway (ICW). Understanding how the water is stored or lost to the system is important to better predict exchange and flood risks. Further measurements of water levels and fluxes inside the backbay, marsh, ICW, and neighboring inlets during large wave events are needed to evaluate the connectivity of the system and wave-driven changes to exchange in the larger system.

In Chapter 4, it was shown that a laboratory-tested analytical model for vertically varying crosschannel dynamics resolves the flows at the sharp bend reasonably well during low wind conditions. However, there is vertical variability in the flow measurements that is not captured by the analytical model, which may in part be owing to a non-parabolic eddy viscosity profile (Vennell and Old, 2007) and wind effects. Measurements of Reynolds stresses in the water column are needed to test the parabolic eddy viscosity profile assumption and examine variability in the stress profile during strong winds. 


\section{References}

Apotsos, A., B. Raubenheimer, S. Elgar, and R. T. Guza (2008), Wave-driven setup and alongshore flows observed onshore of a submarine canyon, Journal of Geophysical Research, 113(C7), 1-9, doi:10.1029/2007JC004514.

Apotsos, A., B. Raubenheimer, S. Elgar, R. T. Guza, and J. A. Smith (2007), Effects of wave rollers and bottom stress on wave setup, Journal of Geophysical Research, 112, C02003, doi:10.1029/2006JC003549.

Aubrey, D. G., T. R. McSherry, and P. P. Eliet (1993), Effects of multiple inlet morphology on tidal exchange: Waquoit Bay, Massachusetts, Coastal and Estuarine Studies, 44, 213 235.

Becherer, J., M. T. Stacey, L. Umlauf, and H. Burchard (2015), Lateral circulation generates flood tide stratification and estuarine exchange flow in a curved tidal inlet, Journal of Physical Oceanography, 45, 638-656, doi:10.1175/JPO-D-14-0001.1.

Bertin, X., A. B. Fortunato, and A. Oliveira (2009), A modeling-based analysis of processes driving wave-dominated inlets, Continental Shelf Research, 29, 819-834, doi:10.1016/j.csr.2008.12.019.

Blanckaert, K. (2010), Topographic steering, flow recirculation, velocity redistribution, and bed topography in sharp meander bends, Water Resources Research, 46(9), doi:10.1029/2009WR008303.

Blanckaert, K. (2011), Hydrodynamic processes in sharp meander bends and their morphological implications, Journal of Geophysical Research: Earth Surface, 116(F1), F01003, doi:10.1029/2010JF001806.

Blanckaert, K. and H. J. de Vriend (2003), Nonlinear modeling of mean flow redistribution in curved open channels, Water Resources Research, 39(12), 1375-1388, doi:10.1029/2003WR002068.

Blanton, J. O., G. Lin, and S. A. Elston (2002), Tidal current asymmetry in shallow estuaries and tidal creeks, Continental Shelf Research, 22, 1731-1743, doi:10.1016/S02784343(02)00035-3.

Booij, N., R. C. Ris, and L. H. Holthuijsen (1999), A third-generation wave model for coastal regions: 1. Model description and validation, Journal of Geophysical Research, 104(C4), 7649-7666, doi:10.1029/98JC02622.

Boon, J. D. and R. J. Byrne (1981), On basin hypsometry and the morphodynamic response of coastal inlet systems, Marine Geology, 40, 27-48, doi:10.1016/0025-3227(81)90041-4. 
Boussinesq, J. (1868), Memoir on the influence of friction in the regular motion of fluids, Journal de Mathématiques Pures et Appliquées, 2(13), 209-241.

Brown, J. M. and J. Wolf (2009), Coupled wave and surge modelling for the eastern Irish Sea and implications for model wind-stress, Continental Shelf Research, 29(10), 1329-1342, doi:10.1016/j.csr.2009.03.004.

Brown, J. M., R. Bolaños, and J. Wolf (2013), The depth-varying response of coastal circulation and water levels to $2 \mathrm{D}$ radiation stress when applied in a coupled wave-tide-surge modelling system during an extreme storm, Coastal Engineering, 82, 102-113, doi:10.1016/j.coastaleng.2013.08.009.

Brown, J. M., R. Bolaños, M. J. Howarth, and A. J. Souza (2012), Extracting sea level residual in tidally dominated estuarine environments, Ocean Dynamics, 62, 969-982, doi:10.1007/s10236-012-0543-7.

Brown, W. S. and R. P. Trask (1980), A study of tidal energy dissipation and bottom stress in an estuary, Journal of Physical Oceanography, 10, 1742-1754, doi:10.1175/15200485(1980)010<1742:ASOTED>2.0.CO;2.

Buijsman, M. C. and H. Ridderinkhof (2007), Long-term ferry-ADCP observations of tidal currents in the Marsdiep inlet, Journal of Sea Research, 57, 237-256, doi:10.1016/j.seares.2006.11.004.

Cáceres, M., A. Valle-Levinson, and L. Atkinson (2003), Observations of cross-channel structure of flow in an energetic tidal channel, Journal of Geophysical Research, 108, 3114-3124, doi:10.1029/2001JC000968.

Chant, R. J. (2001), Tidal and subtidal motion in a shallow bar-built multiple inlet/bay system, Journal of Coastal Research, SI(32), 102-114.

Chant, R. J. and R. E. Wilson (1997), Secondary circulation in a highly stratified estuary, Journal of Geophysical Research: Oceans, 102(C10), 23207-23215, doi:10.1029/97JC00685.

Charnock, H. (1955), Wind stress on a water surface, Quarterly Journal of the Royal Meteorological Society, 81, 639-640, doi:10.1002/qj.49708135027.

Chen, C. -I. (1991), Unified theory on power laws for flow resistance, Journal of Hydraulic Engineering, 117(3), 371-389, doi:10.1061/(ASCE)0733-9429(1991)117:3(371).

Chen, J. -L., T. J. Hsu, F. Shi, B. Raubenheimer, and S. Elgar (2014), Hydrodynamic modeling of New River Inlet, North Carolina using NearCoM-TVD, Coastal Engineering Proceedings, 1(34), doi:10.9753/icce.v34.currents.41. 
Chen, J. -L., T. -J. Hsu, F. Shi, B. Raubenheimer, and S. Elgar (2015), Hydrodynamic and sediment transport modeling of New River Inlet (NC) under the interaction of tides and waves, Journal of Geophysical Research: Oceans, 120(6), 4028-4047, doi:10.1002/2014JC010425.

Chen, S. -N., L. P. Sanford, and D. K. Ralston (2009), Lateral circulation and sediment transport driven by axial winds in an idealized, partially mixed estuary, Journal of Geophysical Research: Oceans, 114(C12), C12006, doi:10.1029/2008JC005014.

Csanady, G. T. (1973), Wind-induced barotropic motions in long lakes, Journal of Physical Oceanography, 3, 429-438, doi:10.1175/15200485(1973)003<0429:WIBMIL>2.0.CO;2.

Dodet, G., X. Bertin, N. Bruneau, A. B. Fortunato, A. Nahon, and A. Roland (2013), Wavecurrent interactions in a wave-dominated tidal inlet, Journal of Geophysical Research, 118, 1587-1605, doi:10.1002/jgrc.20146.

Elgar, S., B. Raubenheimer, and R. T. Guza (2001), Current Meter Performance in the Surf Zone, Journal of Atmospheric and Oceanic Technology, 18, 1735-1746, doi:10.1175/1520-0426(2001)018<1735:CMPITS>2.0.CO;2.

Elgar, S., B. Raubenheimer, and R. T. Guza (2005), Quality control of acoustic Doppler velocimeter data in the surfzone, Measurement Science and Technology, 16, 1889-1893, doi:10.1088/0957-0233/16/10/002.

Elgar, S., T. H. C. Herbers, and R. T. Guza (1994), Reflection of ocean surface gravity waves from a natural beach, Journal of Physical Oceanography, 24, 1503-1511, doi:10.1175/1520-0485(1994)024<1503:ROOSGW>2.0.CO;2.

Elston, S. A. (2005), Secondary circulation in a sinuous coastal plain estuary, Ph.D. dissertation, Georgia Institute of Technology, Atlanta.

Emery, W. J. and R. E. Thomson (2001), Data Analysis Methods in Physical Oceanography, 2nd ed., Elsevier Science B. V., Amsterdam, The Netherlands.

Feddersen, F. (2004), Effect of wave directional spread on the radiation stress: comparing theory and observations, Coastal Engineering, 51, 473-481, doi:10.1016/j.coastaleng.2004.05.008.

Feddersen, F., R. T. Guza, and S. Elgar (2004), Inverse modeling of one-dimensional setup and alongshore current in the nearshore, Journal of Physical Oceanography, 34, 920-933, doi:10.1175/1520-0485(2004)034<0920:IMOOSA>2.0.CO;2. 
Fong, D. A., S. G. Monismith, M. T. Stacey, and J. R. Burau (2009), Turbulent stresses and secondary currents in a tidal-forced channel with significant curvature and asymmetric bed forms, Journal of Hydraulic Engineering, 135(3), 198-208, doi:10.1061/(ASCE)0733-9429(2009)135:3(198).

Fortunato, A. B., A. Oliveira, and A. M. Baptista (1999), On the effect of tidal flats on the hydrodynamics of the Tagus estuary, Oceanologica Acta, 22, 31-44, doi:10.1016/S03991784(99)80030-9.

Friedrichs, C. T. and D. G. Aubrey (1988), Non-linear tidal distortion in shallow well-mixed estuaries: a synthesis, Estuarine, Coastal and Shelf Science, 27(5), 521-545, doi:10.1016/0272-7714(88)90082-0.

Friedrichs C. T. and D. G. Aubrey (1994), Tidal propagation in strongly convergent channels, Journal of Geophysical Research, 99(C2), 3321-3336, doi:10.1029/93JC03219.

Friedrichs, C. T. and O. S. Madsen (1992), Nonlinear diffusion of the tidal signal in frictionally dominated embayments, Journal of Geophysical Research, 97, 5637-5650, doi:10.1029/92JC00354.

Gerbi, G. P., J. H. Trowbridge, J. B. Edson, A. J. Plueddemann, E. A. Terray, and J. J. Fredericks (2009), Measurements of momentum and heat transfer across the air-sea interface, Journal of Physical Oceanography, 38, 1054-1072, doi:10.1175/2007JPO3739.1.

Geyer, W. R. (1993), Three-dimensional tidal flow around headlands, Journal of Geophysical Research, 98(C1), 955-966, doi:10.1029/92JC02270.

Geyer, W. R. (1997), Influence of wind on dynamics and flushing of shallow estuaries, Estuarine, Coastal and Shelf Science, 44, 713-722, doi:10.1006/ecss.1996.0140.

Geyer, W. R. and P. MacCready (2014), The estuarine circulation, Annual Review of Fluid Mechanics, 46, 175-197, doi:10.1146/annurev-fluid-010313-141302.

Geyer, W. R., J. H. Trowbridge, and M. M. Bowden (2000), The dynamics of a partially mixed estuary, Journal of Physical Oceanography, 30, 2035-2048, doi:10.1175/15200485(2000)030<2035:TDOAPM>2.0.CO;2.

Giddings, S. N., S. G. Monismith, D. A. Fong, and M. T. Stacey (2014), Using depth-normalized coordinates to examine mass transport residual circulation in estuaries with large tidal amplitude relative to the mean depth, Journal of Physical Oceanography, 44, 128-148, doi:10.1175/JPO-D-12-0201.1.

Grant, W. D. and O. S. Madsen (1979), Combined wave and current interaction with a rough bottom, Journal of Geophysical Research, 84(C4), 1797-1808, doi:10.1029/JC084iC04p01797. 
Grant, W. D. and O. S. Madsen (1986), The continental-shelf bottom boundary layer, Annual Review of Fluid Mechanics, 18, 265-305, doi:10.1146/annurev.fl.18.010186.001405.

Hearn, C. J., J. R. Hunter, and M. L. Heron (1987), The effects of a deep channel on the windinduced flushing of a shallow bay or harbor, Journal of Geophysical Research, 92(C4), 3913-3924, doi:10.1029/JC092iC04p03913.

Hench, J. L. and R. A. Luettich (2003), Transient tidal circulation and momentum balances at a shallow inlet, Journal of Physical Oceanography, 33, 913-932, doi:10.1175/15200485(2003)33<913:TTCAMB>2.0.CO;2.

Hench, J. L., B. O. Blanton, and R. A. Luettich (2002), Lateral dynamic analysis and classification of barotropic tidal inlets, Continental Shelf Research, 22, 2615-2631, doi:10.1016/S0278-4343(02)00117-6.

Herbers, T. H. C. and R. T. Guza (1990), Estimation of directional wave spectra from multicomponent observations, Journal of Physical Oceanography, 20, 1703-1724, doi:10.1175/1520-0485(1990)<1703:EODWSF>2.0.CO;2.

Hinata, H., N. Kanatsu, and S. Fujii (2010), Dependence of wind-driven current on wind stress direction in a small semienclosed, homogeneous rotating basin, Journal of Physical Oceanography, 40(7), 1488-1500, doi:10.1175/2010JPO4363.1.

Huijts, K. M. H., H. M. Schuttelaars, H. E. de Swart, and C. T. Friedrichs (2009), Analytical study of the transverse distribution of along-channel and transverse residual flows in tidal estuaries, Continental Shelf Research, 29(1), 89-100, doi:10.1016/j.csr.2007.09.007.

Jay, D. A. (1991), Green's law revisited: tidal long-wave propagation in channels with strong topography, Journal of Geophysical Research, 96, 20585-20598, doi:10.1029/91JC01633.

Jessup, A., R. A. Holman, C. Chickadel, S. Elgar, G. Farquharson, M. C. Haller, A. L. Kurapov, H. T. Özkan- Haller, B. Raubenheimer, and J. M. Thomson (2012), Data Assimilation and Remote Sensing for Littoral Applications, Abstract OS14A-01, presented at 2012 Fall Meeting, AGU, San Francisco, Calif., 3-7 Dec, 2012.

Kaimal, J. C., J. C. Wyngaard, Y. Izumi, and O. R. Cote (1972), Spectral characteristics of surface-layer turbulence, Quarterly Journal of the Royal Meteorological Society, 98(417), 563-589, doi:10.1002/qj.49709841707.

Kalkwijk, J. P. T. and R. Booij (1986), Adaptation of secondary flow in nearly-horizontal flow, Journal of Hydraulic Research, 24(1), 19-37, doi:10.1080/00221688609499330.

Kang, K. and D. Di Iorio (2006), Depth- and current-induced effects on wave propagation into the Altamaha River Estuary, Georgia, Estuarine, Coastal and Shelf Science, 66(3-4), 395-408, doi:10.1016/j.ecss.2005.09.008. 
Kjerfve, B. (1975), Velocity averaging in estuaries characterized by a large tidal range to depth ratio, Estuarine and Coastal Marine Science, 3(3), 311-323, doi:10.1016/03023524(75)90031-6.

Kraus, E. (1972), Atmosphere-Ocean interaction, Oxford University Press, London, 275 pp.

Kuik, A. J., G. Ph. van Vledder, and L. H. Holthuijsen (1988), A method for the routine analysis of pitch-and-roll buoy wave data, Journal of Physical Oceanography, 18, 1020-1034, doi:10.1175/1520-0485(1988)018<1020:AMFTRA>2.0.CO;2.

Lacy, J. R. and S. G. Monismith (2001), Secondary currents in a curved, stratified, estuarine channel, Journal of Geophysical Research: Oceans, 106(C12), 31283-31302, doi:10.1029/2000JC000606.

Large, W. and S. Pond (1981), Open ocean momentum flux measurements in moderate to strong winds, Journal of Physical Oceanography, 11, 324-336, doi:10.1175/15200485(1981)011<0324:OOMFMI>2.0.CO;2.

Lentz, S., R. T. Guza, S. Elgar, F. Feddersen, and T. H. C. Herbers (1999), Momentum balances on the North Carolina inner shelf, Journal of Geophysical Research, 104, 18205-18226, doi:10.1029/1999JC900101.

Lerczak, J. A. and W. R. Geyer (2004), Modeling the lateral circulation in straight, stratified estuaries, Journal of Physical Oceanography, 34, 1410-1428, doi:10.1175/15200485(2004)034<1410:MTLCIS>2.0.CO;2.

Li, C. (2013), Subtidal water flux through a multiple-inlet system: Observations before and during a cold front event and numerical experiments, Journal of Geophysical Research, 118, 1877-1892, doi:10.1002/jgrc.20149.

Li, C. and J. O'Donnell (1997), Tidally driven residual circulation in shallow estuaries with lateral depth variation, Journal of Geophysical Research: Oceans, 102(C13), 2791527929, doi: 10.1029/97JC02330.

Li, C. and J. O'Donnell (2005), The effect of channel length on the residual circulation in tidally dominated channels, Journal of Physical Oceanography, 35, 1826-1840, doi:10.1175/JPO2804.1.

Li, Y. and M. Li (2012), Wind-driven lateral circulation in a stratified estuary and its effects on the along-channel flow, Journal of Geophysical Research, 117(C9), C09005, doi:10.1029/2011JC007829.

Lippmann, T. C., J. D. Irish, and J. Hunt (2013), Subtidal flow structure in tidally modulated inlets, In P. Bonneton and T. Garlan (Eds.), Proceedings of Coastal Dynamics 2013, 1095-1104, Arcachon, France. 
Longuet-Higgins, M. S. and R. W. Stewart (1964), Radiation stresses in water waves; a physical discussion, with applications, Deep-Sea Research, 11, 529-562, doi:10.1016/00117471(64)90001-4.

Luettich, R. A., J. J. Westerink, and N. W. Scheffner (1992), ADCIRC: An advanced threedimensional model for shelves, coasts, and estuaries. Report 1. Theory and methodology of ADCIRC 2DDI and ADCIRC 3-DL, Dredging Research Program Technical Report DRP-92-6, Coastal Engineering Research Center, U.S. Army Corps of Engineers, Waterways Experiment Station, p141.

Lumley, J. L. and E. A. Terray (1983), Kinematics of turbulence convected by a random wave field, Journal of Physical Oceanography, 13, 2000-2007, doi:10.1175/15200485(1983)013<2000:KOTCBA>2.0.CO;2.

MacMahan, J., J. van de Kreeke, A. Reniers, S. Elgar, B. Raubenheimer, E. Thornton, M. Weltmer, P. Rynne, and J. Brown (2014), Fortnightly tides and subtidal motions in a choked inlet, Estuarine, Coastal and Shelf Science, 150B, 325-331, doi:10.1016/j.ecss.2014.03.025.

MacVean, L. J. and J. R. Lacy (2014), Interactions between waves, sediment, and turbulence on a shallow estuarine mudflat, Journal of Geophysical Research: Oceans, 119(3), 15341553, doi:10.1002/2013JC009477.

Malhadas, M. S., P. C. Leitão, A. Silva, and R. Neves (2009), Effect of coastal waves on sea level in Óbidos Lagoon, Portugal, Continental Shelf Research, 29, 1240-1250, doi:10.1016/j.csr.2009.02.007.

Mathieu, P. P., E. Deleersnijder, B. Cushman-Roisin, J. -M. Beckers, and K. Bolding (2002), The role of topography in small well-mixed bays, with application to the lagoon of Mururoa, Continental Shelf Research, 22(9), 1379-1395. doi:10.1016/S02784343(02)00002-X.

Nadaoka, K. and T. Kondoh (1982), Laboratory measurements of velocity field structure in the surf zone by LDV, Coastal Engineering in Japan, 25, 125-145.

Nidzieko, N. J., J. L. Hench, and S. G. Monismith (2009), Lateral circulation in well-mixed and stratified estuarine flows with curvature, Journal of Physical Oceanography, 39, 831851, doi:10.1175/2008JPO4017.1.

Olabarrieta, M., J. C. Warner, and N. Kumar (2011), Wave-current interaction in Willapa Bay, Journal of Geophysical Research, 116, C12014, doi:10.1029/2011JC007387.

Olabarrieta, M., R. Medina, and S. Castanedo (2010), Effects of wave-current interaction on the current profile, Coastal Engineering, 57(7), 643-655, doi:10.1016/j.coastaleng.2010.02.003. 
Olabarrieta, M., W. R. Geyer, and N. Kumar (2014), The role of morphology and wave-current interaction at tidal inlets: An idealized modeling analysis, Journal of Geophysical Research: Oceans, 119(12), 8818-8837, doi:10.1002/2014JC010191.

Orescanin, M., B. Raubenheimer, and S. Elgar (2014), Observations of wave effects on inlet circulation, Continental Shelf Research, 82, 37-42, doi:10.1016/j.csr.2014.04.010.

Pacheco, A., Ó. Ferreira, J. J. Williams, E. Garel, A. Vila-Concejo, and J. A. Dias (2010), Hydrodynamics and equilibrium of a multiple-inlet system, Marine Geology, 274, 32-42, doi:10.1016/j.margeo.2010.03.003.

Peña, A. and S.-E. Gryning (2008), Charnock's roughness length model and non-dimensional wind profiles over the sea, Boundary-Layer Meteorology, 128, 191-203, doi:10.1007/s10546-008-9285-y.

Piedracoba, S., C. Souto, M. Gilcoto, and P. C. Pardo (2005), Hydrography and dynamics of the Ría de Ribadeo (NW Spain), a wave driven estuary, Estuarine, Coastal and Shelf Science, 65, 726-738, doi:10.1016/j.ecss.2005.07.013.

Ponte, A.L., G. Gutiérrez de Velasco, A. Valle-Levinson, K. B. Winters, and C. D. Winant (2012), Wind-driven subinertial circulation inside a semienclosed bay in the Gulf of California, Journal of Physical Oceanography, 42, 940-955, doi:10.1175/JPO-D-110103.1 .

Putrevu, U. and I. A. Svendsen (1999), Three-dimensional dispersion of momentum in waveinduced nearshore currents, European Journal of Mechanics - B/Fluids, 18(3), 409-427, doi:10.1016/S0997-7546(99)80038-7.

Rabiner, L. and B. Gold (1975), Theory and Application of Digital Signal Processing, PrenticeHall, Englewood Cliffs, NJ.

Raubenheimer, B., R. T. Guza, and S. Elgar (2001), Field observations of wave-driven setdown and setup, Journal of Geophysical Research, 106, 4629-4638, doi:10.1029/2000JC000572.

Raubenheimer, B., S. Elgar, and R.T. Guza (1998), Estimating wave heights from pressure measured in sand bed, Journal of Waterway, Port, Coastal, and Ocean Engineering, 151154, doi:10.1061/(ASCE)0733-950X(1998)124:3(151).

Riggs, S. R., W. J. Cleary, and S. W. Snyder (1995), Influence of inherited geologic framework on barrier shoreface morphology and dynamics, Marine Geology, 126, 213-234, doi:10.1016/0025-3227(95)00079-E.

Ris, R. C. and L. H. Holthuijsen (1996), Spectral modelling of current induced wave-blocking, Proceedings of 25th Conference on Coastal Engineering, 1246-1254, Orlando, Florida. 
Rogowski, P., E. Terrill, and J. Chen (2014), Observations of the frontal region of a buoyant river plume using an autonomous underwater vehicle, Journal of Geophysical Research: Oceans, 119(11), 7549-7567, doi:10.1002/2014JC010392.

Rozovskii, I. L. (1957), Flow of water in bends of open channels, Academy of Sciences of the Ukrainian SSR, 233 pp.

Salles, P. (2001), Hydrodynamic controls on multiple tidal inlet persistence, Ph.D. Dissertation, Massachusetts Institute of Technology and Woods Hole Oceanographic Institution, 272pp.

Salles, P., G. Voulgaris, and D. G. Aubrey (2005), Contribution of nonlinear mechanisms in the persistence of multiple tidal inlet systems, Estuarine, Coastal and Shelf Science, 65, 475491, doi:10.1016/j.ecss.2005.06.018.

Sanay, R. and A. Valle-Levinson (2005), Wind-induced circulation in semienclosed homogeneous, rotating basins, Journal of Physical Oceanography, 35, 2520-2531, doi:10.1175/JPO2831.1.

Seim, H. E. and M. C. Gregg (1997), The importance of aspiration and channel curvature in producing strong vertical mixing over a sill, Journal of Geophysical Research: Oceans, 102(C2), 3451-3472, doi:10.1029/96JC03415.

Sempreviva, A. M., S. E. Larsen, N. G. Mortensen, and I. Troen (1990), Response of neutral boundary layers to changes of roughness, Boundary-Layer Meteorology, 50, 205-225, doi:10.1007\%2FBF00120525.

Shi, F., D. M. Hanes, J. T. Kirby, L. Erikson, P. Barnard, and J. Eshleman (2011), Pressuregradient-driven nearshore circulation on a beach influenced by a large inlet-tidal shoal system, Journal of Geophysical Research: Oceans, 116(C4), C04020, doi:10.1029/2010JC006788.

Shi, F., I. A. Svendsen, J. T. Kirby, and J. M. Smith (2003), A curvilinear version of a quasi-3D nearshore circulation model, Coastal Engineering, 49(1-2), 99-124, doi:10.1016/S03783839(03)00049-8.

Signell, R. P. and W. R. Geyer (1991), Transient eddy formation around headlands, Journal of Geophysical Research, 96, 2561-2575, doi:10.1029/90JC02029.

Smagorinsky, J. (1963), General circulation experiments with the primitive equations. I. The basic experiment, Monthly Weather Review, 91, 99-164, doi:10.1175/15200493(1963)091<0099:GCEWTP>2.3.CO;2.

Smith, J. M. (2002), Wave pressure gauge analysis with current, Journal of Waterway, Port, Coastal and Ocean Engineering, 128, 271-275, doi:10.1061/(ASCE)0733950X(2002)128:6(271). 
Smith, N. P. (1993), Tidal and nontidal flushing of Florida's Indian River Lagoon, Estuaries, 16, 739-746, doi:10.2307/1352432.

Smith, R. (1976), Longitudinal dispersion of a buoyant contaminant in a shallow channel, Journal of Fluid Mechanics, 78, 677-688, doi:10.1017/S0022112076002681.

Smith, S. D. (1980), Wind stress and heat flux over the ocean in gale force winds, Journal of Physical Oceanography, 10, 709-726, doi:10.1175/15200485(1980)010<0709:WSAHFO>2.0.CO;2.

Soulsby, R. L., L. Hamm, G. Klopman, D. Myrhaug, R. R. Simons, and G. P. Thomas (1993), Wave-current interaction within and outside the bottom boundary layer, Coastal Engineering, 21(1-3), 41-69, doi:10.1016/0378-3839(93)90045-A.

Speer, P. E. and D. G. Aubrey (1985), A study of non-linear tidal propagation in shallow inlet/estuarine systems part II: theory, Estuarine, Coastal and Shelf Science, 21, 207-224, doi:10.1016/0272-7714(85)90097-6.

Spydell, M. S., F. Feddersen, M. Olabarrieta, J. Chen, R. T. Guza, B. Raubenheimer, and S. Elgar (2015), Observed and modeled drifters at a tidal inlet, Journal of Geophysical Research: Oceans, 120(7), 4825-4844, doi:10.1002/2014JC010541.

Stommel, H. and H. G. Farmer (1952), On the nature of estuarine circulation, Ref. 52-88, Woods Hole Oceanographic Institution, Woods Hole, MA.

Svendsen, I. A. (1987), Analysis of surf zone turbulence, Journal of Geophysical Research: Oceans, 92(C5), 5115-5124, doi:10.1029/JC092iC05p05115.

Svendsen, I. A., K. Haas, and Q. Zhao (2002), Quasi-3D nearshore circulation model SHORECIRC: Version 2.0, CACR-02-01 research report, Center for Applied Coastal Research, University of Delaware.

Swenson, E. M. and W. S. Chuang (1983), Tidal and subtidal water volume exchange in an estuarine system, Estuarine, Coastal and Shelf Science, 16, 229-240, doi:10.1016/02727714(83)90142-7.

Taylor, G. I. (1938), The spectrum of turbulence, Proceedings of the Royal Society of London. Series A, Mathematical and Physical Sciences, 164(919), 476-490, doi:10.1098/rspa.1938.0032.

Thomson, W. (1876), On the origin of windings of rivers in alluvial plains, with remarks on the flow of water round bends in pipes, Proceedings of the Royal Society of London, 25, 5-8. 
Trowbridge, J. H. (1998), On a technique for measurement of turbulent shear stress in the presence of surface waves, Journal of Atmospheric and Oceanic Technology, 15, 290 298, doi:10.1175/1520-0426(1998)015<0290:OATFMO>2.0.CO;2.

Trowbridge, J. and S. Elgar (2003), Spatial scales of stress-carrying nearshore turbulence, Journal of Physical Oceanography, 33, 1122-1128, doi:10.1175/15200485(2003)033<1122:SSOSNT>2.0.CO;2.

Tutak, B. and Y. P. Sheng (2011), Effect of tropical cyclones on residual circulation and momentum balance in a subtropical estuary and inlet: observation and simulation, Journal of Geophysical Research, 116, C06014, doi:10.1029/2011JC006988.

Vennell, R. and C. Old (2007), High-resolution observations of the intensity of secondary circulation along a curved tidal channel, Journal of Geophysical Research, 112(C11), C11008, doi:10.1029/2006JC003764.

Wargula, A., B. Raubenheimer, and S. Elgar (2013), The effects of wave forcing on circulation at New River Inlet, NC, In P. Bonneton and T. Garlan (Eds.), Proceedings of Coastal Dynamics 2013, 1871-1880, Arcachon, France.

Wargula, A., B. Raubenheimer, and S. Elgar (2014), Wave-driven along-channel subtidal flows in a well-mixed ocean inlet, Journal of Geophysical Research: Oceans, 119(5), 29873001, doi:10.1002/2014JC009839.

Waterhouse, A. F. and A. Valle-Levinson (2010), Transverse structure of subtidal flow in a weakly stratified subtropical tidal inlet, Continental Shelf Research, 30, 281-292, doi:10.1016/j.csr.2009.11.008.

Winant, C. D. (2004), Three-dimensional tidal flow in an elongated, rotating basin, Journal of Physical Oceanography, 37(9), 2345-2362, doi:10.1175/JPO3122.1.

Winant, C. D. (2008), Three-dimensional residual tidal circulation in an elongated, rotating basin, Journal of Physical Oceanography, 38, 1278-1295, doi:10.1175/2007JPO3819.1.

Wong, K. -C. (1994), On the nature of transverse variability in a coastal plain estuary, Journal of Geophysical Research: Oceans, 99(C7), 14209-14222, doi:10.1029/94JC00861.

Wong, K. -C. and J. E. Moses-Hall (1998), On the relative importance of the remote and local wind effects to the subtidal variability in a coastal plain estuary, Journal of Geophysical Research, 103(C9), 18393-18404, doi:10.1029/98JC01476.

Wong, K. -C. and A. Valle-Levinson (2002), On the relative importance of the remote and local wind effects on the subtidal exchange at the entrance to the Chesapeake Bay, Journal of Marine Research,60(3), 477-498, doi:10.1357/002224002762231188. 
Xie, X., M. Li, and W. C. Boicourt (2017), Baroclinic effects on wind-driven lateral circulation in Chesapeake Bay, Journal of Physical Oceanography, 47(2), 433-445, doi:10.1175/JPO-D-15-0233.1.

Zippel, S. and J. Thomson (2012), Wave Breaking at New River Inlet, Abstract OS11G-03, presented at 2012 Fall Meeting, AGU, San Francisco, Calif., 3-7 Dec, 2012.

Zippel, S. and J. Thomson (2015), Wave breaking and turbulence at a tidal inlet, Journal of Geophysical Research: Oceans, 120(2), 1016-1031, doi:10.1002/2014JC010025. 